Prepared for the U.S. Department of Energy

under Contract DE-AC05-76RL01830

\title{
FY-2010 Process Monitoring Technology Final Report
}

CR Orton

SA Bryan

AJ Casella

JW Hines

TG Levitskaia
JJ Henkel JM Schwantes

EA Jordan

AM Lines

CG Fraga
JM Peterson

DE Verdugo

RN Christensen

SM Peper

January 2011

Pacific Northwest

NATIONAL LABORATORY

Proudly Operated by Battelle Since 1965 


\title{
DISCLAIMER
}

This report was prepared as an account of work sponsored by an agency of the United States Government. Neither the United States Government nor any agency thereof, nor Battelle Memorial Institute, nor any of their employees, makes any warranty, express or implied, or assumes any legal liability or responsibility for the accuracy, completeness, or usefulness of any information, apparatus, product, or process disclosed, or represents that its use would not infringe privately owned rights. Reference herein to any specific commercial product, process, or service by trade name, trademark, manufacturer, or otherwise does not necessarily constitute or imply its endorsement, recommendation, or favoring by the United States Government or any agency thereof, or Battelle Memorial Institute. The views and opinions of authors expressed herein do not necessarily state or reflect those of the United States Government or any agency thereof.

\author{
PACIFIC NORTHWEST NATIONAL LABORATORY \\ operated by \\ BATTELLE \\ for the \\ UNITED STATES DEPARTMENT OF ENERGY \\ under Contract DE-AC05-76RL01830
}

Printed in the United States of America
Available to DOE and DOE contractors from the
Office of Scientific and Technical Information,
P.O. Box 62, Oak Ridge, TN 37831-0062;
ph: (865) 576-8401
fax: $(865)$ 576-5728
email: reports@adonis.osti.gov

Available to the public from the National Technical Information Service

5301 Shawnee Rd., Alexandria, VA 22312

ph: (800) 553-NTIS (6847)

email: orders@ntis.gov $<$ http://www.ntis.gov/about/form.aspx $>$

Online ordering: http://www.ntis.gov

This document was printed on recycled paper. 
PNNL-20022

\section{FY-2010 Process Monitoring Technology Final Report}

\author{
CR Orton ${ }^{1}$ \\ SA Bryan ${ }^{1}$ \\ AJ Casella ${ }^{1}$ \\ JW Hines ${ }^{3}$ \\ TG Levitskaia ${ }^{1}$
}

\author{
JJ Henkel $^{3}$ \\ JM Schwantes ${ }^{1}$ \\ EA Jordan ${ }^{1}$ \\ AM Lines $^{1}$ \\ CG Fraga ${ }^{1}$
}

\author{
JM Peterson $^{1}$ \\ DE Verdugo ${ }^{1}$ \\ RN Christensen ${ }^{2}$ \\ SM Peper ${ }^{1}$
}

January 2011

Prepared for

the U.S. Department of Energy

under Contract DE-AC05-76RL01830

Pacific Northwest National Laboratory

Richland, Washington 99352

\footnotetext{
${ }^{1}$ Pacific Northwest National Laboratory, Richland, Washington

2 The Ohio State University, Columbus, Ohio

${ }^{3}$ University of Tennessee, Knoxville, Tennessee
} 



\section{Executive Summary}

The diversion of special nuclear materials (SNM) and the monitoring of process conditions within nuclear reprocessing facilities are of significant interest to international safeguards facility regulators (e.g., the International Atomic Energy Agency (IAEA)) as well as nuclear material reprocessing facility operators. For large throughput nuclear facilities, such as commercial reprocessing plants, it is difficult to satisfy the IAEA safeguards accountancy goal for detection of abrupt diversion. Process monitoring helps detect diversion by using process control measurements to detect abnormal plant operation. In recent years, the Office of Nuclear Safeguards and Security (NA-241) at the National Nuclear Security Administration (NNSA) has funded a Process Monitoring Working Group (PMWG) to study various mechanisms for diverting nuclear material from spent nuclear fuel (SNF) reprocessing facilities. Common approaches for diverting special nuclear material can occur via removal of separated bulk nuclear materials, or more likely, from minor modifications to processing conditions. Therefore, there is a need for technologies that are capable of detecting minor modifications to reprocessing solutions. To address this need, the PMWG, in support of the Next-Generation Safeguards Initiative (NGSI), commissioned the Pacific Northwest National Laboratory (PNNL) to demonstrate the efficacy of two technologies in detecting minor diversions in process conditions analogous to those used in nuclear reprocessing facilities: the Spectroscopy-Based Monitoring System and the Multi-Isotope Process Monitor (MIP). The development of these technologies was sponsored by the Office of Nuclear Energy (DOE-NE) via the Advanced Fuel Cycle Initiative (AFCI) Separations and Safeguards Campaigns, respectively. This report describes the findings from the demonstration of these two technologies.

Demonstration testing of the Spectroscopy-Based Process Monitoring system included diverting a sample from the aqueous feed while monitoring the process in every phase using the on-line spectroscopic process monitoring system. The purpose of this demonstration was to test whether the process monitoring system was able detect and quantify the diversion of material from the system during a real-time continuous solvent extraction experiment. The system was designed to mimic a PUREX-type extraction process with a bank of four centrifugal contactors. The aqueous feed contained neodymium nitrate $\mathrm{Nd}\left(\mathrm{NO}_{3}\right)_{3}$ in aqueous nitric acid $\left(\mathrm{HNO}_{3}\right)$, and the organic phase was composed of $\mathrm{TBP} / n$ dodecane. The amount of sample observed to be diverted by on-line spectroscopic process monitoring was measured to be $3 \mathrm{mmol}\left(3 \times 10^{-3} \mathrm{~mol}\right) \mathrm{Nd}^{3+}$. This value was in excellent agreement with the 2.9 mmol $\mathrm{Nd}^{3+}$ value based on the known mass of sample taken (i.e., diverted) directly from the system feed solution. A paper discussing past work associated with this project has been submitted to the peerreviewed journal Radiochimica Acta; a copy of the paper is provided in Appendix A.

The Multi-Isotope Process (MIP) Monitor is a new approach to process monitoring in reprocessing facilities under international safeguards. It uses gamma spectroscopy of spent fuel, product streams, and waste streams combined with multivariate analysis to autonomously and automatically monitor process conditions to verify nominal operations in near-real-time. In addition, the approach can potentially be used to quantify process variables and fuel characteristics. Proof-of-concept simulations and experiments to demonstrate the validity and partial application of this tool were performed in previous years. This report details the efforts undertaken at PNNL during FY 2010 to further develop and demonstrate the capabilities of the MIP Monitor and explore its application in a process monitoring system. 



\section{Acronyms and Abbreviations}

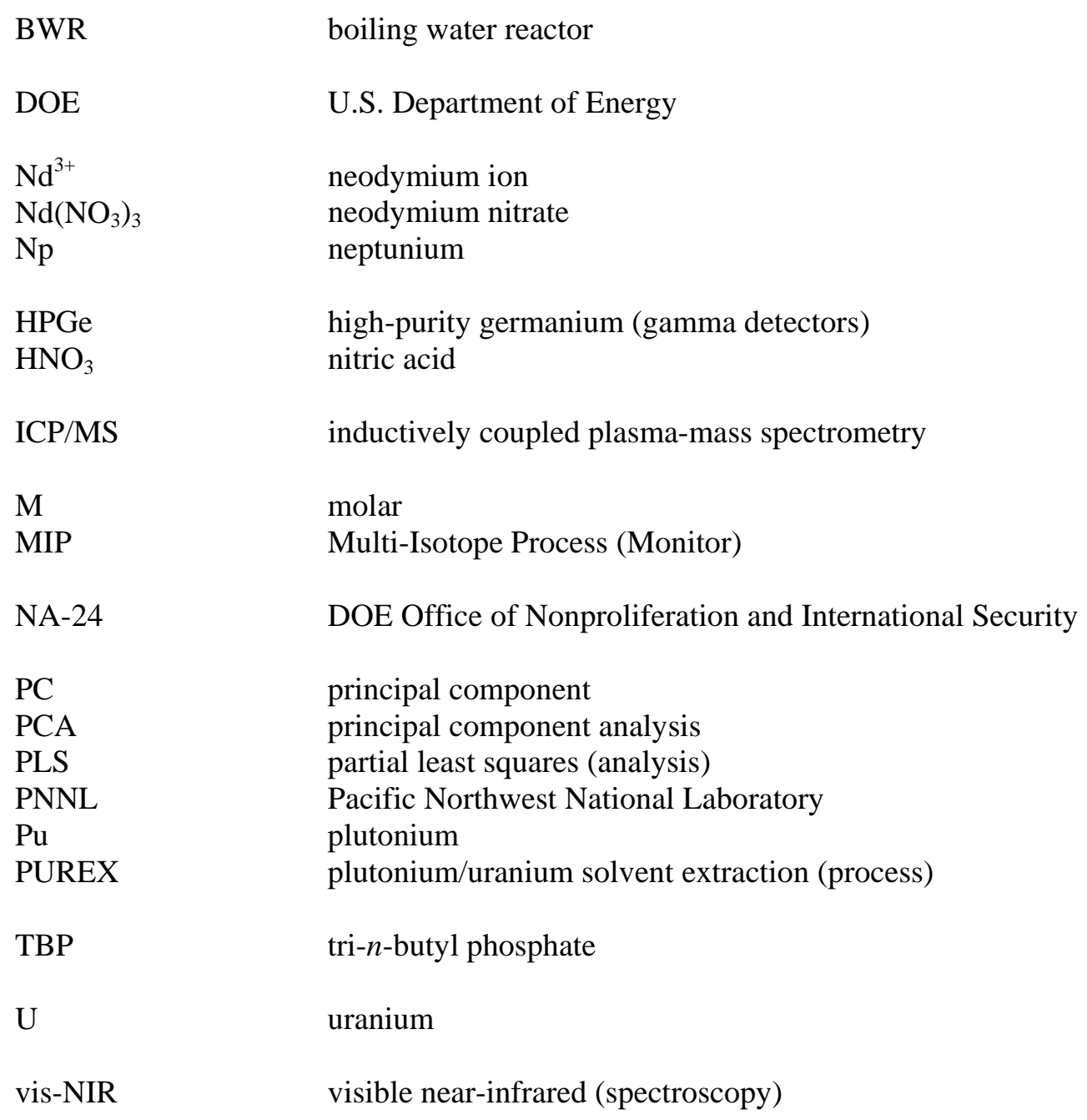





\section{Contents}

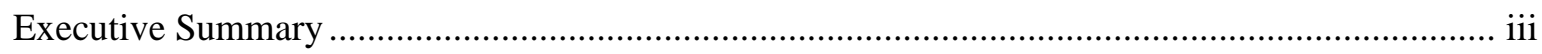

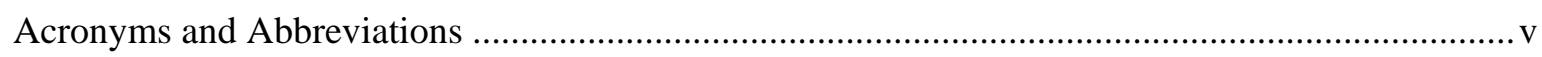

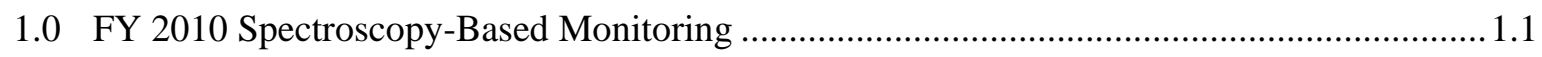

1.1 Process Monitoring Demonstration Using Centrifugal Contactors................................1.1

1.1.1 Spectroscopic Monitoring of Neodymium Nitrate in an Extraction System........1.2

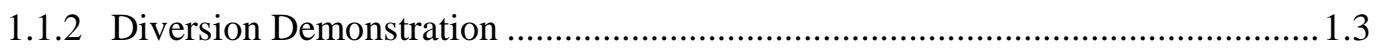

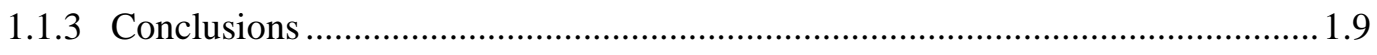

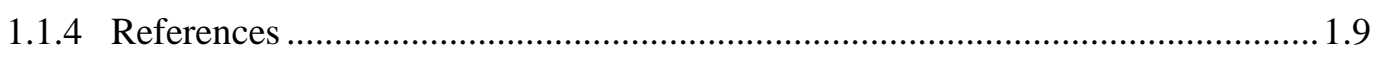

2.0 FY-2010 Multi-Isotope Process Monitoring …............................................................. 2.1

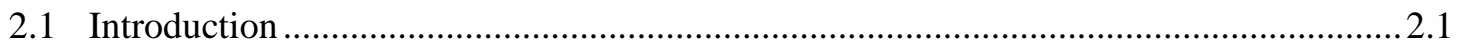

2.2 FY 2010 Overview of Tasks and Accomplishments................................................... 2.1

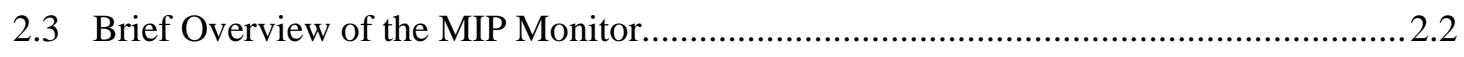

2.4 Experimental Efforts - Sample Archival .................................................................... 2.3

2.5 Advanced Multivariate Analysis Methods .................................................................. 2.4

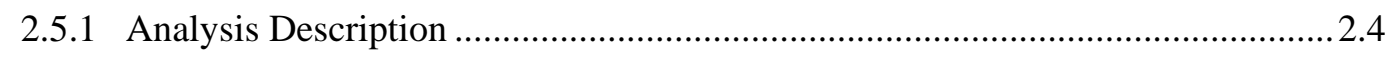

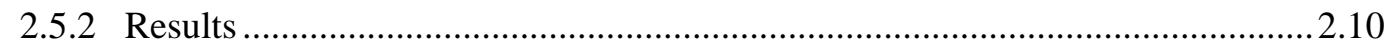

2.5.3 Advanced Multivariate Analysis Conclusions …..............................................

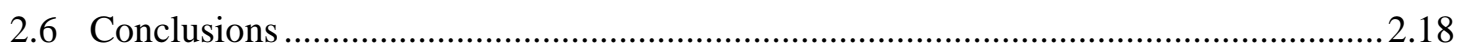

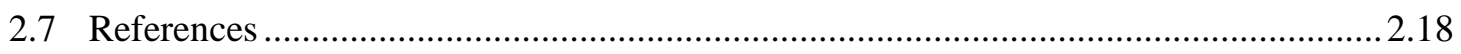

Appendix A: Journal Article, Submitted to Radiochimica Acta: Spectroscopic Monitoring of

Nuclear Spent Fuel Reprocessing Streams: An Evaluation of Spent Fuel Solutions via

Raman, Visible, and Near-Infrared Spectroscopy …............................................................ 1 


\section{Figures}

1.1 Schematic of the centrifugal contactor system used in this study ................................................. 1.1

1.2 Photograph of the centrifugal contactor system used in this study ............................................. 1.2

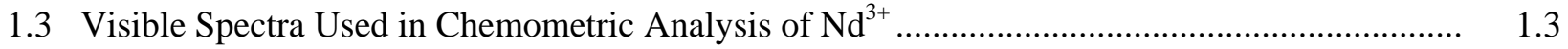

1.4 Chemometric Model for $\mathrm{Nd}^{3+}$ in Aqueous and Organic Systems ............................................ 1.3

1.5 Measured Flow Rates for Each of the Inlet and Outlet Streams ................................................... 1.4

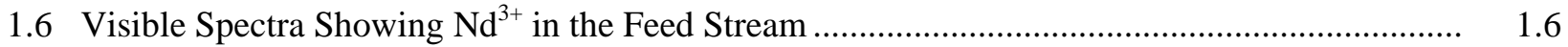

1.7 Visible Spectra Showing $\mathrm{Nd}^{3+}$ in the Organic Product Stream ................................................. 1.6

1.8 Visible Spectra Showing $\mathrm{Nd}^{3+}$ in the Raffinate Stream ........................................................ 1.7

$1.9 \mathrm{Nd}^{3+}$ Extraction and Measurement in the Contactor System .................................................... 1.7

$1.10 \mathrm{Nd}^{3+}$ Extraction and Measurement in the Contactor System ................................................... 1.8

2.1 Gamma Spectrum of the Organic Fraction of the ATM109 Fuel Dissolved and Separated in

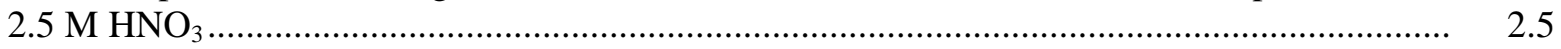

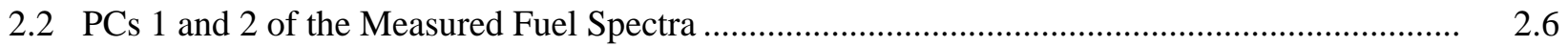

2.3 Gamma Spectrum of the Organic Extract of ATM109 Fuel Expressed as the Number of Standard Deviations Above the Baseline.................................................................................. 2.8

2.4 The Measured Gamma Spectrum from the Organic Extract of the ATM109 Fuel Dissolved and Separated at 2.5M $\mathrm{HNO}_{3}$, the Extract Continuum, and the Channels at Least Three Standard Deviations Above the Compton Continuum................................................................. 2.9

2.5 The Measured Gamma Spectrum from the ATM109 Fuel Dissolved in $2.5 \mathrm{M} \mathrm{HNO}_{3}$, the Extract Continuum, and the Channels at the Gamma Peak Centers. ..........................................

2.6 Plot of the Scores of PC 1 and PC 2 for Unsupervised PCA Model 1..................................... 2.11

2.7 Plot of the Scores of PC 1 and PC 2 for Unsupervised PCA Model 2 ...................................... 2.12

2.8 Plot of the Scores of PC 1 and PC 2 for Unsupervised PCA Model 1........................................ 2.13

2.9 Plot of the Scores of PC 1 and PC 2 for Unsupervised PCA Model 2 ...................................... 2.13

2.10 Plot of the Scores of Q-Residuals and $\mathrm{T}^{2}$ Statistics for the Supervised PCA Model 1............... 2.15

2.11 Plot of the Scores of Q-Residuals and $\mathrm{T}^{2}$ Statistics for Supervised PCA Model 2..................... 2.15 


\section{Tables}

Table 1.1. Flow Rates and Amounts from the Diversion Experiment .......................................... 1.5

Table 2.1. Summary of BWR Fuel Properties ...............................................................................2.4

Table 2.2. Variance Captured by the First Four PCs for the Unsupervised PCA Model to

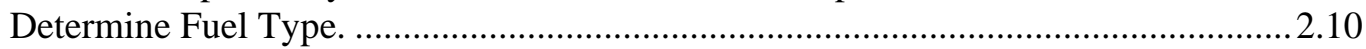

Table 2.3. Summary of Unsupervised PCA Clustering Performance.......................................... 2.12

Table 2.4. Variance Captured by the First Four PCs for the Unsupervised PCA Model to

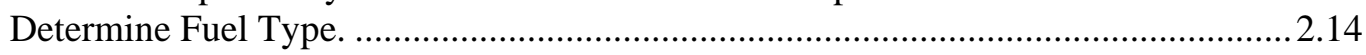

Table 2.5. Summary of Unsupervised PCA Clustering Performance. ........................................... 2.14

Table 2.6. Summary of Supervised PCA Clustering Performance. ............................................ 2.16

Table 2.7. Summary of PLS Modeling Results........................................................................ 2.17

Table 2.8. Summary of PLS Modeling Results....................................................................... 2.17 



\subsection{FY 2010 Spectroscopy-Based Monitoring}

\subsection{Process Monitoring Demonstration Using Centrifugal Contactors}

A flow test designed to demonstrate diversion of an aqueous component from a PUREX-type extraction scheme was performed using the centrifugal contactor system at PNNL. The purpose of this demonstration was to test whether monitoring is capable of determining the mass balance of metal nitrate species involved in a cross-current solvent-extraction scheme while also diverting a sample from the system. The test scenario involved diverting a portion of the feed from a counter-current extraction system while a continuous extraction experiment was underway. A successful test would demonstrate the ability of the process-monitoring system to detect and quantify the diversion of material from the system during a real-time continuous solvent extraction experiment. The system was designed to mimic a PUREX-type extraction system with a bank of four centrifugal contactors. The aqueous feed contained neodymium nitrate $\left(\mathrm{Nd}\left(\mathrm{NO}_{3}\right)_{3}\right)$ in nitric acid $\left(\mathrm{HNO}_{3}\right)$, and the organic phase was composed of $\mathrm{TBP} / n$ dodecane.

The centrifugal contactor system was instrumented with spectroscopic probes at the feed, raffinate, and organic product inlet/outlet lines of the contactor system. A schematic showing the bank of four centrifugal contacts with associated points of spectroscopic sampling is shown in Figure 1.1. Visible (vis)-near infrared (NIR) and Raman spectroscopic probes mounted within each inlet and outlet position monitored the inlet and outlet streams during flow testing. A photograph of the assembled system is shown in Figure 1.2, with the labels for feed and raffinate spectroscopic probes.

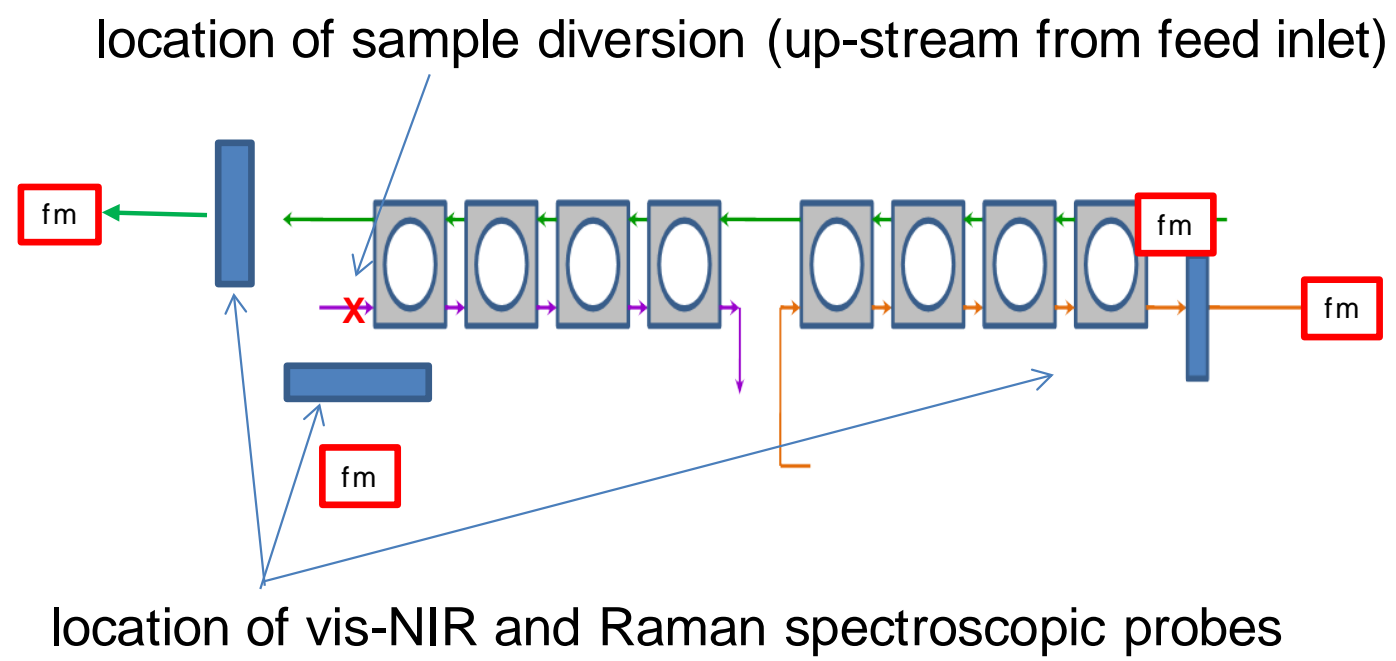

Figure 1.1. Schematic of the centrifugal contactor system used in this study. The location of the feed, raffinate, organic inlet, and loaded organic product are shown. The vis-NIR and Raman monitoring probes are positioned on the feed, raffinate, and organic product streams. The sample diversion location, designated with an " $X$," is upstream of the feed inlet into the first contactor. The flow meters are located on all inlet and outlet streams and are designated with "fm" in the figure. 


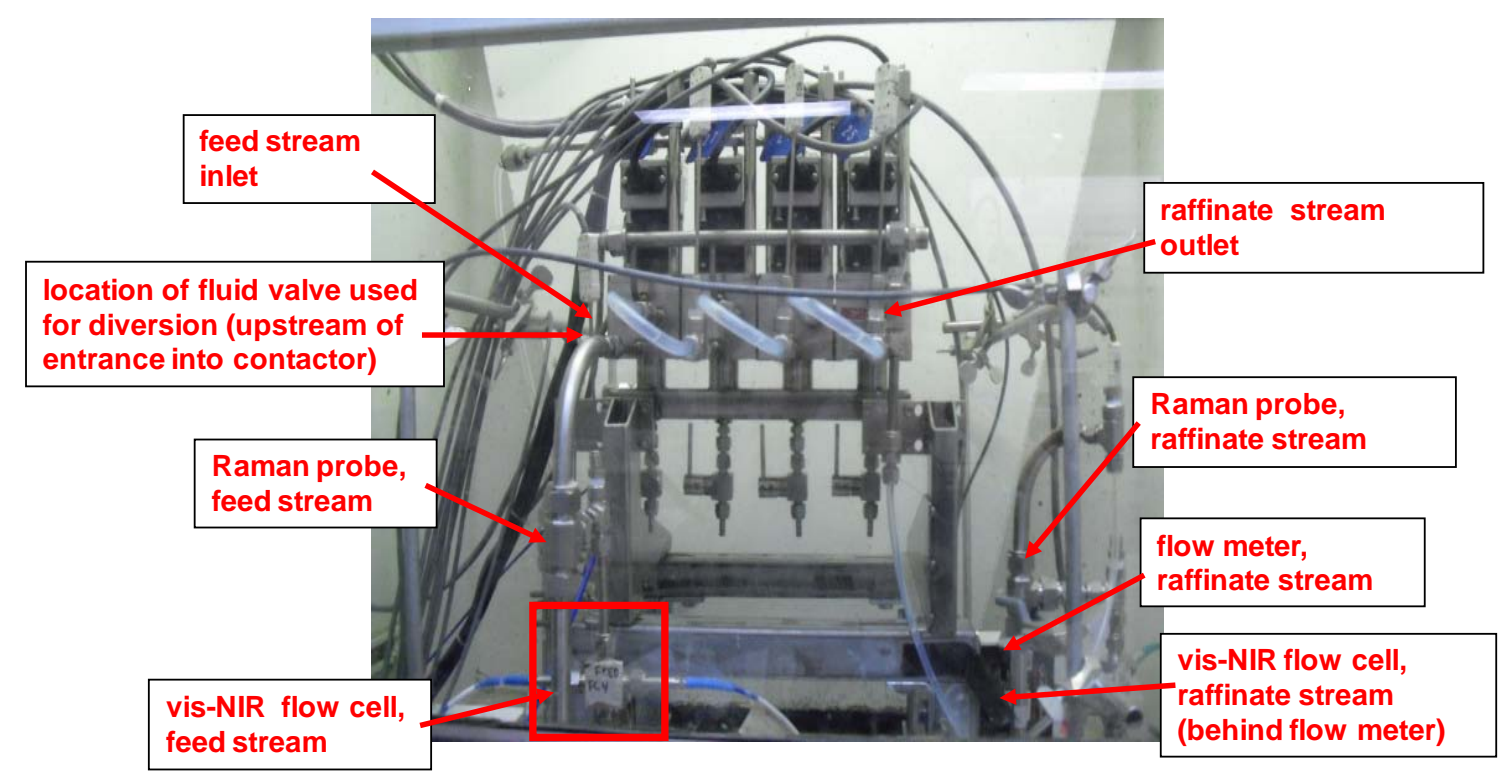

Figure 1.2. Photograph of the centrifugal contactor system used in this study. The location of feed inlet and raffinate outlet are shown. The vis-NIR and Raman monitoring probes are positioned on the feed, raffinate (shown), and organic product streams (not shown in the figure).

\subsubsection{Spectroscopic Monitoring of Neodymium Nitrate in an Extraction System}

The concentration of $\mathrm{Nd}\left(\mathrm{NO}_{3}\right)_{3}$ can be determined quantitatively within a PUREX solvent system via spectroscopic monitoring. For neodymium ions $\left(\mathrm{Nd}^{3+}\right)$, the vis-NIR spectra have multiple bands suitable for use in this regard. Figure 1.3 contains the vis-NIR spectra of different concentrations of $\mathrm{Nd}_{(}\left(\mathrm{NO}_{3}\right)_{3}$ in $4 \mathrm{M} \mathrm{NaNO}_{3} / 0.1 \mathrm{M} \mathrm{HNO}_{3}$ solution. The constructed spectral database was used for interpretation of the new spectra acquired during a contactor run with different solutions and for the determination of $\mathrm{Nd}\left(\mathrm{NO}_{3}\right)_{3}$ concentrations in these solutions. Chemometric data analyses of Raman and vis-NIR spectra for the quantitative determination of $\mathrm{Nd}^{3+}$ (from vis-NIR) were performed using a commercial software package (MATLAB). Figure1.4 contains the calibration plots for $\mathrm{Nd}^{3+}$ based on the vis-NIR spectra using standard solutions for the calibration method.

Solutions used for the contactor run were prepared as follows. The aqueous feed solution was prepared to contain $20 \mathrm{mM} \mathrm{Nd}\left(\mathrm{NO}_{3}\right)_{3}$ and $4.0 \mathrm{M} \mathrm{NaNO}$ in $0.1 \mathrm{M} \mathrm{HNO}_{3}$. The organic solvent used in this demonstration was TBP/n-dodecane. Two liters (2 L) of feed and organic TBP/n-dodecane were prepared for the experiment. The TBP/n-dodecane was water washed prior to use. 


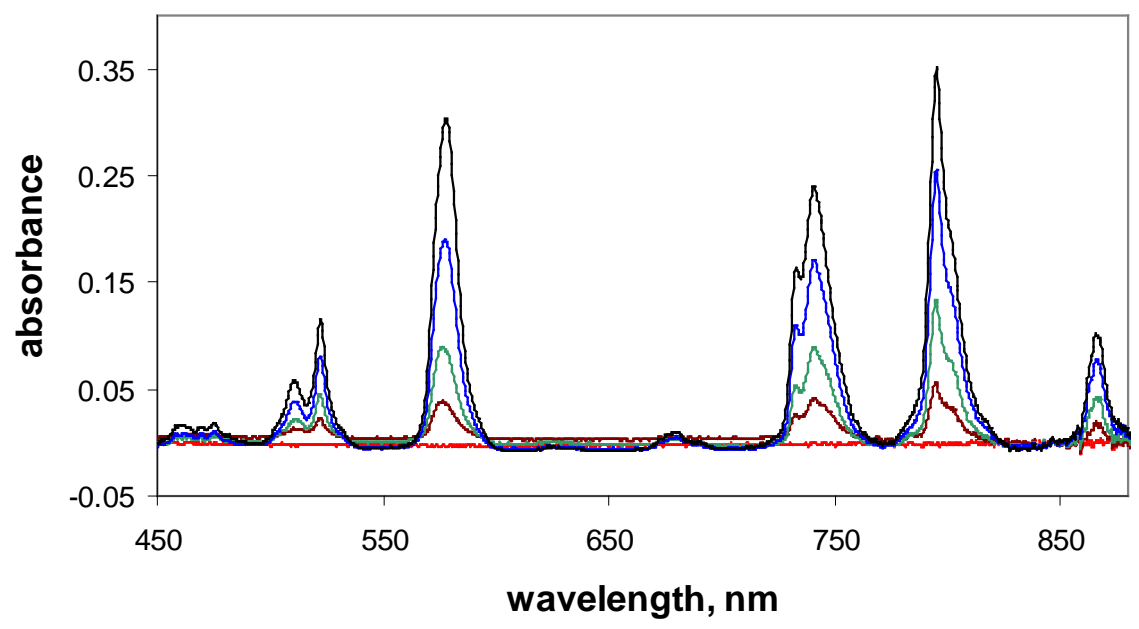

Figure 1.3. Visible Spectra Used in Chemometric Analysis for $\mathrm{Nd}^{3+}$.
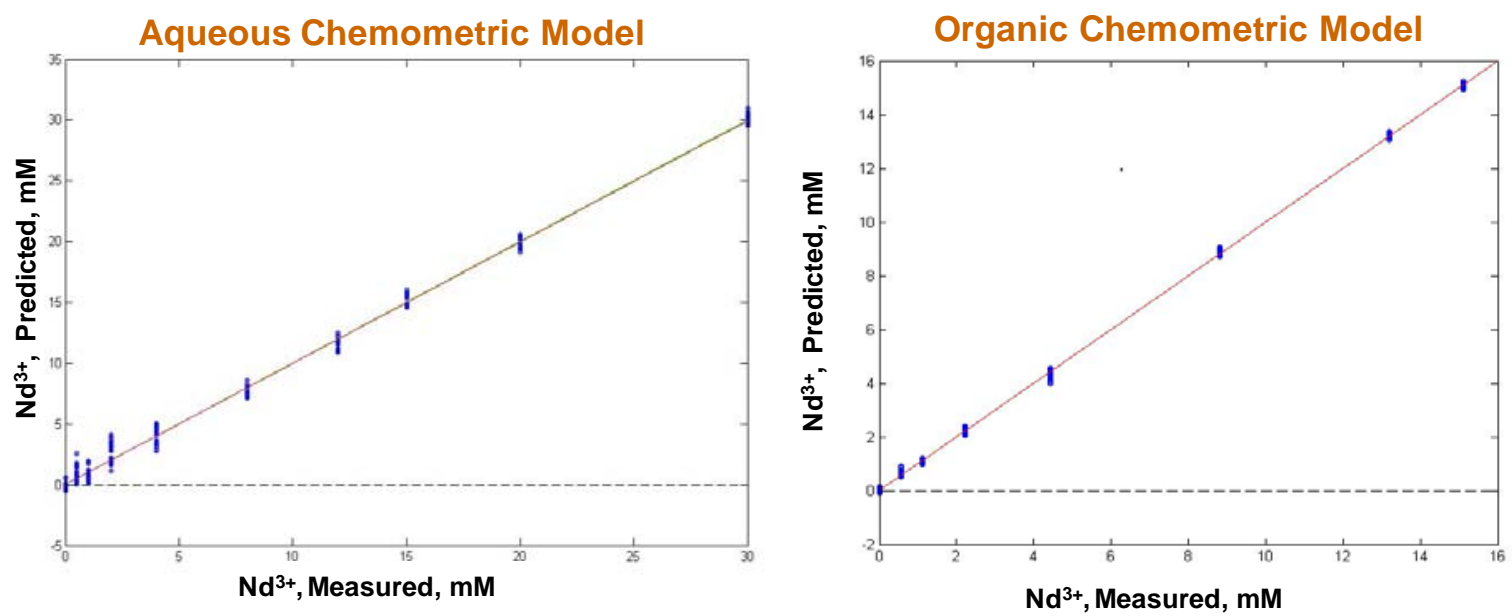

Figure 1.4. Chemometric Model for $\mathrm{Nd}^{3+}$ in Aqueous (feed and raffinate, left) and Organic Systems (TBP/n-dodecane, right).

\subsubsection{Diversion Demonstration}

The centrifugal contactor system test was initially started with an aqueous feed composed of water and an organic phase at flow rates of approximately 11 and $10.5 \mathrm{~mL} / \mathrm{min}$ respectively. The centrifugal contactor system was allowed to completely fill with the feed and organic solvent. At this point in time, solutions started to flow from the raffinate and organic product stream outlets. When the aqueous feed/raffinate and organic solvent/product flows reached steady state (i.e., the same volumes flowing in and out of the system), the aqueous feed was switched from water to the solution, which contained 20 $\mathrm{mM} \mathrm{Nd}\left(\mathrm{NO}_{3}\right)_{3}$ in $4 \mathrm{M} \mathrm{NaNO} / 0.1 \mathrm{M} \mathrm{HNO}_{3}$. Switching from water to the neodymium feed solution signaled the start of the test.

Figure 1.5 shows the flow rates as a function of time for all four flow meters monitoring the inlet (feed and organic solvent) and outlet (raffinate and organic product) streams. The system test was 
designed to run a total of approximately 160 minutes. After the steady state flow for both aqueous and sustained for 87 minutes, a valve was opened at the entrance into the contactor feed inlet, and a fraction of the feed solution was diverted at an average flow rate of $3.3 \mathrm{~mL} / \mathrm{min}$ over the time of diversion. After approximately 47 minutes, the diversion of material was stopped (i.e., 134 minutes after the start of experiment), and the normal feed flow (i.e., with no diversion) into the contactor system was reestablished. The plot of the flow rates for the feed and raffinate during the entire continuous contactor run shows the point at which diversion was initiated at 87 minutes and then stopped at 134 minutes from the start of the experiment (Figure 1.5). The plot of feed rate versus time in Figure 1.5 shows a steady feed flow rate into the contactor for the entire duration of the experiment. When the diversion was occurring (between 87 minutes and 134 minutes, Figure 1.5), the feed rate remained similar to that prior to the diversion because the diversion point into the feed inlet of the contactor was located downstream of the feed flow meter. The raffinate stream recorded a difference in flow rate shortly (within 2 minutes) after the diversion was started during this test. The flow meter located on the raffinate stream records the aqueous stream leaving the contactor bank, and because the flow rate of the aqueous feed was reduced, the aqueous (raffinate) stream leaving the contactor was also reduced. The average raffinate flow rate during diversion was $8.1 \mathrm{~mL} / \mathrm{min}$, reflecting the diversion of $\sim 3 \mathrm{~mL} / \mathrm{min}$ at the aqueous feed. When the diversion was stopped at 134 minutes, the raffinate flow rate returned to the pre-diversion rate of approximately $10-11 \mathrm{~mL} / \mathrm{min}$. The flow rates for the organic solvent and organic product streams are also shown in Figure 1.5. These streams maintain relatively constant flows (between $10-11 \mathrm{~mL} / \mathrm{min}$ ) during the entire test, including the time when diversion was occurring. Table 1 contains a summary of the flow data for the feed, raffinate, organic solvent, and organic product streams, taken during the entire flow test throughout the three test regions for the flow rate: 1) before diversion started, 2) during diversion, and 3) after diversion was stopped. The source of the noise within the flow data (Figure 1.5) was identified and is associated with the inner diameter (ID) and material of piping used between stages in the centrifugal contactor system. Improvements are being made to the system to resolve this problem.

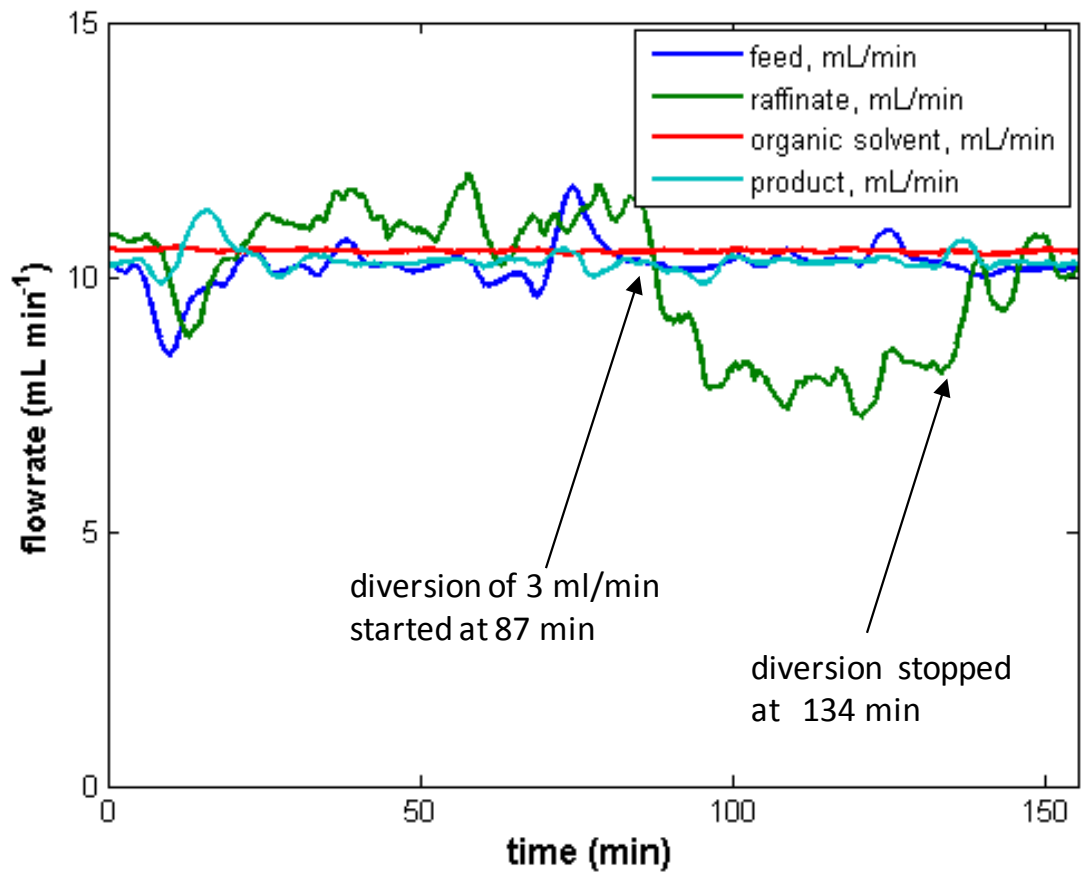

Figure 1.5. Measured Flow Rates (mL/min) for Each of the Inlet and Outlet Streams. 
Table 1.1. Flow Rates and Amounts from the Diversion Experiment.

\begin{tabular}{lcccc}
\hline Solutions & \multicolumn{3}{c}{ Flow Rates (mL/min) } & Density $(\mathrm{g} / \mathrm{mL})$ \\
\hline Feed & Initial & During Diversion & After & \\
Raffinate & 11.2 & 11.0 & 10.7 & 1.205 \\
Solvent & 11.2 & 8.1 & 10.2 & 1.202 \\
Loaded Solvent & 10.5 & 10.5 & 10.5 & 0.808 \\
Diversion Stream & 10.2 & 10.3 & 10.3 & 0.816 \\
\hline
\end{tabular}

Spectroscopic monitoring of the feed, raffinate, and organic product steams was conducted during the entire flow test. Vis-NIR spectra were recorded every 15 seconds, and Raman spectra were recorded every 30 seconds. Figure 1.6 contains the vis-NIR measurements of the aqueous feed during the continuous contactor experiment. The characteristic absorbance bands for the $\mathrm{Nd}^{3+}$ ion are shown in this series of spectra taken over the entire duration of the run ( 0 to 150 minutes). The location of the spectroscopic probes on the feed inlet is upstream from the point of sample diversion during this experiment, and therefore, the series of absorbance spectra for the feed did not change during the diversion. This is not the case for the spectra associated with the organic stream. Figure 1.7 contains the series of vis-NIR spectra measured at the organic outlet location during the extraction experiment. The vis-NIR spectra show the typical absorbance spectra associated with $\mathrm{Nd}^{3+}$ in solution, the increase in $\mathrm{Nd}^{3+}$ in the extraction phase after the initiation of the experiment, and a plateau in absorbance after about 20 minutes following the start of the experiment. However, at the approximate point of diversion (87 minutes) the absorbance value for the $\mathrm{Nd}^{3+}$ band significantly decreased, and remained at a suppressed level until the diversion was stopped (134 minutes into the run), after which time the measured absorbance increased to its pre-diversion value. The raffinate stream also showed the affects of sample diversion. Figure 1.8 contains the series of spectra taken using the flow cell at the location of the raffinate stream. This series shows the characteristic absorbance bands for $\mathrm{Nd}^{3+}$ during the extraction experiment. In general, the absorbance of the $\mathrm{Nd}^{3+}$ increased after the start of the experiment and remained relatively constant until the start of the diversion at 87 minutes. At this point, the measured absorbance of the $\mathrm{Nd}^{3+}$ bands decreased until the diversion was stopped at 134 minutes, after which time the absorbance bands increased to approximately the pre-diversion values.

Concentrations of $\mathrm{Nd}^{3+}$ in the feed, organic product, and raffinate phases for the spectra from Figure 1.6, Figure 1.7, and Figure 1.8, respectively, are shown in Figure 1.9. These concentrations were determined by employing chemometric analysis using $\mathrm{Nd}^{3+}$ standards measured in both the aqueous and organic phases (see Figure 1.4 and related discussion). Figure 1.9 shows that the concentration of the $\mathrm{Nd}^{3+}$ in the feed increased from $\sim 0$ to $20 \mathrm{mM}$ immediately after switching from the water wash to the $\mathrm{Nd}^{3+}$ feed solution. The amount of $\mathrm{Nd}^{3+}$ detected in the organic product and raffinate streams also increased, but after an additional time lag because of the in-process volume of the contactor system. Because the contactor system contained approximately $40 \mathrm{~mL}$ each of the aqueous and organic phases, the time for the $\mathrm{Nd}^{3+}$ to enter the contactor system and emerge in either the raffinate or product stream (flowing at $\sim 10 \mathrm{~mL} / \mathrm{min}$ ) was $\sim 4$ to 5 minutes. The additional time observed for the $\mathrm{Nd}^{3+}$ to appear in the product and raffinate stream after first detection in the feed stream was approximately 4 to 5 minutes, as was expected. 


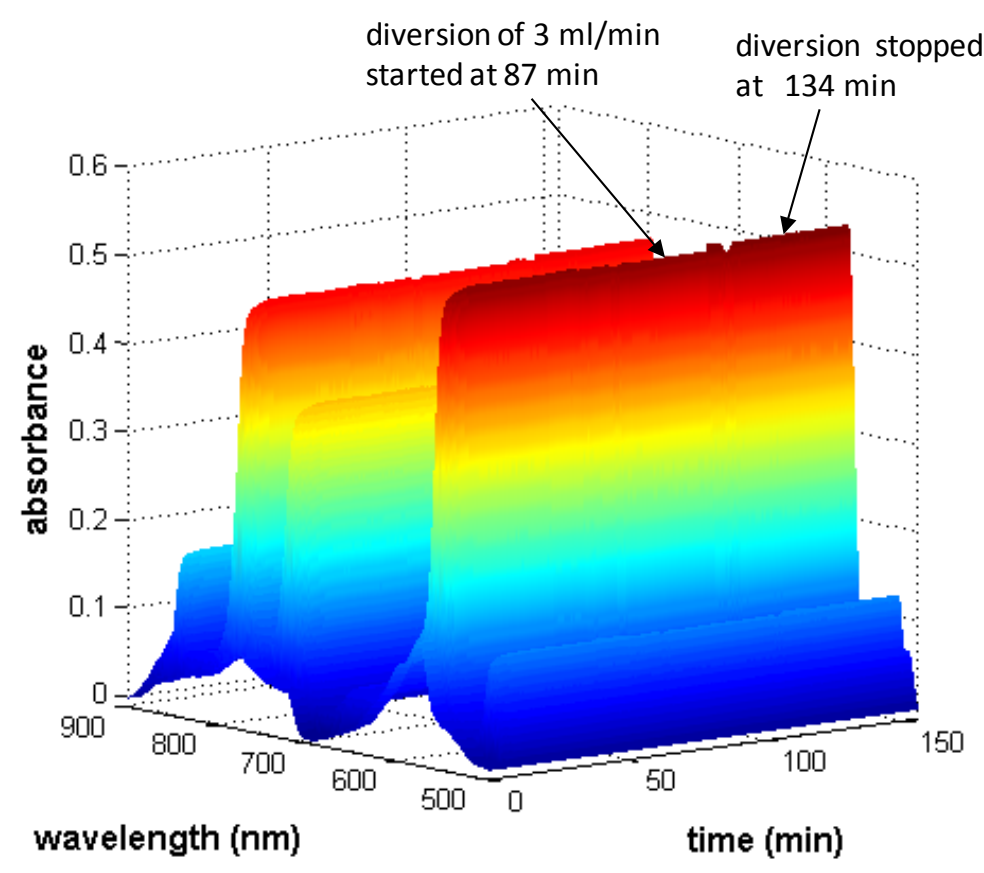

Figure 1.6. Visible Spectra Showing $\mathrm{Nd}^{3+}$ in the Feed Stream.

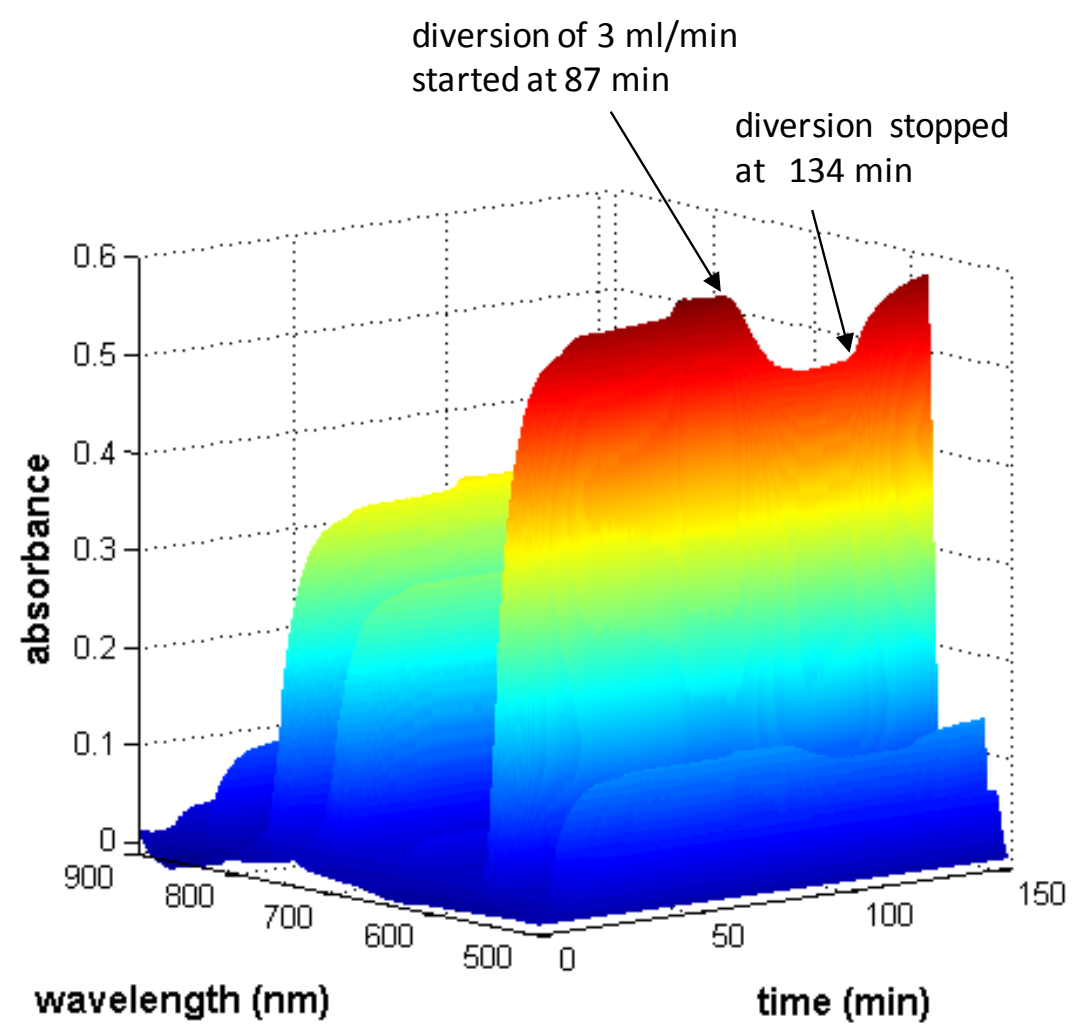

Figure 1.7. Visible Spectra Showing $\mathrm{Nd}^{3+}$ in the Organic Product Stream. 


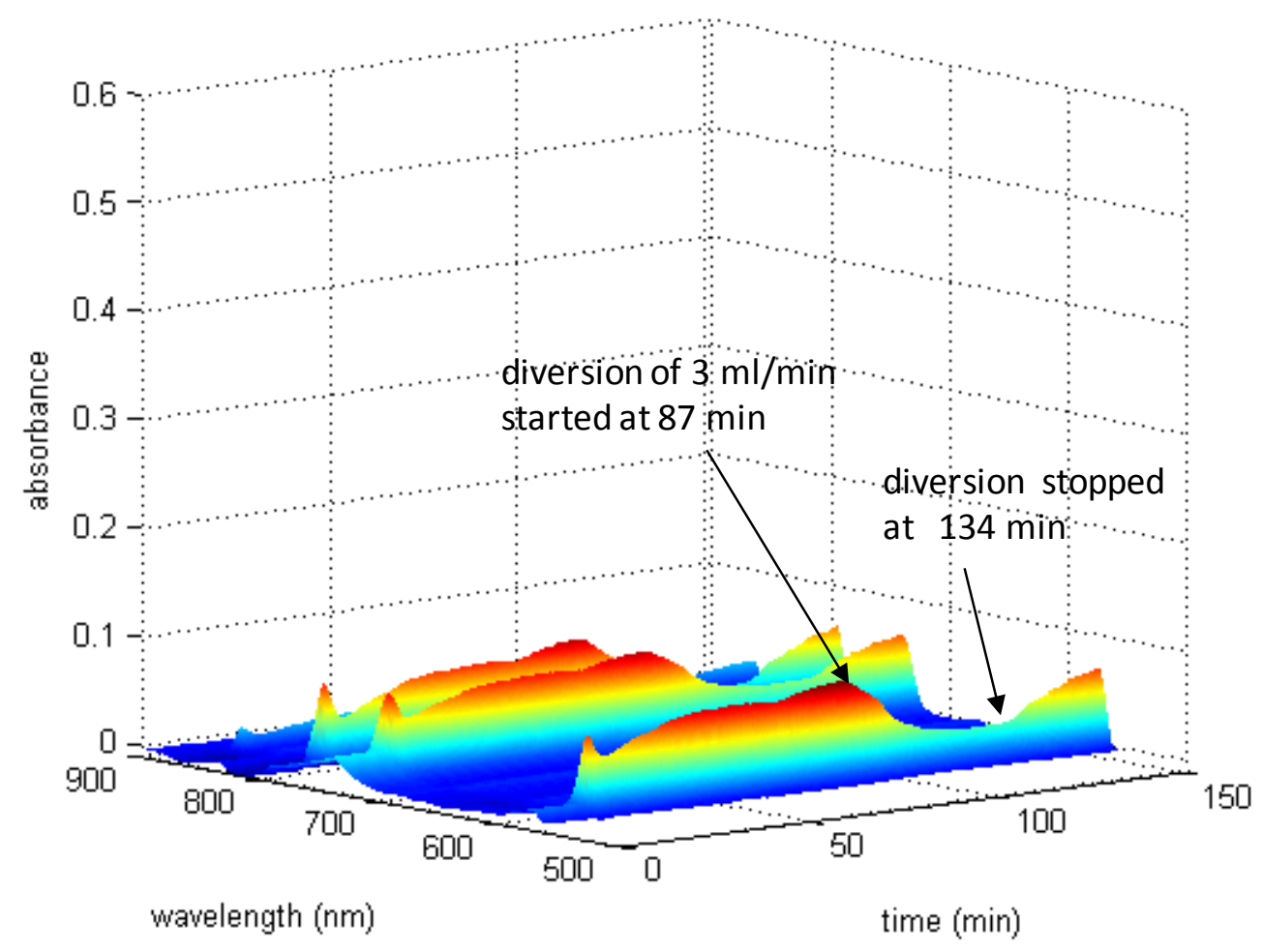

Figure 1.8. Visible Spectra Showing $\mathrm{Nd}^{3+}$ in the Raffinate Stream.

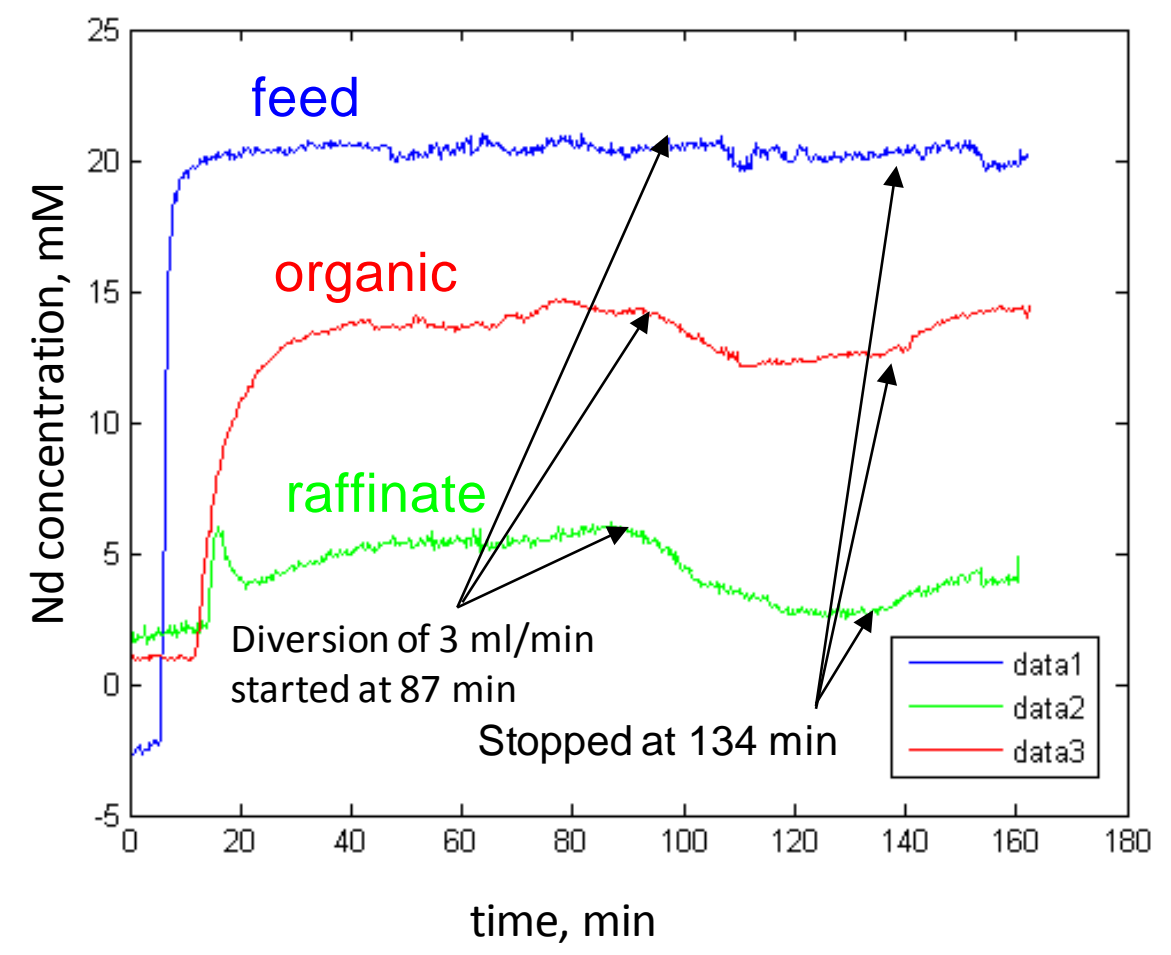

Figure 1.9. $\mathrm{Nd}^{3+}$ Extraction and Measurement in the Contactor System. 
By combining the flow rate information (Figure 1.5) with the concentration of $\mathrm{Nd}^{3+}$ in each phase (Figure 1.9), it was possible to determine the cumulative total (integrated amount) of $\mathrm{Nd}^{3+}$ detected in each stream. Figure 1.10 shows the integrated total of $\mathrm{Nd}^{3+}$ measured in the feed, raffinate and organic product streams during the entire experiment. The sum of the millimole values for the organic product and raffinate steams (labeled "organic + raffinate" in Figure 1.10) should equal the total millimoles of $\mathrm{Nd}^{3+}$ measured for the feed. The curve for the "organic + raffinate" is parallel to that for the feed measurement prior to the diversion, which started 87 minutes into the experiment. The difference between the "organic + raffinate" and the feed measurements is constant because of the in-process amount of $\mathrm{Nd}^{3+}$ that is still within the contactor system and, therefore, has not yet been measured by the spectroscopic probes on the outlet of the system. This difference in measurements, which is labeled "delta from in-process" in Figure 1.10, is simply the difference in millimoles between the two curves (delta-y on xy-plot). After the start of the diversion (i.e., at 87 minutes into the run), the "organic + raffinate" curve further deviates from the "feed" curve, while during the time when the diversion occurred (i.e., between 87 minutes and 134 minutes into the run) the two curves are no longer parallel. After diversion was stopped (at 134 minutes) the "organic + raffinate" curve then becomes parallel with the "feed" curve. By extrapolating a line from the "organic + raffinate" curve prior to diversion, we are able to estimate the amount of $\mathrm{Nd}^{3+}$ material diverted by subtracting the extrapolated value (prior to diversion) from the measured value after diversion. Based on this graphical analysis of the data in Figure 1.10, the difference was determined to be $3 \mathrm{mmol}\left(3 \times 10^{-3} \mathrm{~mol}\right) \mathrm{Nd}^{3+}$ diverted. This value is in excellent agreement with the mass balance value shown in Table $1.1\left(2.9 \mathrm{mmol} \mathrm{Nd}^{3+}\right)$.

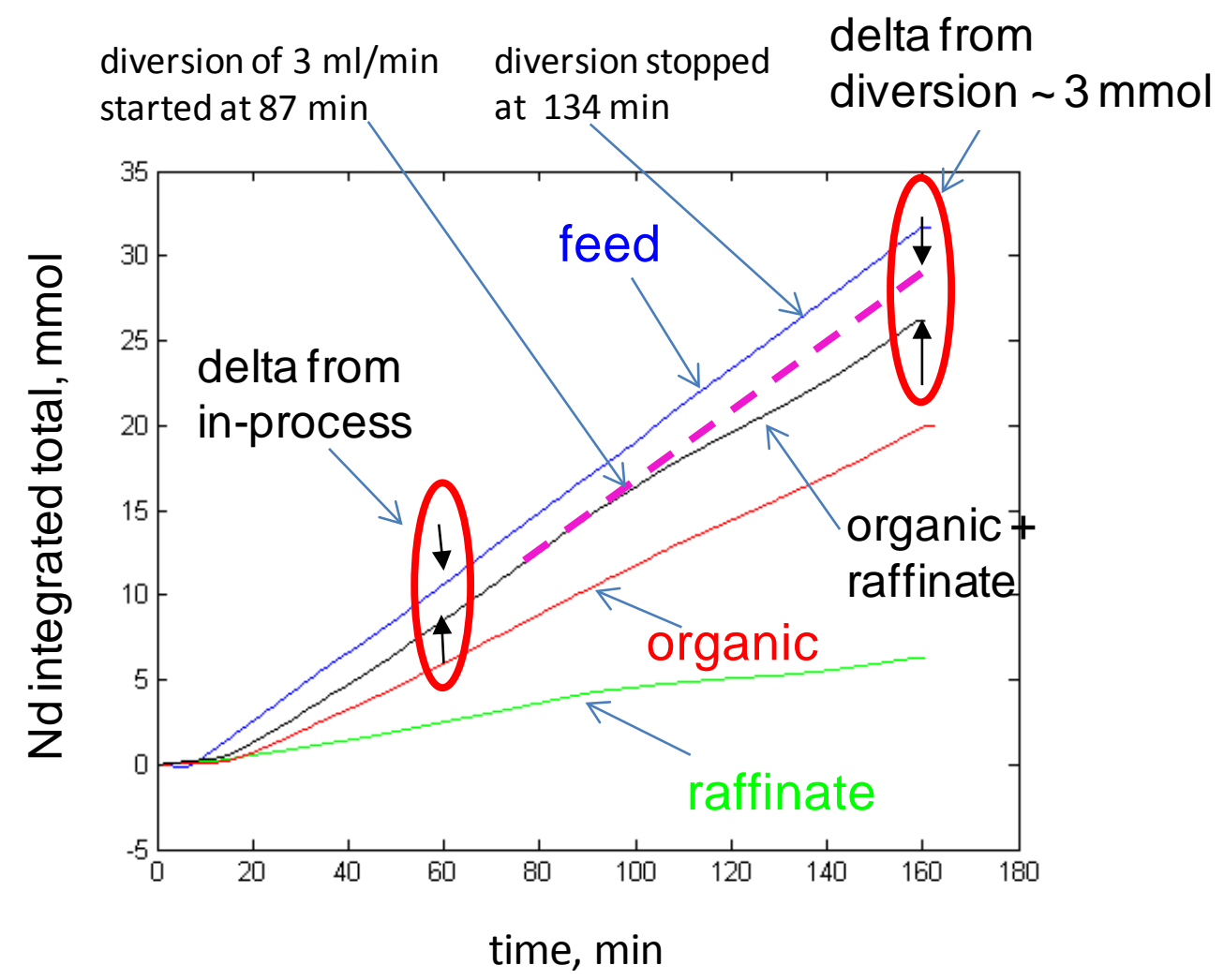

Figure 1.10. $\mathrm{Nd}^{3+}$ Extraction and Measurement in the Contactor System. 


\subsubsection{Conclusions}

Our ability to identify material intentionally diverted from a liquid-liquid solvent extraction contactor system was successfully tested using a centrifugal contactor system at PNNL instrumented for on-line process monitoring. A portion of the feed from a counter-current extraction system was diverted while a continuous extraction experiment was underway. The on-line process monitoring system simultaneously measured the feed, raffinate and organic products streams. The system was designed to mimic a PUREX type extraction system with a bank of four centrifugal contactors. The aqueous feed contained neodymium nitrate in nitric acid and the organic phase was composed of TBP/n-dodecane. The amount diverted determined by on-line process monitoring, which combines spectroscopic and flow rate measuring techniques, was $3 \mathrm{mmol}\left(3 \times 10^{-3} \mathrm{~mol}\right) \mathrm{Nd}^{3+}$, which is in excellent agreement with the 2.9 mmol $\mathrm{Nd}^{3+}$ value based on the known mass of sample directly taken (diverted) from the system feed solution. We conclude that real-time process monitoring is a useful tool for the immediate detection of diverted material.

A paper discussing our experimental work associated with this project has been submitted to a peerreviewed journal, Radiochimica Acta. This past work includes spectroscopic measurements of aqueous and solvent PUREX simulant solutions containing $\mathrm{U}, \mathrm{Pu}$, Np, nitric acid, and/or TBP-dodecane. Chemometric modeling using Raman spectral data for the quantitative prediction of $\mathrm{UO}_{2}{ }^{2+}$, nitric acid, and $\mathrm{NO}_{3}{ }^{-}$in PUREX feed simulant solutions was performed, as well as chemometric modeling using visNIR spectral data for predicting $\mathrm{Pu}(\mathrm{IV}), \mathrm{UO}_{2}{ }^{2+}$, and $\mathrm{Np}(\mathrm{V})$ in PUREX feed simulant solutions.

\subsubsection{References}

1. Orton, Chris, Bryan, Samuel A, Schwantes, Jon M, Levitskaia, Tatiana G, Fraga, Carlos G; Peper, Shane M; Advanced Process Monitoring Techniques for Safeguarding Reprocessing Facilities; Proceedings of the IAEA Symposium on International Safeguards: Preparing for Future Verification Challenges PNNL-SA-75173; November, 2010.

2. Bryan, Samuel A; Levitskaia, Tatiana G; Lines, Amanda M; Billing, Justin M; Casella, Amanda J; Johnsen, Amanda M; Peterson, James M; Thomas, Elizabeth M: ON-LINE MONITORING FOR CONTROL AND SAFEGUARDING OF RADIOCHEMICAL STREAMS AT SPENT FUEL REPROCESSING PLANT PNNL-SA-70056; 2nd Japan-IAEA Workshop on Advanced Safeguards Technology for the Future Nuclear Fuel Cycle.

3. Bryan, Samuel A; Levitskaia, Tatiana G; Lines, Amanda M; Billing, Justin M; Casella, Amanda J; Johnsen, Amanda M; Peterson, James M; Thomas, Elizabeth M: ON-LINE MONITORING FOR CONTROL AND SAFEGUARDING OF RADIOCHEMICAL STREAMS AT SPENT FUEL REPROCESSING PLANT PNNL-SA-70056; 2nd Japan-IAEA Workshop on Advanced Safeguards Technology for the Future Nuclear Fuel Cycle.

4. Bryan, Samuel A; Levitskaia, Tatiana G: On-Line Monitoring for Control and Safeguarding of Radiochemical Streams at Spent Fuel Reprocessing Plant PNNL-SA-70825; JAEA Workshop at PNNL; February 12, 2010.

5. Bryan, Samuel A; Levitskaia, Tatiana G; Casella, Amanda J; Peterson, James M; Johnsen, Amanda M; Lines, Amanda M; Thomas, Elizabeth M; Orton, Chris: Spectroscopic On-Line 
Monitoring for Process Control and Safeguarding of Radiochemical Streams; PNNL-SA-70392; Book Title: Advanced separation techniques for nuclear fuel reprocessing and radioactive waste treatment; Publisher: Woodhead Publishing Ltd; CRC Press LLC.

6. Lines, Amanda M; Levitskaia, Tatiana G; Bryan, Samuel A: Monitoring of PUREX Radiochemical Processes for Control and Safeguards; PNNL-SA-73427; Joint 65th Northwest/22nd Rocky Mountain Regional Meeting, Pullman, WA June 21, 2010.

7. Casella, Amanda J; Bryan, Samuel A; Levitskaia, Tatiana G; Peterson, James M: Development of Spectroscopic On-line Measurements for Spent Fuel Reprocessing Plants PNNL-SA-73123; 2010 ANS Winter Meeting and Nuclear Technology Expo, Las Vegas, NV, November 7, 2010.

8. Levitskaia, Tatiana G; Bryan, Samuel A; Casella, Amanda J; Peterson, James M: On-Line Monitoring of Spent Fuel Reprocessing Streams; PNNL-SA-71610; ACS National Meeting ; San Francisco, CA; March 25, 2010.

9. Johnsen, Amanda M; Soderquist, Chuck Z; Peterson, James M; Bryan, Samuel A; Levitskaia, Tatiana G: Online Process Monitoring of Commercial Spent Fuel Reprocessing Streams PNNLSA-69614; American Nuclear Society Winter Conference; Washington, DC ; November 17, 2009.

10. Bryan, Samuel A; Levitskaia, Tatiana G, Lines, Amanda M, Billing, Justin M, Casella, Amanda J, Johnsen, Amanda M, Peterson, James M, and Thomas, Elizabeth M: On-Line Monitoring for Control and Safeguarding of Radiochemical Streams at Spent Fuel Reprocessing Plant PNNLSA-69297; Japan - IAEA Workshop; Tokai-Mura , November 10, 2009.

11. Casella, Amanda J; Levitskaia, Tatiana G; Bryan, Samuel A; Billing, Justin M; Peterson, James M; Lines, Amanda M; Johnsen, Amanda M; Thomas, Elizabeth M: On-Line Monitoring and Control of Radiochemical Streams at Spent Fuel Reprocessing Plants PNNL-SA-69055; Sixteenth Symposium on Separation Science and Technology for Energy Applications; Gatlinburg, TN , October 21, 2009. 


\subsection{FY-2010 Multi-Isotope Process Monitoring}

\subsection{Introduction}

The Multi-Isotope Process (MIP) Monitor is a new approach to process monitoring in reprocessing facilities under international safeguards. It uses gamma spectroscopy of spent fuel, product streams, and waste streams combined with multivariate analysis to autonomously and automatically monitor process conditions (e.g., acid concentrations) to verify nominal operations in near-real-time. In addition, the approach can potentially be used to quantify process variables and fuel characteristics (e.g., spent fuel burnup). Proof-of-concept simulations and experiments to demonstrate the validity and partial application of this tool were performed in previous years. This report details the efforts undertaken at PNNL during FY 2010 to further develop and demonstrate the capabilities of the MIP Monitor and explore its application in a process monitoring system. These efforts were funded by the U.S. Department of Energy's (DOE) Office of Nonproliferation and International Security (NA-24).

\subsection{FY 2010 Overview of Tasks and Accomplishments}

During FY 2010, the following tasks were completed at PNNL:

- Spent nuclear fuel samples from previous NA-24-funded reprocessing demonstration experiments performed at PNNL were archived to maintain samples for future analyses and demonstrations. The intent of this effort was to preserve resources for future technology development and demonstration. The raw spent fuel used in the earlier demonstrations was slated for disposal during FY 2010.

- The PNNL research team worked with researchers at the University of Tennessee-Knoxville to apply advanced multivariate techniques on the gamma spectra that were collected or simulated. The purpose of this task was to improve the accuracy and increase the capability of the MIP Monitor.

This report is intended to give an overview of efforts that were focused on these tasks; however, additional accomplishments were made during FY 2010. Two conference manuscripts giving an overview of the MIP Monitor and reporting some results from initial experiments and simulations were submitted. One of the manuscripts accompanied a presentation made at the Second Japan-International Atomic Energy Agency Workshop on Advanced Safeguards Technology for the Future Nuclear Fuel Cycle, which was held November 10-13, 2009, in Tokai-mura, Ibaraki, Japan [7]. The other paper was submitted to accompany a poster presentation at the Symposium on International Safeguards: Preparing for Future Verification Challenges, which was held November 1-5, 2010, in Vienna, Austria.

A journal article detailing the experimental demonstrations funded in past years by NA-24 is being written. (An additional journal article detailing the proof-of-concept simulations was submitted in FY 2010; however, the work was funded by the Fuel Cycle Research and Development Program of the DOE Office of Nuclear Energy). The work is primarily based on the dissertation of Christopher Orton, who finished his Ph.D. during FY 2010 and continues to contribute to the MIP Monitor project as a PNNL staff member. A portion of Dr. Orton's dissertation research was funded by NA-24, and he is an example of efforts by NA-24 and PNNL to train young scientists in safeguards-related topics. 
Presentations describing the MIP Monitor were given at PNNL to foreign representatives on two separate occasions. The first presentation was given in February 2010 to Michio Seya (Principal Engineer, Nuclear Nonproliferation Science and Technology Center) and Soichiro Katsumura from the Japan Atomic Energy Agency. The second presentation was given to Dr. Klaus Mayer (Nuclear Safeguards and Security) from the European Commission, Joint Research Center, Institute for Transuranium Elements.

\subsection{Brief Overview of the MIP Monitor}

Conventional approaches for safeguarding nuclear materials rely, in large part, on destructive analyses to quantify the amount of nuclear material within bulk handling facilities and to verify the location of all material within a significant quantity. Although the accuracies of destructive analyses are superb, they are extremely resource intensive, have limited sampling rates, and are associated with a significant time lag from sampling to final reporting. In addition, the error associated with these analyses scales with the size of the facility [1]. As such, highly precise destructive measurements of special nuclear material alone at large facilities may not be adequate to ensure that diversions have not occurred. While it is not likely that more precise destructive measurement techniques will be developed in the near future, intelligent integration of a variety of online process monitoring tools capable of near-real-time, nondestructive measurements may be successful in adequately safeguarding even the largest envisioned facility. A combination of these techniques could provide a more robust framework that would use both material accountancy and augmented material control via continuous process flow sheet verification.

PNNL currently is developing and demonstrating the MIP Monitor, which is capable of monitoring conditions at a nuclear reprocessing plant online, nondestructively, and in near-real-time. [2-7]. Modern industrial reprocessing techniques, including the PUREX and UREX+ family of separations technologies, employ liquid-liquid extraction techniques to recycle spent nuclear fuel. The fuel is first dissolved into an aqueous solution, and then, the products (e.g., actinides) are extracted by contacting the fuel solution with an organic solution that preferentially (i.e., thermodynamically) removes them from contaminants (e.g., fission and activation products) [8]. In these two-phase systems, small amounts of both product and contaminants remain in the other phase. The distribution of each element between the organic and aqueous phases is determined by major process variables such as acid concentration, organic ligand concentration, reduction potential, and temperature. Hence, for a consistent industrial process (i.e., steady-state and reproducible conditions), the distribution of each element between the organic and aqueous phases should be relatively constant. Consequently, the pattern of elements distributing into product and waste streams at each stage in the facility should be reproducible, within normal industrial variations, resulting in a signature indicative of process conditions that can be considered "normal." Under abnormal conditions (such as those expected under some protracted diversion scenarios), patterns of elements within the various streams would be expected to change measurably.

The MIP Monitor is designed to track changes in the distribution of gamma-emitting elements as indicators that process conditions are changing. In-process surveillance by the MIP Monitor is accomplished by coupling the gamma spectra recorded from constituent streams with multivariate analysis, such as principal component analysis (PCA). PCA is a chemometrics tool that finds combinations of variables (principal components or PCs) that best describe the variance between differing datasets [9]. The MIP technique evaluates patterns of the gamma-emitting nuclides in near-real-time for statistically relevant signs of significant process changes. By measuring the process against declared 
parameters, the MIP Monitor can detect and warn of possible process migrations to undeclared operations. Because the pattern comparison is automatic and autonomous, proprietary operational or fuel information can be protected while assuring process integrity. However, if desired, process conditions can also be quantified using a multivariate calibration technique such as partial least squares (PLS) analyses [10].

Another advantage of the MIP Monitor is that gamma detectors could be placed throughout a reprocessing facility. Gamma detectors can be small and easily collimated, thereby facilitating deployment to locations in the process line where other monitoring systems might be restricted because of their size, maintenance, or technical limitations. While high-purity germanium (HPGe) gamma detectors provide superior resolution, they need cryogenic cooling and are relatively fragile, which make them less desirable for deployment behind a biological shield where maintenance would be difficult. In addition, data at the resolution they can provide may not be necessary for the MIP Monitor analysis techniques. Multivariate analysis can be tailored to consider overall shifts in the spectra, as opposed to focusing solely on isotopic analysis, to monitor changes even when peaks are not completely resolved. Medium resolution gamma detectors require less maintenance and no cooling appendages, thus optimizing their deployment and maintenance. Our initial experimental and modeling efforts indicate that the MIP Monitor is capable of the described operations. More detailed overviews of the MIP Monitor can be found in the technical literature [2-7].

\subsection{Experimental Efforts - Sample Archival}

Since 2008, extensive experimental efforts have been conducted at PNNL to test and improve the MIP Monitor. Four different segments of commercial spent nuclear have been dissolved and separated using the PUREX method. Variations in the acid concentrations were made to provide samples for proofof-principle measurements and analysis by the MIP Monitor. These samples also were used for testing by the spectroscopic methods being studied at PNNL [11]. All of the fuel segments were from boiling water reactors (BWR). Three segments originated from the same fuel rod, but were taken at locations that had experienced different burnup levels. The reactor residence and cooling times for all the segments were the same. The irradiation levels ranged from a low burnup of $16 \mathrm{MWd} / \mathrm{kgU}$ to a midrange burnup of $30 \mathrm{MWd} / \mathrm{kgU}$. The fourth segment was from a different commercial reactor and had a much higher burnup of $\sim 70 \mathrm{MWd} / \mathrm{kgU}$ and a shorter cooling time. These samples provided an excellent array of fuel characteristics to test the MIP Monitor against different feedstock solutions. In addition, the dissolved fuel, organic extract (containing mostly $\mathrm{Pu}$ and $\mathrm{U}$ ), and aqueous raffinate (containing fission and activation products) samples from extractions performed at different acid concentrations provided an excellent selection of chemical conditions for testing.

During FY 2010, the samples from the experiments were reviewed and checked for sample and container integrity. Duplicate samples were disposed of. In addition, general laboratory waste from the hot cell dissolutions was packaged and half of it was sealed in a shielded drum that is ready for disposal. Cleanup of the wastes generated during the dissolutions continues. Samples from all of the solutions created during the experiments were preserved for future use. Containers that appeared to be degrading from the high radiation dose were properly disposed of, and the liquid samples were moved to new containers. The samples are inspected on a periodic basis and maintained as needed. 


\subsection{Advanced Multivariate Analysis Methods}

The PNNL research team worked with researchers at the University of Tennessee-Knoxville to explore advanced multivariate analysis techniques to apply to the gamma spectra recorded from process streams at a reprocessing facility. The FY 2010 effort of the University of Tennessee researchers to improve on our initial multivariate efforts is described in the sections below.

\subsubsection{Analysis Description}

The MIP Monitor used an HPGe detector to perform gamma-ray spectroscopy on BWR fuel elements dissolved in batch samples that represented different stages in a reprocessing stream. Spectra were taken at three different stages in the reprocessing stream: 1) the aqueous feed material at the beginning of the stream, 2) the organic product extract at the end of the stream, and 3) the aqueous waste, referred to as the raffinate, at the end of the stream. The three BWR samples discussed in this work are ATM105P, ATM105A, and ATM109. The ATM105A and ATM105P come from the same fuel rod, but from different axial locations. Each sample had different burnup and cooling times. A summary of the burnup and cooling times for the different fuels is provided in Table 2.1.

Table 2.1. Summary of BWR Fuel Properties

\begin{tabular}{ccc}
\hline Fuel Type & Burnup (GWD/MTU) & Cooling Time (Years) \\
\hline ATM105A & 16 & 26 \\
ATM105P & 30 & 26 \\
ATM109 & 70 & 16 \\
\hline
\end{tabular}

Each fuel sample was initially dissolved and brought up into five different $\mathrm{HNO}_{3}$ concentrations: 0.3 $\mathrm{M}, 1.3 \mathrm{M}, 2.5 \mathrm{M}$, 3.8 M, and 5.1 M. The $2.5 \mathrm{M} \mathrm{HNO}_{3}$ concentration was considered the normal operating condition [8]. Ten sample spectra were taken of the organic product from each of the separations performed at the five acid concentrations, resulting in 50 samples per fuel or 150 samples total. The spectrum was collected over 8190 channels, in approximately $0.5 \mathrm{KeV}$ increments, with a maximum energy of $3.5 \mathrm{MeV}$. A sample spectrum from the ATM109 fuel dissolved in $2.5 \mathrm{M} \mathrm{HNO}_{3}$ is shown in Figure 2.1.

The spectra were analyzed using PCA and PLS regression. Previous research used the entire spectrum in developing the PCA and PLS models. This research developed the methodology to extract relevant peaks above the Compton continuum, and then used only the peaks (instead of the entire spectrum) to develop the PCA and PLS models. This research also developed meaningful statistics to compare the performance of each model. 


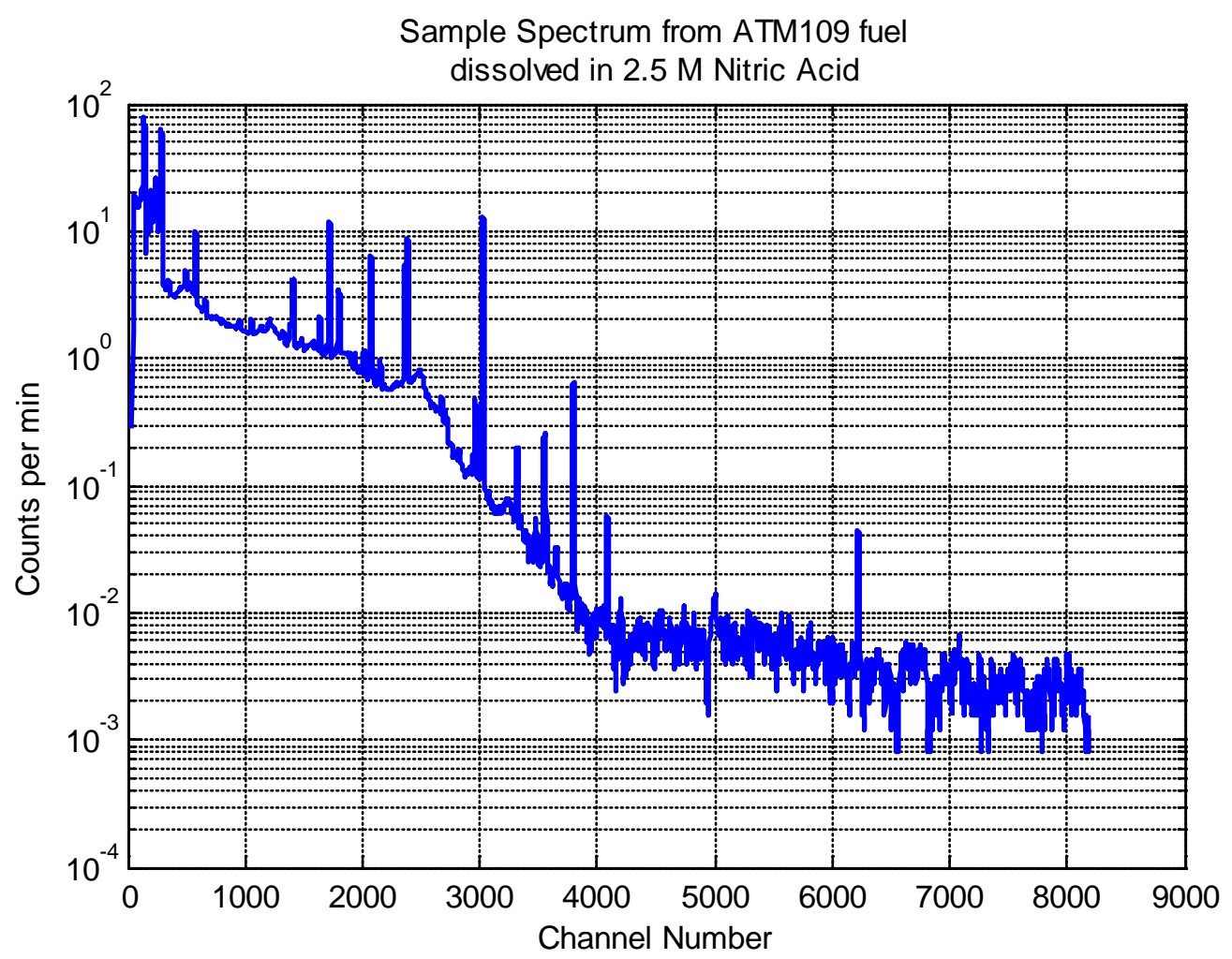

Figure 2.1. Gamma Spectrum of the Organic Fraction of the ATM109 Fuel Dissolved and Separated in $2.5 \mathrm{M} \mathrm{HNO}_{3}$.

\subsubsection{Principal Component Analysis}

PCA linearly transforms a data set into a set of orthogonal variables, called PCs, in which each variable is optimized to capture the common variance in the original data set. The number of PCs is generally limited to the number of variables or the number of observations, whichever is smaller. However, generally only a few PCs are needed to capture the majority of the dataset's variance, and the other PCs are ignored. For instance, the BWR fuel spectra consist of 8190 variables (one variable for each channel) and are generally compressed into less than five PCs. Figure 2.2 shows the first two PCs when the 150 gamma spectra are transformed into the principal component space. In PCA, there is no quantity being predicted; the PCs are used to group the data. The analysis of the PCs consists of two steps: 1) unsupervised analysis and 2) supervised modeling. A complete explanation of PCA can be found in reference [9].

In unsupervised PCA, all the spectra were used to create the PCs, and then the ability of the PCs to distinguish the different fuel types was evaluated. To measure the ability of the PCs to groups the data, the statistic $\mathrm{D}$ is used, where $\mathrm{D}$ is: 


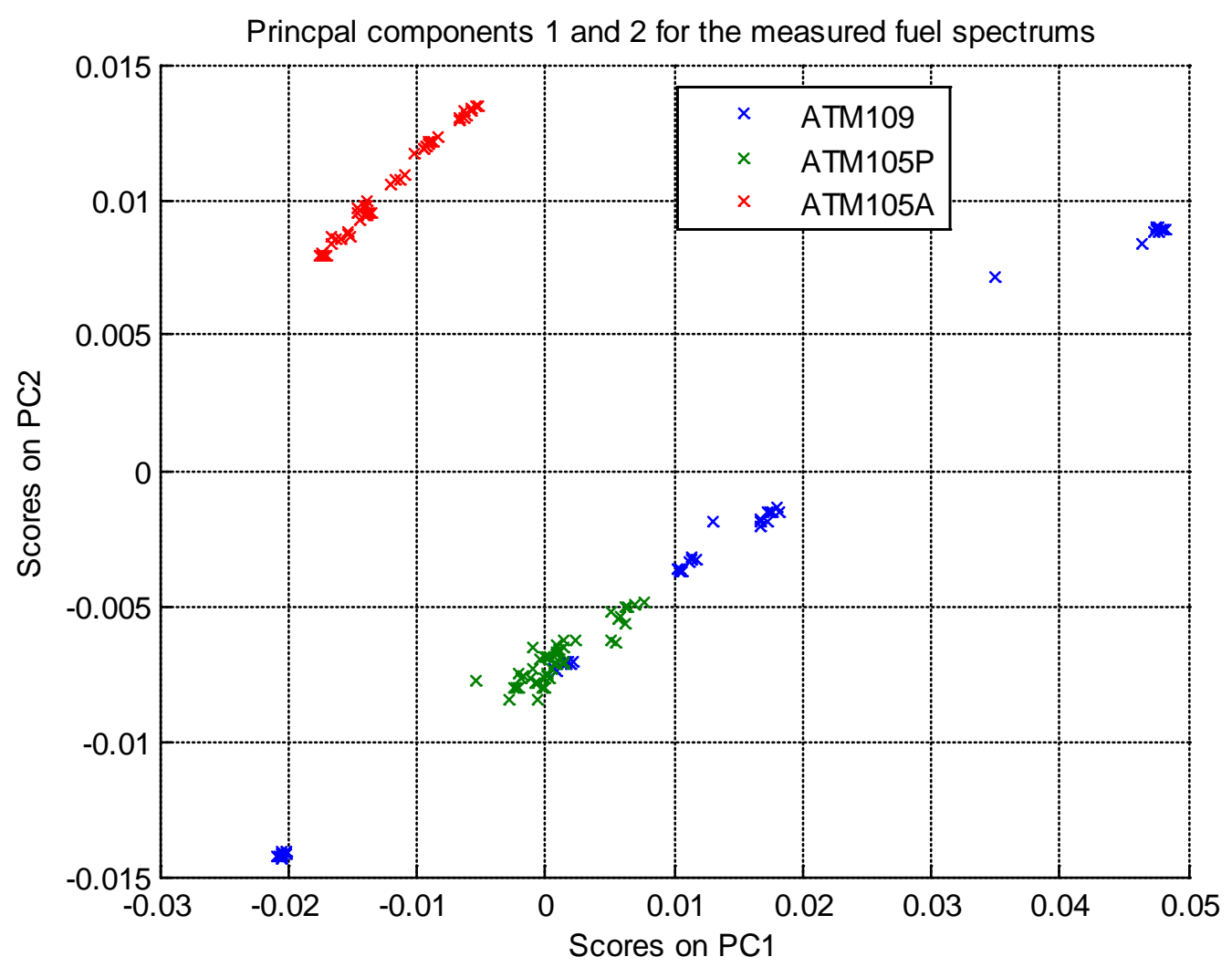

Figure 2.2. PC 1 and PC 2 of the Measured Fuel Spectra.

$\mathrm{M}_{\mathrm{a}}$ and $\mathrm{M}_{\mathrm{b}}$ are the mean of PC $\mathrm{N}$ for groups $\mathrm{A}$ and $\mathrm{B}$, and $\sigma_{a}$ and $\sigma_{b}$ are the standard deviations of principal component $\mathrm{N}$ for groups $\mathrm{A}$ and $\mathrm{B}$. The $\mathrm{D}$ statistic, which is the ratio of the distance between the mean of two clusters divided by the groups combined standard deviation, essentially provides a quantitative way to determine how well each PC groups the data. In this analysis, the intrinsic grouping of the data (i.e., grouping based on fuel type or acid concentration) was used to define each group cluster. However, one limitation of the D statistic is that it evaluates each PC individually. For example, in Figure 2.2 there would be three groups: 1) ATM 109 fuel, 2) ATM105A fuel, and 3) ATM105P fuel. The $\mathrm{D}$ statistic can be interoperated as the ability to draw horizontal and vertical lines between the groups. A higher D statistic means the clusters are well separated. Generally, a D value less than three means the groups are not well separated.

In supervised PC modeling, spectra from the normal operating conditions (when the fuel is dissolved in $2.5 \mathrm{M} \mathrm{HNO}_{3}$ ) are used to develop the PCs. Then, the spectra from off-normal operating conditions are projected onto the previously developed PCs for normal operating conditions, and the ability of the model to distinguish between normal and off-normal operating conditions is evaluated. The standard statistics for measuring the ability of a PC model to evaluate normal versus off-normal conditions and the Qresidual and the $\mathrm{T}^{2}$ variables. See references $[9,10]$ for explanations of these statistics.

\subsubsection{Partial Least Squares Regression Analysis}

PLS regression analysis, like PCA, is another technique that transforms a known data set into orthogonal variables, called latent factors. However, with PLS regression analysis, two data sets are used 
to develop the orthogonal variables: 1) a set of predictor variables and 2) a dataset containing the quantities of interest. For the MIP Monitor, the predictor variables are the collected gamma spectra, and the quantities of interest are the acid concentrations at which the liquid-liquid separation is performed. With PCA, the principal components were optimized to capture the variance in the predictor data set (because there were no quantities of interest). With PLS regression analysis, the latent factors are optimized to not only capture the variance in the predictor data set, but to also correlate with the quantity of interest. Once a PLS regression model is made, a query vector is applied to the model to predict a quantity of interest. For the MIP Monitor, once a model has been created with known spectra and known acid concentrations, the model would be applied to a measured spectrum to provide an estimate of an unknown acid concentration. A more complete explanation of PLS regression analysis can be found in references $[9,10]$.

\subsubsection{Gamma Peak Extraction}

Previous research with the MIP Monitor used the entire gamma spectrum to develop the PCA and PLS models. The gamma spectrum spans 8190 channels with energy bins approximately $0.5 \mathrm{KeV}$ wide. Because HPGe has such fine energy resolution, the gamma peaks are very narrow and the channels between peaks (especially channels higher than the Compton continuum) generally have count rates several orders of magnitude below the peak values. Including these superfluous variables in the development of the PCA and PLS models could potentially make the models less robust.

Because the gamma peaks are narrow, they can be treated as noise spikes and extracted using standard de-noising techniques, such as a median filter that extracts the median values through a moving window of the raw data. Applying this filter to an HPGe gamma spectrum removes all the peaks above the Compton continuum. The peaks then can be quantitatively defined as channels that have a threshold number of counts above the extracted Compton continuum. To calculate the threshold, the measured spectrum was converted from raw counts to a count rate by dividing by the measurement time. Then, the standard deviation of each channel can be calculated using the following relationship [12]:

$\mathrm{G}$ is the gross counts in each channel of the measured spectrum, and $\mathrm{T}$ is the measurement time. Finally by subtracting the filtered spectrum from the measured spectrum, and dividing the residuals by the standard deviation, each channel can be expressed as the number of standard deviations above the Compton continuum. Figure 2.3 shows the measured gamma spectrum expressed as the number of standard deviations above the Compton continuum. 


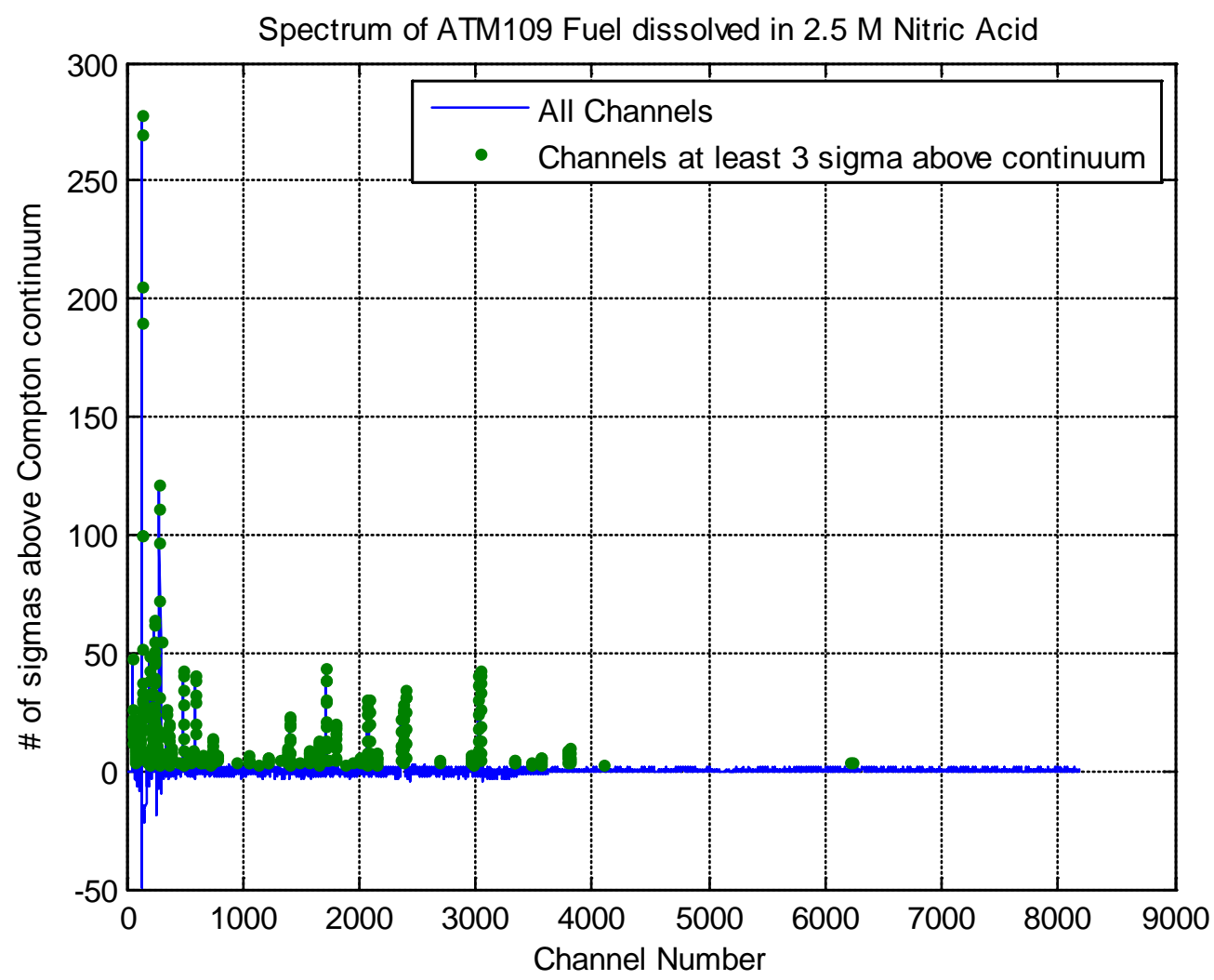

Figure 2.3. Gamma Spectrum of the Organic Extract of ATM109 Fuel Expressed as the Number of Standard Deviations Above the Baseline. The green dots represent channels that were at least three standard deviations above the Compton continuum.

Figure 2.4 shows the results of the peak extraction algorithm. The blue line is the measured count rate. The green line is the continuum extracted using the median filter and it is used to calculate the standard deviations. The red dots represent the channels that were at least three standard deviations above the continuum. For a single spectrum, the number of channels that were at least three standard deviations above the continuum was generally around 400; when multiple spectra from all three fuel types were included, the number of significant channels was about 1200. The number of significant channels is not a representation of the number of gamma peaks. Because each gamma peak has a finite width and spans multiple channels, the actual number of gamma peaks may only be on the order of 30. The PCA and PLS models were developed using the entire spectrum and only using the channels that contained peaks identified by a three standard deviations above the Compton continuum.

To provide further data reduction, a technique was investigated that reduced the number of channels by extracting only the center channel of each gamma peak. This refinement further reduced the number of channels to about 70. A sample spectrum with the peaks extracted is shown in Figure 2.5. 


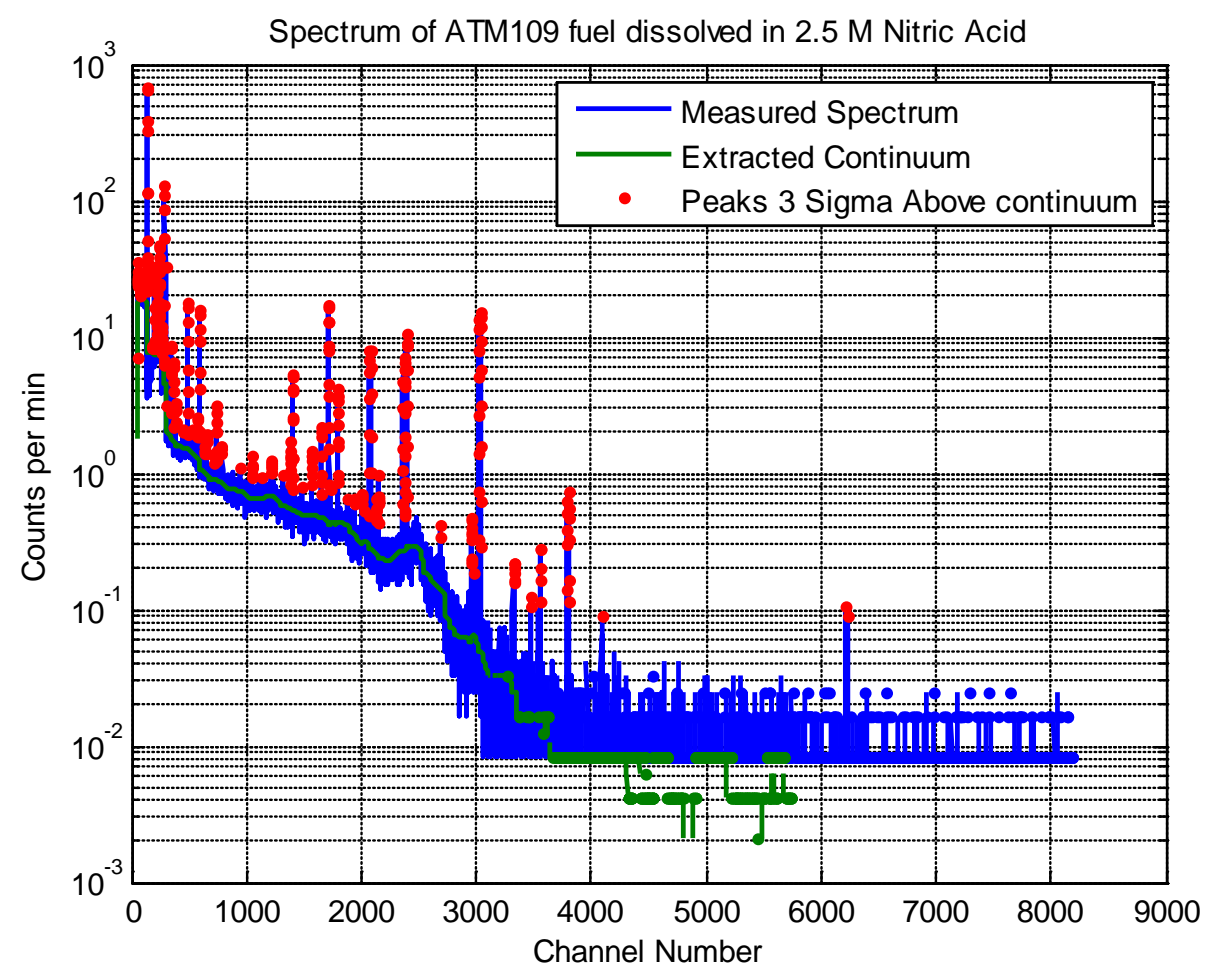

Figure 2.4. The Measured Gamma Spectrum from the Organic Extract of an ATM109 Fuel Dissolved and Separated in $2.5 \mathrm{M} \mathrm{HNO}_{3}$, the Extracted Continuum, and the Channels at Least Three Standard Deviations Above the Compton Continuum.

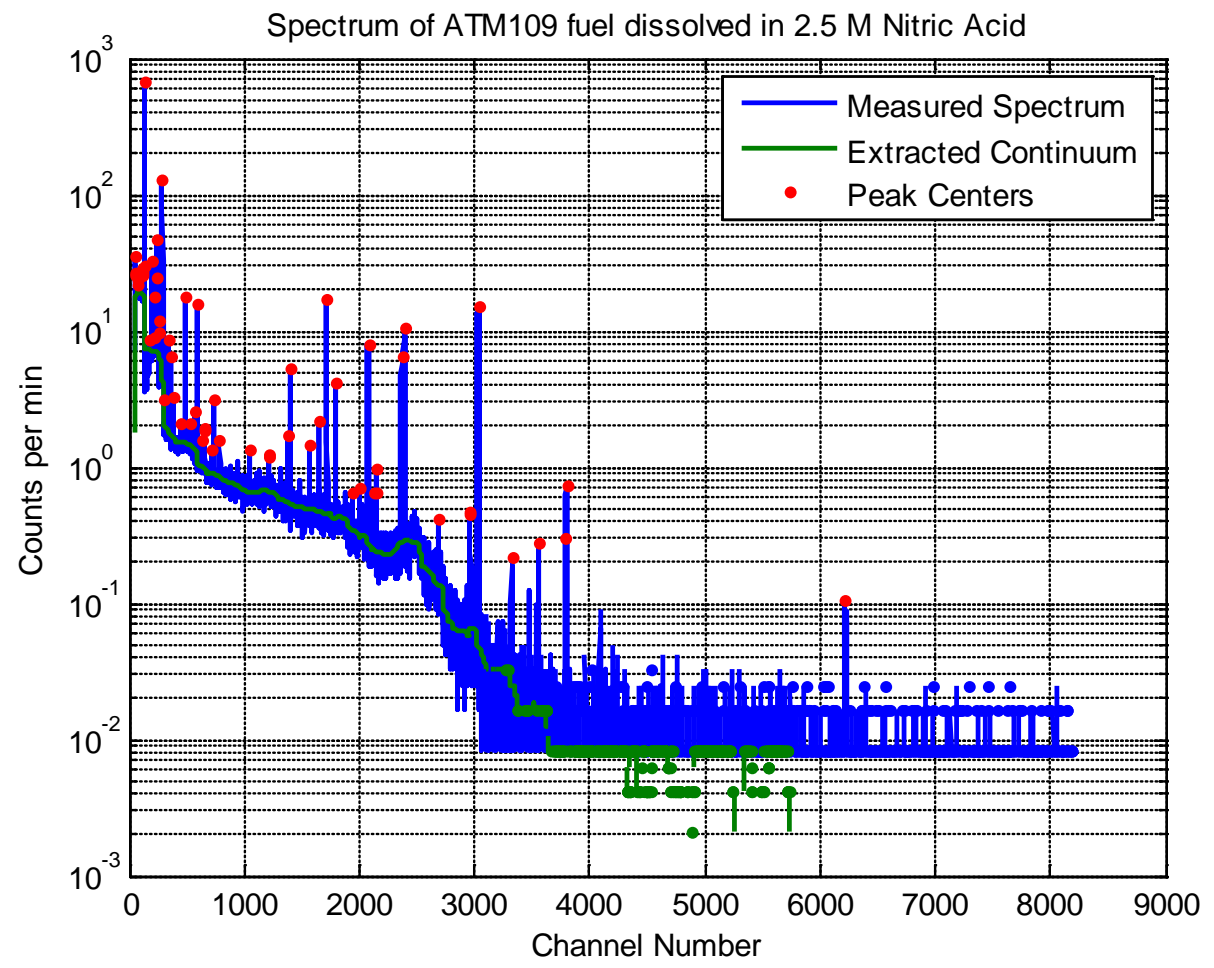

Figure 2.5. The Measured Gamma Spectrum from an ATM109 Fuel Dissolved in $2.5 \mathrm{M} \mathrm{HNO}_{3}$, the Extracted Continuum, and the Channels at the Gamma Peak Centers. 
Then, to calculate the integral of the peak, the peak width is calculated using the energy resolution of the HPGe detector. The following relationship is used to make this calculation:

$$
\mathrm{FWHM}=0.47 * \mathrm{SQRT}\left(\mathrm{E}_{\mathrm{keV}}\right)
$$

For each extracted peak, the integral is summed over the calculated width. For example, the full width at half maximum (FWHM) for a $100 \mathrm{keV}$ photon is $1.2 \mathrm{keV}$. The energy width of a channel is $0.4290 \mathrm{keV}$. The FWHM is about $2.3548 \sigma$. The sigma is then $1.2 \mathrm{keV}$ divided by 2.3548, which is 0.5. Therefore, at $100 \mathrm{keV}$, the standard deviation of the energy resolution is about the same as the width of the channel. To calculate the integral of the peak, we sum \pm 3 sigma of the peak center. In this example, the peak is at $100 \mathrm{keV}$ (corresponding to a channel number of 230), and the sigma is approximately one channel, so the integral would be the sum of counts in channels 227 to 233 .

This methodology could be expanded to handle different detector types, as long as the energy resolution is known. Though this technique was explored, it was not used for the PCA and PLS analyses in this report because of time and resource constraints. Further research is necessary to investigate its potential utility for improving multivariate analysis.

\subsubsection{Results}

Previous research developed PCA and PLS models for three purposes: 1) identification of fuel type, 2) identification of off-normal operation, and 3) prediction of fuel parameters, specifically acid concentration. Previously these models were developed using the entire gamma spectrum, and no quantitative results were given from the PCA models. For this most recent research, each model was made with the full gamma spectrum and with only the channels containing peaks at least three standard deviations above the Compton continuum.

The input for the PCA models was every gamma spectrum from every fuel type (a total of 150 spectra). Model 1 used the entire spectrum consisting of all 8190 channels. Model 2 used only the channels that were at least three standard deviations above the Compton continuum, thus reducing the dimensionality of the spectrum from 8190 to 1142 . For each model, two PCs were enough to capture most of the variation in the spectrum. The variances captured by the first four PCs are summarized in Table 2.2. The variances for PCs numbers 3 and 4 add little to the amount of variance captured; therefore, they were attributed to noise in the spectrum and were not used for analysis.

Table 2.2. Variance Captured by the First Four PCs for the Unsupervised PCA Model to Determine Fuel Type.

\begin{tabular}{ccccc}
\hline & \multicolumn{2}{c}{ Model 1 - Unsupervised } & \multicolumn{2}{c}{ Model 2 - Unsupervised } \\
\cline { 2 - 5 } PC & Variance Captured & $\begin{array}{c}\text { Cumulative } \\
\text { Variance Captured }\end{array}$ & $\begin{array}{c}\text { Variance Captured } \\
\text { by this PC }\end{array}$ & $\begin{array}{c}\text { Cumulative } \\
\text { Variance Captured }\end{array}$ \\
\hline 1 & by this PC & $86.16 \%$ & $85.54 \%$ & $85.54 \%$ \\
2 & $86.16 \%$ & $98.70 \%$ & $9.33 \%$ & $94.86 \%$ \\
3 & $12.54 \%$ & $99.40 \%$ & $1.15 \%$ & $96.02 \%$ \\
4 & $0.70 \%$ & $99.65 \%$ & $1.01 \%$ & $97.03 \%$ \\
\hline
\end{tabular}

Note. Model 1 used every channel of the spectrum to create the model, while Model 2 used only the channels at least three standard deviations above the Compton continuum. 
Figure 2.6 and Figure 2.7 plot the loadings on PC 1 and 2 for models 1 and 2, respectively. Both plots show good separation between the ATM109 and ATM105A fuel and between the ATM105P and ATM105A fuel. However, the ATM109 and ATM105P fuels are not well separated in either model. For grouping purposes, group one was the ATM109 fuel, group two was the ATM105P fuel, and group three was the ATM105A fuel. Table 2.3 summarizes the clustering performance of each model.

The D statistic in Table 2.3 shows that groups one and two are not well separated by either PC 1 or PC 2. The D statistic also indicated that neither PC 1 nor PC 2 is enough to individually identify the ATM109 and ATM105A fuel, which is somewhat counterintuitive to Figure 2.6. The ATM109 and ATM105A fuels cannot be separated easily in Figure 2.6 by drawing a horizontal or vertical line, but they could be separated easily by drawing a sloping line between the data set. The D statistic only identifies the ability for a single PC to delineate data groups and is therefore unable to quantify to ability of several PCs working together to delineate data groups. Therefore, the D statistic is a poor measure of clustering when the data exhibits the kinds of trends shown in Figure 2.6. Table 2.3, Figure 2.6, and Figure 2.7 show that, in general, model 2 does a better job of separating the fuel types although neither model 1 nor model 2 adequately separate the ATM109 and ATM105P fuel.

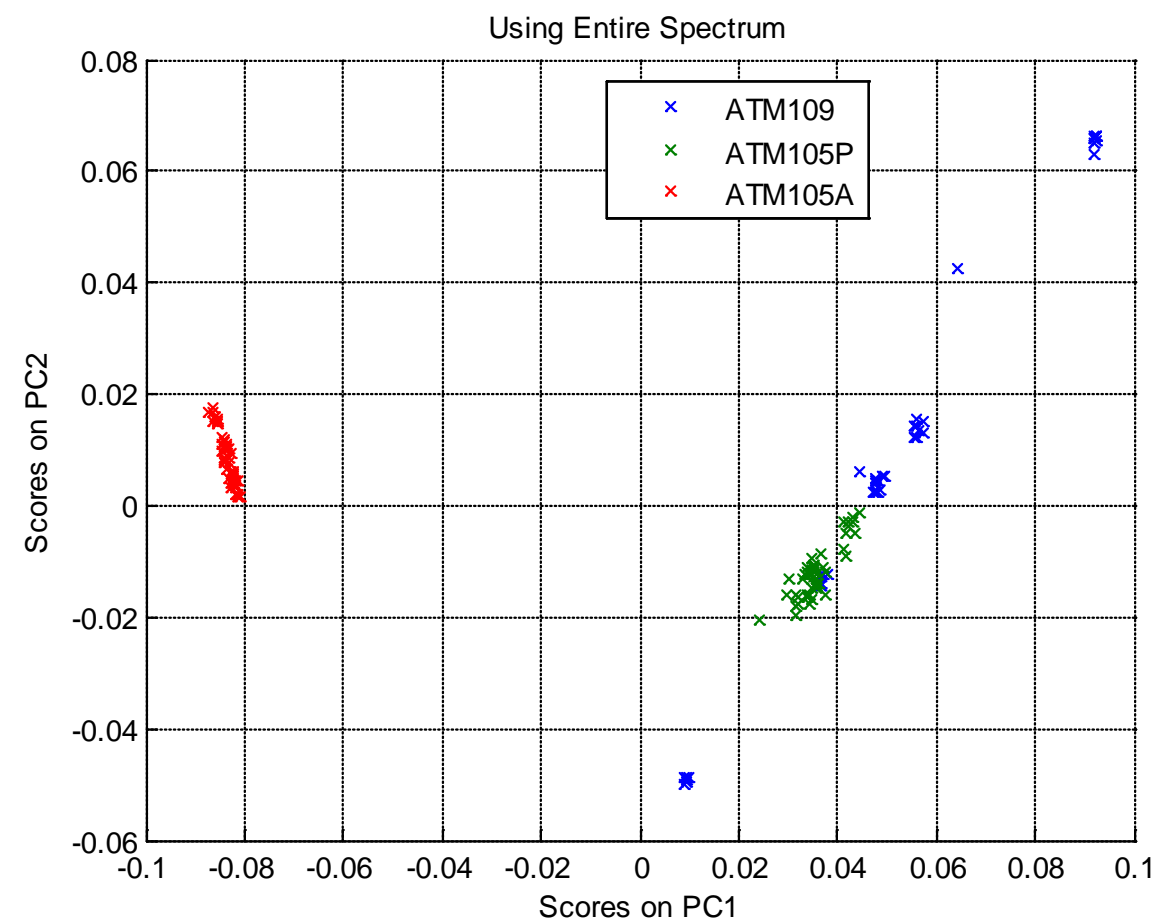

Figure 2.6. Plot of the Scores of PC 1 and PC 2 for Unsupervised PCA Model 1. The input to the model was the entire gamma spectrum. 


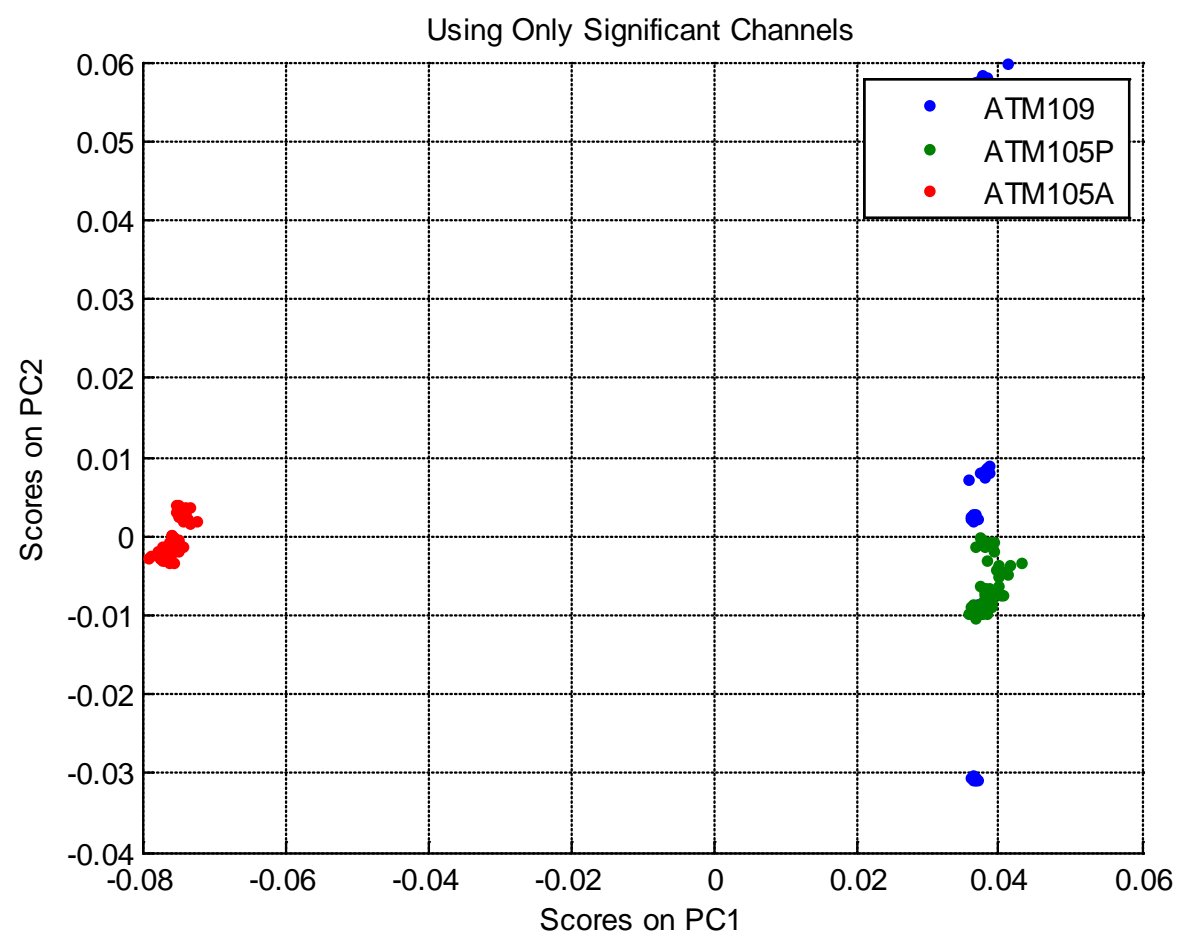

Figure 2.7. Plot of the Scores of PC 1 and PC 2 for Unsupervised PCA Model 2. The input to the model was only the significant channels defined by having a count rate at least three standard deviations above the Compton continuum.

Table 2.3. Summary of Unsupervised PCA Clustering Performance.

\begin{tabular}{ccc}
\hline D Statistic & Model 1 - Unsupervised & Model 2 - Unsupervised \\
\hline $\mathrm{D}_{121}$ & 0.45 & 0.78 \\
$\mathrm{D}_{122}$ & 0.42 & 0.39 \\
$\mathrm{D}_{131}$ & 4.94 & 63.71 \\
$\mathrm{D}_{132}$ & 0.13 & 0.19 \\
$\mathrm{D}_{231}$ & 27.33 & 54.41 \\
$\mathrm{D}_{232}$ & 3.09 & 1.49 \\
\hline
\end{tabular}

Note. In Model 1, every channel in the spectrum was used in the model, while in Model 2, only the channels at least three standard deviations above the Compton continuum were used. $\mathrm{D}_{121}$ identifies the separations for Group 1 and Group 2 by PC 1 . A higher value indicates better separation; a value of three is a minimum requirement. Groups 1, 2, and 3 are the ATM109, ATM105P, and ATM105A fuels, respectively.

In the unsupervised PCA model, both normal $\left(2.5 \mathrm{M} \mathrm{HNO}_{3}\right)$ and off-normal operating conditions were used to make the model. One method to improve the model would be to use only the normal operating data to create a PCA model. An assumption of this model is that the data is assumed to come from normal operation. Figure 2.8 and Figure 2.9 show the scores on PC 1 and PC 2. Table 2.4 and Table 2.5 summarize the variance captured by each PC and the clustering performance of each model. Again PCs 3 and 4 add little to the amount of the variances captured; therefore, they are attributed to noise in the spectrum and are not used for analysis. $\mathrm{D}_{122}$ has a value of 7.90 and 18.74 for models 1 and 2, respectively, meaning that groups 1 and 2 are well separated by PC 2 . 


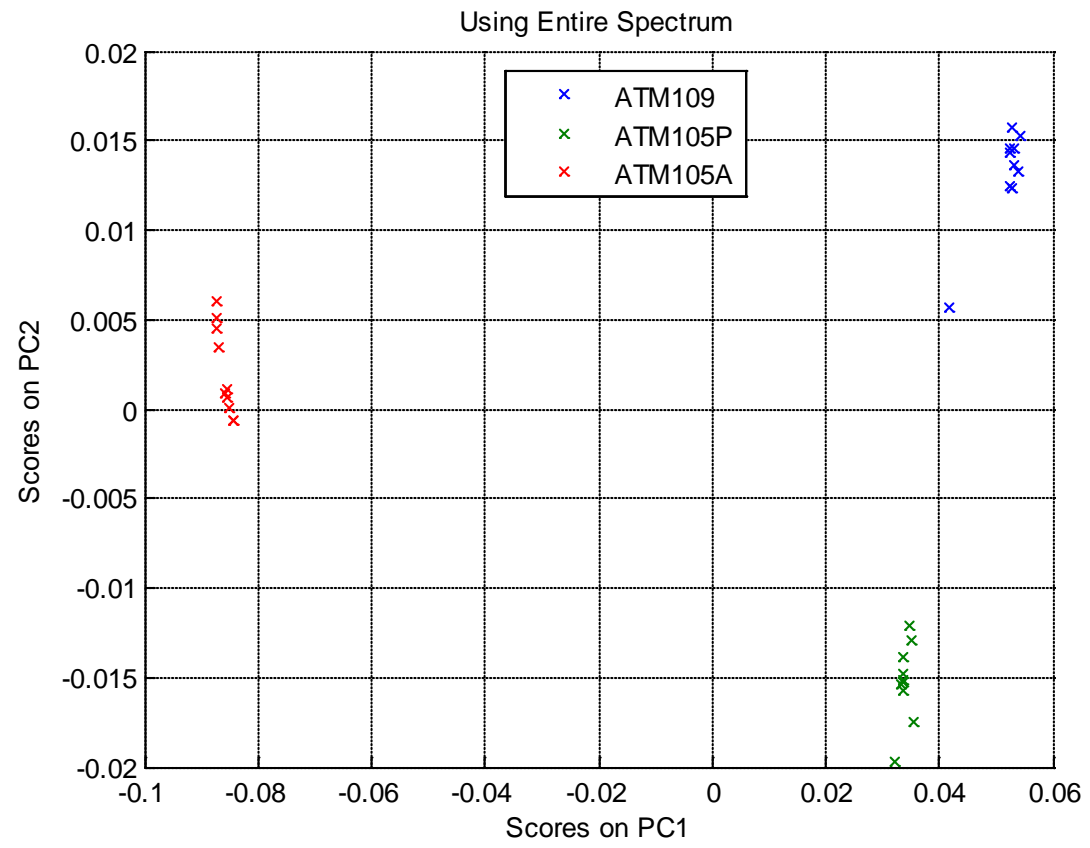

Figure 2.8. Plot of the Scores of PC 1 and PC 2 for Unsupervised PCA Model 1. The input to the model was the entire gamma spectrum for each fuel type assuming that the fuel was dissolved and separated under normal operating conditions (2.5M $\left.\mathrm{HNO}_{3}\right)$.

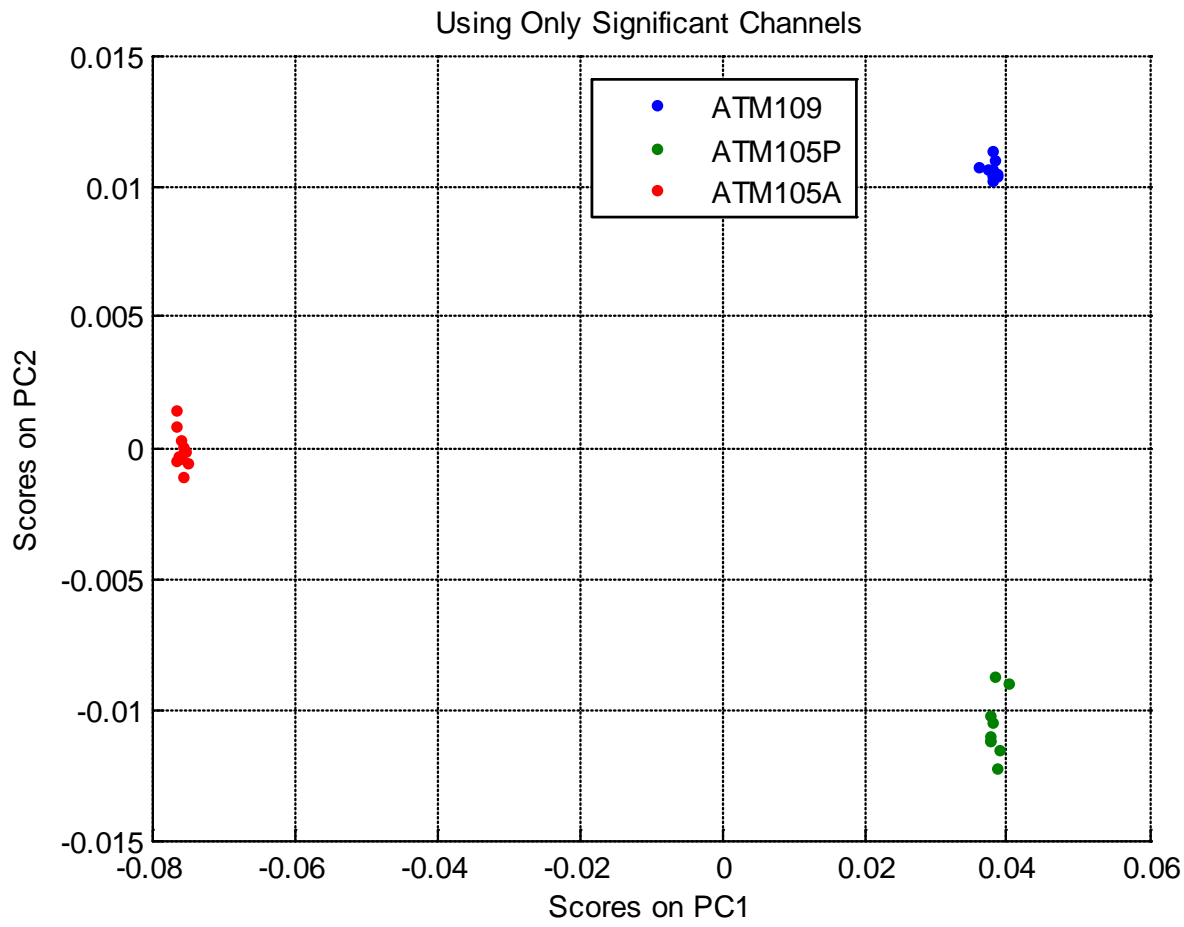

Figure 2.9. Plot of the Scores of PC 1 and PC 2 for Unsupervised PCA Model 2. The input to the model was only the significant channels defined by having a count rate at least three standard deviations above the Compton continuum. Each spectrum was assumed to be dissolved and separated under normal conditions $\left(2.5 \mathrm{M} \mathrm{HNO}_{3}\right)$. 
Table 2.4. Variance Captured by the First Four PCs for the Unsupervised PCA Model to Determine Fuel Type.

\begin{tabular}{|c|c|c|c|c|}
\hline \multirow[b]{2}{*}{$\begin{array}{c}\text { PC } \\
\text { Number }\end{array}$} & \multicolumn{2}{|c|}{ Model 1 - Unsupervised } & \multicolumn{2}{|c|}{ Model 2 - Unsupervised } \\
\hline & $\begin{array}{c}\text { Variance Captured } \\
\text { by this PC }\end{array}$ & $\begin{array}{c}\text { Cumulative Variance } \\
\text { Captured }\end{array}$ & $\begin{array}{c}\text { Variance Captured } \\
\text { by this PC }\end{array}$ & $\begin{array}{c}\text { Cumulative Variance } \\
\text { Captured }\end{array}$ \\
\hline 1 & $95.92 \%$ & $95.95 \%$ & $95.30 \%$ & $95.30 \%$ \\
\hline 2 & $3.65 \%$ & $99.56 \%$ & $2.50 \%$ & $97.81 \%$ \\
\hline 3 & $0.17 \%$ & $99.74 \%$ & $0.79 \%$ & $98.60 \%$ \\
\hline 4 & $0.11 \%$ & $99.85 \%$ & $0.31 \%$ & $98.91 \%$ \\
\hline
\end{tabular}

Table 2.5. Summary of Unsupervised PCA Clustering Performance.

\begin{tabular}{ccc}
\hline D Statistic & Model 1 - Unsupervised & Model 2 - Unsupervised \\
\hline $\mathrm{D}_{121}$ & 4.80 & 0.37 \\
$\mathrm{D}_{122}$ & 7.90 & 18.74 \\
$\mathrm{D}_{131}$ & 35.98 & 124.24 \\
$\mathrm{D}_{132}$ & 2.93 & 13.14 \\
$\mathrm{D}_{231}$ & 78.86 & 117.64 \\
$\mathrm{D}_{232}$ & 5.24 & 8.04 \\
\hline
\end{tabular}

Note. Model 1 used every channel in the spectrum to create the model, while Model 2 used only the channels at least three standard deviations above the Compton continuum. For both models, only spectra resulting from normal operations were used. $D_{121}$ identifies the separation for Group 1 and Group 2 by PC 1 . A higher value indicated better separation; a value of three is a minimum requirement. Groups 1, 2, and 3 are the ATM109, ATM105P, and ATM105A fuels, respectively.

\subsubsection{Identifying Off-Normal Operation}

If a fuel spectrum is known to come from normal operating conditions, it can be used to make a supervised PCA model. Then, an unknown fuel spectrum can be projected onto that PCA space to determine if the fuel spectrum was collected under normal operating conditions. Assuming the fuel type is known, a separate supervised PCA model can be made for each fuel type. The Q-residual and $\mathrm{T}^{2}$ statistic are used to measure the ability of a supervised PCA model to distinguish between normal and off-normal operating conditions. The Q-residual is related to the variation a query input has outside the normal PCA model. A large Q-residual means that the data in the query vector do not have the same internal relationships as the data that made the PCA model. The $\mathrm{T}^{2}$ statistic is related to the variation a query input has within the PCA model. Therefore, a large $\mathrm{T}^{2}$ statistic means that the data in the query vector may have the same internal relationships, but the data may be outside the training space of the PCA model.

To make a supervised PCA model, the spectra of the organic extract from when the fuel was dissolved and separated in $2.5 \mathrm{M} \mathrm{HNO}_{3}$ were considered normal operating conditions. All other acid concentrations were considered to be from off-normal operations. Supervised PCA model 1 used the entire gamma spectrum, while supervised PCA model 2 used only the significant channels. Figure 2.10 and Figure 2.11 are plots of the Q-residuals and $\mathrm{T}^{2}$ statistics, and their 99\% confidence levels, for model 1 and model 2, respectively. 


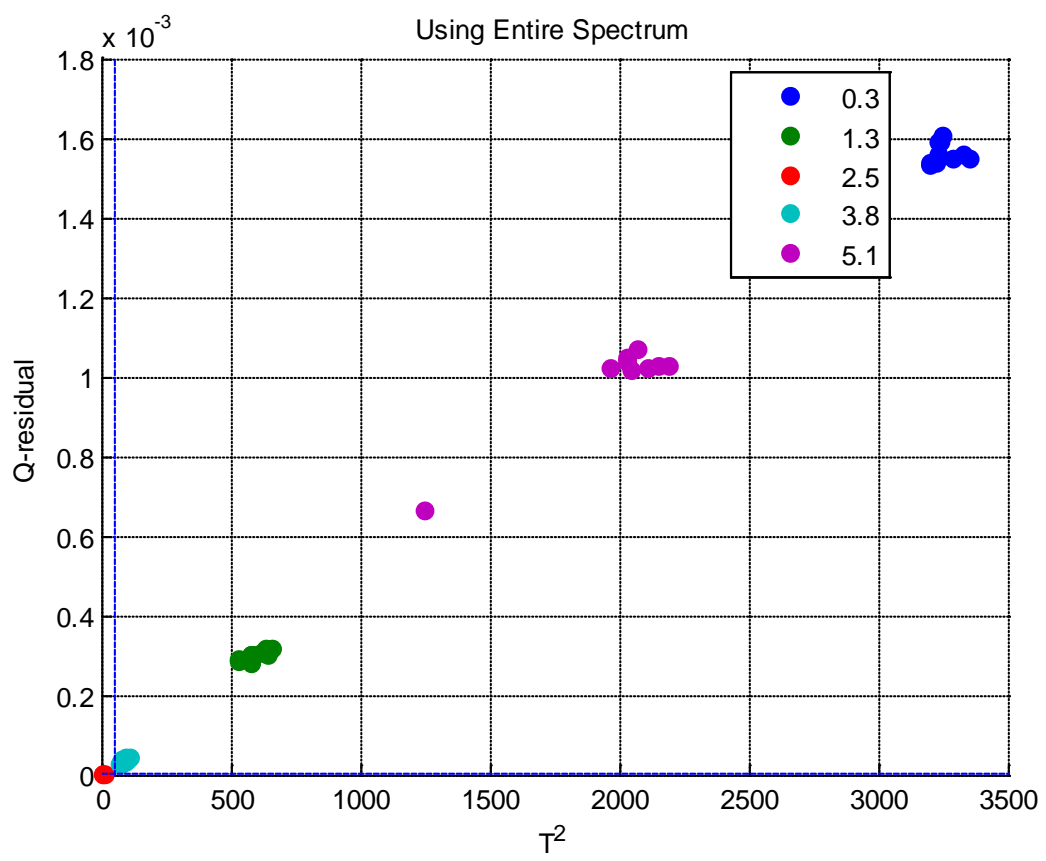

Figure 2.10. Plot of the Scores of Q-Residuals and $\mathrm{T}^{2}$ Statistics for the Supervised PCA Model 1. The dotted lines are the 99 percent confidence intervals for the respective statistics. Input for the model was the entire gamma spectrum for the organic extract of each fuel type, assuming that the fuel was dissolved and separated under normal operating conditions $\left(2.5 \mathrm{M} \mathrm{HNO}_{3}\right)$.

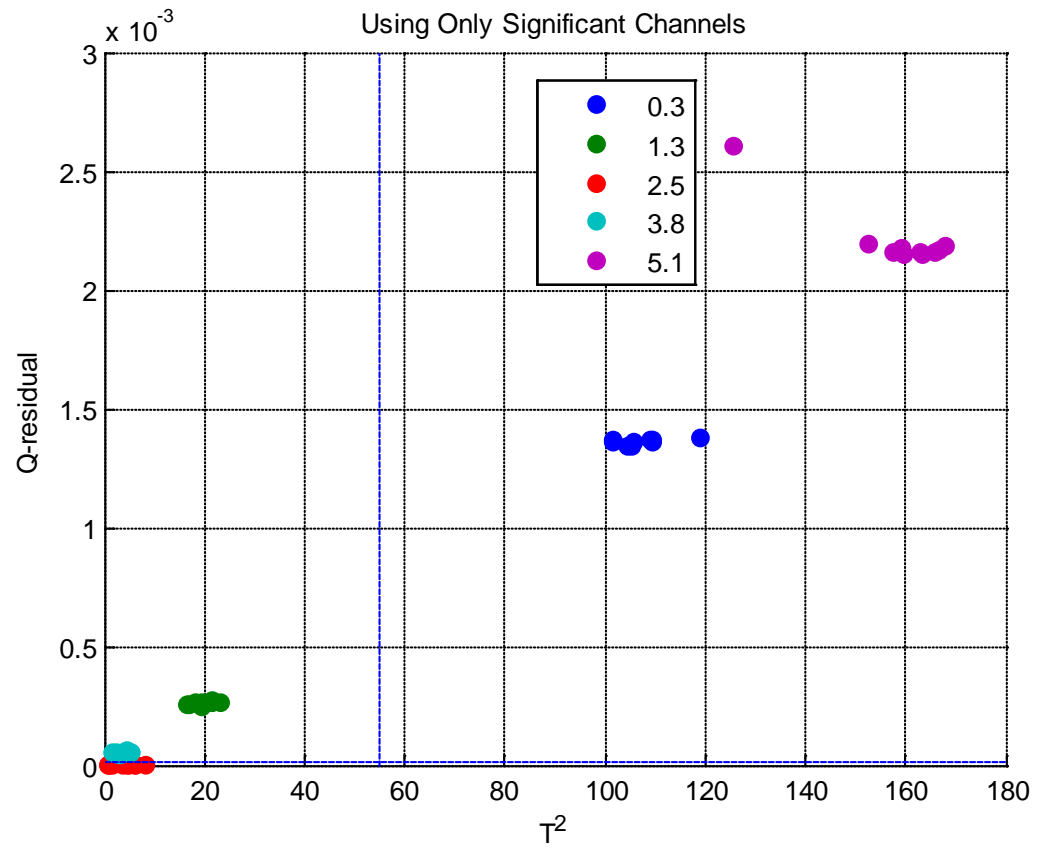

Figure 2.11. Plot of the Scores of Q-Residuals and $T^{2}$ Statistics for Supervised PCA Model 2. The dotted lines are the 99 percent confidence intervals for the respective statistics. Input for the model were the significant channels defined by having a count rate at least three standard deviations above the Compton continuum. Each spectrum of the organic extract was assumed to be from a separation performed under normal conditions (2.5 $\left.\mathrm{M} \mathrm{HNO}_{3}\right)$. 
While both models were able to distinguish between normal and off-normal operating conditions based solely on the Q-residual, model 1 (using the entire gamma spectrum) does a much better job identifying the off-normal operating conditions. In model 1 , all the off-normal spectra are beyond the 99 percent confidence level for both the Q-residuals and the $T^{2}$ statistics, essentially meaning that the PCA model is very sensitive to different acid concentrations. In model 2, all the off-normal spectra are beyond the 99 percent confidence level for the Q-residuals, but the $1.3 \mathrm{M}$ and $3.8 \mathrm{M} \mathrm{HNO}_{3}$ concentrations are within the 99 percent $\mathrm{T}^{2}$ statistic. This means that the $1.3 \mathrm{M}$ and $3.8 \mathrm{M} \mathrm{HNO}_{3}$ concentrations show some of the same internal relationships as the $2.5 \mathrm{M} \mathrm{HNO}_{3}$ concentrations, but their relationships different enough to be separated by the Q-residual. A summary of each group's average distance from the 99 percent confidence level is provided in Table 2.6. Although model 1 shows much better separation than model 2, at the 99 percent confidence levels for both models were able to correctly classify normal and off-normal operations. One possible explanation for the better performance of model 1 may be the amount of data available when the model was developed using the entire gamma spectrum. Model 2 essentially only uses the gamma peaks to develop the model; therefore, it may be missing important information that is captured in the Compton continuum, which is included in model 1 . Another possibility is that either model may be over-fitting the normal data. To correct over-fitting, a larger data set would be required.

Table 2.6. Summary of Supervised PCA Clustering Performance.

\begin{tabular}{ccccc}
\hline & \multicolumn{2}{c}{ Model 1 - Supervised } & \multicolumn{2}{c}{ Model 2 - Supervised } \\
\cline { 2 - 5 } Acid & $\begin{array}{c}\text { Q-residual)/(99\% } \\
\text { Concentration }\end{array}$ & $\begin{array}{c}\left(\mathrm{T}^{2}\right) /(99 \% \\
\text { confidence level) }\end{array}$ & $\begin{array}{c}\text { (Q-residual)/(99\% } \\
\left(\mathrm{T}^{2}\right) /(99 \% \\
\text { confidence level) }\end{array}$ & $\begin{array}{c}\text { confidence level) } \\
\text { confidence level) }\end{array}$ \\
\hline $0.3 \mathrm{M}$ & 772.33 & 10.23 & 123.70 & 1.95 \\
$1.3 \mathrm{M}$ & 148.93 & 0.76 & 23.84 & 0.35 \\
$2.5 \mathrm{M}$ & 0.28 & 1.61 & 0.30 & 0.07 \\
$3.8 \mathrm{M}$ & 18.49 & 36.17 & 5.17 & 0.6 \\
$5.1 \mathrm{M}$ & 494.10 & 200.83 & 2.88 \\
\hline
\end{tabular}

Note. Model 1 used every channel in the spectrum to create the model, while Model 2 used only the channels that were at least three standard deviations above the Compton continuum. For both models, only spectra resulting from normal operation were used to create the model. A value less than one means the data were within the 99 percent confidence level, while a value larger than one means the data were beyond the 99 percent confidence level.

\subsubsection{Quantitative Predictions}

PLS models were developed to quantify distinguishing features of the fuel spectra. Only three features were available: 1) $\mathrm{HNO}_{3}$ concentration, 2) cooling time, and 3) burnup rate. The training space is not well populated because only five different $\mathrm{HNO}_{3}$ concentrations, three different burnup rates, and two different cooling times (both the ATM105A and ATM105P fuels had the same cooling time) were available. If the fuel type is known, then a separate PLS model can be developed for each fuel type; otherwise, a single PLS model will have to encompass all the fuel types. Table 2.7 shows the percent error of the prediction results when the fuel type is not known. Model 1 used the entire gamma spectrum and model 2 used only the significant peaks. The percent errors are an average of using leave-one-out cross validation. For every case, except for the ATM109 0.3M $\mathrm{HNO}_{3}$ and the ATM109 $1.3 \mathrm{M} \mathrm{HNO}$ cases, model 2 performed significantly better. In general, both models had difficultly predicting the lower $\mathrm{HNO}_{3}$ concentration levels. 
Table 2.7. Summary of PLS Modeling Results.

\begin{tabular}{ccccccc}
\hline & \multicolumn{3}{c}{ Percent Error - Model 1 } & \multicolumn{3}{c}{ Percent Error - Model 2 } \\
\cline { 2 - 7 } Actual & ATM109 & ATM105P & ATM105A & ATM109 & ATM105P & ATM105A \\
\hline $0.3 \mathrm{M}$ & 28.40 & 80.46 & 60.73 & 120.30 & 89.02 & 52.17 \\
$1.3 \mathrm{M}$ & 11.31 & 77.34 & 34.03 & 26.64 & 52.62 & 15.26 \\
$2.5 \mathrm{M}$ & 13.32 & 21.22 & 16.69 & 6.00 & 21.05 & 5.49 \\
$3.8 \mathrm{M}$ & 5.54 & 17.70 & 16.72 & 1.78 & 4.71 & 16.22 \\
$5.1 \mathrm{M}$ & 12.41 & 28.50 & 9.53 & 3.22 & 17.63 & 12.84 \\
\hline
\end{tabular}

Note. The percent errors are an average using leave-one-out cross validation. The input to model 1 was the entire gamma spectrum for every fuel type, and the input to model 2 was only the significant channels. Only one model that encompassed all three fuel types was developed.

If the fuel type is known, a separate PLS model can be developed for each specific fuel type. Table 2.8 shows the results of the PLS model assuming the fuel type is known. Table 2.8 shows that, in every case, the predictions provided by model 2 were better than those provided by model 1 , except for the 0.3M ATM105P, the 1.3M ATM105A, and the 2.5M ATM105P samples. Comparing Table 2.7 and Table 2.8 shows that, in general, developing a model specific to each fuel type gives much better performance that just using one general model.

Table 2.8. Summary of PLS Modeling Results.

\begin{tabular}{ccccccc}
\hline & \multicolumn{2}{c}{ Percent Error Model 1 - Supervised } & \multicolumn{3}{c}{ Percent Error Model 2 - Supervised } \\
\cline { 2 - 6 } Actual & ATM109 & ATM105P & ATM105A & ATM109 & ATM105P & ATM105A \\
\hline $0.3 \mathrm{M}$ & 50.35 & 89.18 & 64.02 & 19.80 & 135.96 & 48.98 \\
$1.3 \mathrm{M}$ & 8.00 & 54.85 & 10.48 & 3.77 & 39.57 & 14.86 \\
$2.5 \mathrm{M}$ & 9.33 & 15.90 & 7.17 & 4.58 & 19.12 & 6.92 \\
$3.8 \mathrm{M}$ & 4.93 & 9.88 & 14.96 & 2.25 & 4.97 & 14.28 \\
$5.1 \mathrm{M}$ & 3.66 & 13.27 & 11.14 & 2.14 & 12.14 & 10.89 \\
\hline
\end{tabular}

Note. The percent errors are an average using leave-one-out cross validation. The input to model 1 was the entire gamma spectrum for every fuel type, and the input to model 2 was only the significant channel. Three separate PLS models were developed; one for each fuel type.

The predictions from the PLS models could potentially be improved by continuing to refine the data preprocessing techniques and/or by using alternate multivariate methods, such as non-linear PLS analysis. This research touched only on some of the methods to improve the analysis. Further study is necessary to optimize the quantification of process variables.

\subsubsection{Advanced Multivariate Analysis Conclusions}

Different ways of building PCA and PLS models from measured gamma spectra were examined. The PCA models were used to classify fuel type and identify normal versus off-normal operating conditions, and the PLS models were used to predict distinguishing features of the spectrum, such as the concentration of $\mathrm{HNO}_{3}$ at which the fuel was separated. Each model was built two different waysmodel 1 used the entire gamma spectrum, and model 2 used only the channels corresponding to peaks in the gamma spectrum. The entire gamma spectrum has 8190 channels, and extracting the peaks generally resulted in fewer than 1000 relevant channels. The primary reason for extracting only the peaks is that it 
reduces the dimensionality of the data, which in turn potentially increases a model's robustness and reduces the chance of over-fitting the data.

Model 2 was able to distinguish between the ATM109 and ATM105A fuel, and between the ATM105P and ATM105A fuel. Neither model 1 nor model 2 was able to sufficiently separate the ATM109 and ATM105P fuels. However, if the models were built to use only data from normal operations, then all three fuel types would be well separated in both models. For identifying normal versus off-normal conditions, model 1 performed better than model 2; however, both models were able to correctly identify off-normal operating conditions at the 99 percent confidence level. The better performance provided by Model 1may be partially explained by the amount of data available when the entire spectrum is used instead of only the peaks. Specifically, the shape of the Compton continuum may be a valid indicator of the acid concentration in addition to the peaks. Because model 1 includes the Compton continuum as well as the peaks, it may provide a better data fit.

The PLS models were developed to use spectral data to predict the acid concentration of the separation. The performance of the PLS models was evaluated using leave-one-out cross validation. The following two types of PLS models were examined:

1. If one of the fuel types was unknown, one general PLS model was made for all three fuel types.

2. If the fuel types were known, a unique PLS model was made for each fuel type.

Both models were severely limited by the scope of the training space. Even though 150 spectra were analyzed, the calibration spectra only corresponded to five different $\mathrm{HNO}_{3}$ concentrations. The testing data also were limited to the same five different $\mathrm{HNO}_{3}$ concentrations. For most scenarios, PLS model 2 provided better predictions than PLS model 1. In addition, creating a specific model for each fuel type generally resulted in much better predictions.

\subsection{Conclusions}

Liquid samples from previous spent fuel dissolutions and separations were maintained during FY 2010. Advanced multivariate techniques were explored, and some limited advantages were found in the tested techniques. Further study is necessary to consider other potential advanced techniques to optimize the multivariate approach used by the MIP Monitor.

\subsection{References}

[1] U.S. Congress, Office of Technology Assessment. 1995. "Nuclear Safeguards and the International Atomic Energy Agency, Appendix A.” OTA-ISS-615, U.S. Government Printing Office, Washington, D.C.

[2] Smith LE, JM Schwantes, JJ Ressler, M Douglas, KA Anderson, CG Fraga, PC Durst, CR Orton, and RN Christensen. 2007. "Next Generation On-line MC\&A Technologies for Reprocessing Plants.” Proceedings of the Global 2007 Conference on Future Nuclear Energy Systems, Boise, Idaho. 
[3] Schwantes JM, M Douglas, CR Orton, C Fraga, and RN Christensen. 2008. "Multi-Isotope Process (MIP) Monitor: a Near-Real-Time Monitor for Reprocessing Facilities.” ANS Transactions from the Annual Meeting, Anaheim, California.

[4] Orton CR, JM Schwantes, S Bryan, T Levitskaia, D Duckworth, M Douglas, OT Farmer, C Fraga, S Lehn, M Liezers, S Peper, and RN Christensen. 2008. "Advanced Safeguards Technology Demonstration at Pacific Northwest National Laboratory." Proceedings of the $49^{\text {th }}$ INMM Annual Meeting, Nashville, Tennessee.

[5] Schwantes JM, CR Orton, CG Fraga, M Douglas, and RN Christensen. 2009. "The Multi-Isotope Process (MIP) Monitor: A Near-Real-Time, Nondestructive, Indicator of Spent Nuclear Fuel Reprocessing Conditions.” Proceedings of the $50^{\text {th }}$ INMM Annual Meeting, Tucson, Arizona.

[6] Orton CR, JM Schwantes, CG Fraga, M Douglas, and RN Christensen. 2009. "Experimental Validation of the Multi-Isotope Process Monitor Concept.” Proceedings of Global 2009-The Nuclear Fuel Cycle: Sustainable Options and Industrial Perspectives. Paris, France.

[7] Orton CR, CG Fraga, M Douglas, RN Christensen, and JM Schwantes. 2009. “Monitoring Spent Nuclear Fuel Reprocessing Conditions Non-Destructively and in Near-Real-Time Using The MultiIsotope Process (MIP) Monitor.” Proceedings of the 2nd JAPAN-IAEA Workshop on Advanced Safeguards Technology for the Future Nuclear Fuel Cycle, Tokaimura, Japan.

[8] Benedict M, TM Pigford, and HW Levi. 1981. Nuclear Chemical Engineering. 2nd Ed., McGraw-Hill, New York.

[9] Malinowski E. 2008. Factor Analysis in Chemistry. John Wiley \& Sons, New York.

[10] Beebe KR, RJ Pell, and MB Seasholtz. 1998. Chemometrics: A Practical Guide. John Wiley \& Sons, New York.

[11] Bryan SA and TGLevitskaia. 2007. "Monitoring and Control of UREX Radiochemical Processes." Proceedings of Global 2007 Conference on Future Nuclear Energy Systems, Boise, Idaho.

[12] Tsoulfanidis N. 1995. Measurement and Detection of Radiation. Taylor \& Francis, Washington, D.C. 



\section{Appendix A}

Journal Article, Submitted to Radiochimica Acta: Spectroscopic Monitoring of Nuclear Spent Fuel Reprocessing Streams: An Evaluation of Spent Fuel Solutions via Raman, Visible, and Near-Infrared Spectroscopy 



\section{Appendix A}

\section{Journal Article, Submitted to Radiochimica Acta: Spectroscopic Monitoring of Nuclear Spent Fuel Reprocessing Streams: An Evaluation of Spent Fuel Solutions via Raman, Visible, and Near-Infrared Spectroscopy}

S. A. Bryan,* T. G. Levitskaia,* A. M. Johnsen, C. R. Orton, and J. M. Peterson

Pacific Northwest National Laboratory, P.O. Box 999, Richland, WA 99352

*Corresponding authors: Phone: 509-376-6949; Fax: 509-376-1517;

E-mail: Sam.Bryan@pnl.gov (S.A. Bryan), Tatiana.Levitskaia@pnl.gov (T.G. Levitskaia)

The following article, which was submitted to the journal Radiochimica Acta, summarizes work under this project related to the spectroscopic analysis of commercial nuclear fuel. The work described in the article was supported under NA-24 project entitled PNNL - Spectroscopy-Based Monitoring. 


\title{
Spectroscopic Monitoring of Nuclear Spent Fuel Reprocessing Streams: An Evaluation of Spent Fuel Solutions via Raman, Visible, and Near-Infrared Spectroscopy
}

\author{
S. A. Bryan,* T. G. Levitskaia,* A. M. Johnsen, C. R. Orton, and J. M. Peterson \\ Pacific Northwest National Laboratory, P.O. Box 999, Richland, WA 99352 \\ *Corresponding authors: Phone: 509-376-6949; Fax: 509-376-1517; \\ E-mail: Sam.Bryan@pnl.gov (S.A. Bryan), Tatiana.Levitskaia@pnl.gov (T.G. Levitskaia)
}

Keywords: on-line monitoring, Raman, vis-NIR, spent fuel reprocessing, actinides, TBP/dodecane

\section{A.1 Abstract}

The potential of using optical spectroscopic techniques, such as Raman and Visible/Near Infrared (Vis/NIR), for on-line process control and special nuclear materials accountability applications at a spent nuclear fuel reprocessing facility was evaluated. Availability of on-line real-time techniques that directly measure process concentrations of nuclear materials will enhance performance and proliferation resistance of the solvent extraction processes. Further, on-line monitoring of radiochemical streams will also improve reprocessing plant operation and safety. This report reviews current state of development of the spectroscopic on-line monitoring techniques for such solutions. To further examine applicability of optical spectroscopy for this application, segments of a spent nuclear fuel, with approximate burn-up values of $70 \mathrm{MWd} / \mathrm{kgM}$, were dissolved in concentrated nitric acid and adjusted to varying final concentrations of $\mathrm{HNO}_{3}$. The resulting spent fuel solutions were batch-contacted with tributyl phosphate/dodecane organic solvent. The feed and equilibrium aqueous and loaded organic solutions were subjected to optical measurements. The obtained spectra showed the presence of the quantifiable Raman bands due to $\mathrm{NO}_{3}{ }^{-}$and $\mathrm{UO}_{2}{ }^{2+}$ and Vis/NIR bands due to multiple species of $\mathrm{Pu}(\mathrm{IV}), \mathrm{Pu}(\mathrm{VI})$, $\mathrm{Np}(\mathrm{V})$, the $\mathrm{Np}(\mathrm{V})-\mathrm{U}(\mathrm{VI})$ cation-cation complex, and $\mathrm{Nd}(\mathrm{III})$ in fuel solutions, justifying spectroscopic techniques as a promising methodology for monitoring spent fuel processing solutions in real-time. Quantitative evaluation of the fuel solution was performed based on spectroscopic measurements and compared to ICP-MS analysis and ORIGEN based estimates.

\section{A.2 Introduction}

From an industrial perspective, spent nuclear fuel reprocessing facilities require the ability to precisely monitor process stream constituents in order to achieve efficient separations that allow for the future use of some components, like uranium, and the proper waste disposal of others, such as fission products and actinides. Additionally, the International Atomic Energy Agency (IAEA) has established international safeguards standards for fissionable materials at reprocessing plants to ensure that significant quantities of weapons-grade nuclear material are not diverted from process streams. Because proliferant diversions are possible via sometimes minor modifications of the flowsheet chemistry, it is necessary to verify that a facility is operating under adequate safeguard-declared conditions.

In any reprocessing facility, variability in the process is expected under normal operations, and currently, large deviations can readily be detected and measured. Small-scale deviations in large facilities, however, are not easily detected. This is partly because many of the detection methods require analysis of individual samples at a separate laboratory, which leads to a significant delay between the 
time of sampling and having the data needed to make an accurate assessment of process conditions [1]. In contrast, the availability of on-line monitoring capabilities can provide a unique ability to identify suspect deviations from normal operating conditions accurately and in real-time.

Techniques for on-line control of nuclear fuel reprocessing streams have been investigated since the 1970s [2], and researchers have examined both the direct measurement of actinides via spectrophotometry as well as indirect actinide accounting via physiochemical measurements such as temperature, density, and dialectic properties. These methods can also be used to measure other solution components, such as nitrate ions or organic solvents that control actinide behavior, providing additional methods for actinide quantification.

Once spent fuel solutions are sampled from the various processing streams, they must be measured for actinide and/or fission product content. Actinides are particularly well-suited for measurement via spectrophotometric techniques as their f-orbital interactions provide a unique spectrum for almost every actinide in various oxidation states. Spectrophotometric techniques also allow for several other advantages over other radionuclide measurement methods: many compounds have multiple bands that can be used together for compound identification and quantifications; multiple compounds can be measured simultaneously; and results can be obtained rapidly, on the order of seconds to several minutes $[1,3]$.

Ultra-violet, visible, and near-infrared (UV-Vis-NIR) spectrophotometry has been used for decades to determine actinide speciation and concentrations in a number of aqueous media, such as the salts and acids of $\mathrm{ClO}_{4}{ }^{-}$and $\mathrm{Cl}^{-}$, and the common $\mathrm{NO}_{3}{ }^{-}$reprocessing media [4-9]. Raman spectroscopy is also useful for actinide measurements, and the Raman bands for the An(VI) (An = U, Np, Pu) and An(V) (An $=\mathrm{Np}, \mathrm{Pu}, \mathrm{Am})$ actinide species are well characterized [10-14]. For reprocessing schemes, actinides of interest are $\mathrm{U}(\mathrm{VI}), \mathrm{Np}(\mathrm{IV}), \mathrm{Np}(\mathrm{V}), \mathrm{Np}(\mathrm{VI}), \mathrm{Pu}(\mathrm{IV})$, and $\mathrm{Pu}(\mathrm{VI})$, and changes in their spectroscopic signatures with varying $\mathrm{HNO}_{3}$ concentrations are also documented in the literature [15-18]. The fission product neodymium, which occurs in relatively high concentrations in spent fuel, contains several welldefined and suitable bands for quantification in the visible and near-infrared spectral regions [19].

Spectroscopic techniques can also be used to measure non-actinide solution components that have appreciable absorption bands in the wavelength range of interest. For instance, successful determinations of $\mathrm{U}(\mathrm{VI})$ and nitric acid concentrations were conducted via spectrophotometric measurements from 380$500 \mathrm{~nm}$ (for U(VI)) and 260 - $302 \mathrm{~nm}$ (for nitric acid) and the use of partial least squares techniques for data regression [8]. It was shown that the successive uranyl nitrate complexes from increasing nitrate concentrations can be used to determine nitric acid concentrations in solution. Calibration and test samples with U(VI) concentrations between $1-30 \mathrm{~g} / \mathrm{L}(\sigma=0.19 \mathrm{~g} / \mathrm{L})$ and $0.02-0.3 \mathrm{M}$ nitric acid $(\sigma=$ $0.067 \mathrm{M}$ ) were successfully measured [8].

By the late 1980s and early 1990s, multiple research groups had successfully constructed laboratory scale systems for remote on-line photometric measurements of actinides with spectrometers that were capable of quickly scanning the entire visible and NIR range [8]. More recently, a system was designed on a larger scale, by Lascola and coworkers [20], for on-line measurement of uranium and nitrate from tanks that held process solutions before and after a set of mixer-settler separators. Tank waste samples were routed through an initial vial to ensure proper mixing and were then sent through a flow-through optical cell connected via fiber optics to a diode-array spectrophotometer measuring in the 350-600 nm range. Partial least squares models allowed for concentration estimates up to $11 \mathrm{~g} / \mathrm{L}$ uranium and $6 \mathrm{M}$ 
nitrate, as well as measurement uncertainties ( $2 \sigma$; concentration dependent) no greater than $0.30 \mathrm{~g} / \mathrm{L}$ and $0.32 \mathrm{M}$, respectively. Measurements were completed in less than one minute.

Bryan, Levitskaia, and coworkers have monitored oxyanions of sodium salts simulating Hanford tank waste using a Raman spectrometer supported by a conductivity probe and a Coriolis flow meter [21]. Measurements were taken with a Raman probe directly inserted into a bend in the piping system, and chemometric models were used for data processing. During large scale acceptance testing, the concentration wt\% measurements of all analytes (sodium salts of $\mathrm{OH}^{-}, \mathrm{Al}(\mathrm{OH})_{4}^{-}, \mathrm{CrO}_{4}{ }^{2-}, \mathrm{NO}_{2}^{-}, \mathrm{NO}_{3}{ }^{-}$, $\mathrm{PO}_{4}{ }^{3-}, \mathrm{CO}_{3}{ }^{2-}$, and $\mathrm{SO}_{4}{ }^{2-}$ ) were within $0.5 \%$ of the analytically determined values. This technology is being extended to fuel reprocessing solutions by using a combination of Raman and Vis-NIR spectroscopies [22].

On a smaller scale, Janssens-Maenhout [23] and coworkers demonstrated that neodymium concentrations continue to follow Beer's law when measured in microliter quantities. Absorbance measurements from a 62 microliter sample passing through a $300 \mu \mathrm{m}$ square and $18 \mathrm{~mm}$ long microchannel showed a linear correlation factor greater than $99.9 \%$ for the $740 \mathrm{~nm}$ neodymium peak, although sensitivity was reduced by a factor of about 20. Similar experiments were carried out with $\mathrm{UO}_{2}\left(\mathrm{NO}_{3}\right)_{2}$ and $\mathrm{PuO}_{2}\left(\mathrm{NO}_{3}\right)_{2}$ in $3 \mathrm{M}$ nitric acid, providing an overall detection range of 18 to $230 \mathrm{~g} / \mathrm{L}$ salt [24].

Investigations of spectrophotometric detection methods for on-line process monitoring of spent nuclear fuel reprocessing streams have been limited up to now, in that testing solutions have been spent fuel simulants or actual process streams with limited constituents (e.g., the uranium and nitrate measurements [20]). To remedy this gap, this work used actual spent nuclear fuel and a simple measurement set-up to determine if actual spent nuclear fuel solutions, with high radioactivity and complexity of constituents, could be reliably measured via Raman and vis-NIR spectroscopy. The work reported herein is a part of our ongoing research program for the identification and quantification of actual spent fuel constituents in typical aqueous $\left(\mathrm{HNO}_{3}\right)$ and organic (30\% tributyl phosphate in dodecane) reprocessing solutions via Raman, visible, and near-infrared spectroscopy.

\section{A.3 Experimental}

Aqueous solutions were prepared from distilled water deionized to $18 \mathrm{M} \Omega$-cm with a Barnstead Nanopure water purification system. Nitric acid solutions were prepared from concentrated nitric acid (J.T. Baker, Ultrex II Ultrapure, or Fisher, reagent grade) and were base titrated to verify acid content. Uranyl nitrate solutions were prepared from $\mathrm{UO}_{2}\left(\mathrm{NO}_{3}\right)_{2} \cdot 6 \mathrm{H}_{2} \mathrm{O}$ (National Biochemicals Corp.). Tri-butyl phosphate (TBP, J. T. Baker, purified reagent) and $n$-dodecane (Sigma-Aldrich, 99.9\% anhydrous) were water washed prior to use.

\section{A.4 Spent Fuel}

The ATM-109 fuel sample consisted of six rods that were produced by General Electric (GE) [25, 26]. The rods were initially irradiated in the Quad Cities I reactor from February 1979 until September 1987 in a normal assembly, amassing an average exposure of $43 \mathrm{MWd} / \mathrm{kgU}$. The rods were then moved to a carrier assembly and irradiated from November 1989 until September 1992. When removed from the reactor, the maximum burnup is thought to have reached 70-80 MWd/kgU. The rods spent a total of 3508 
on-power days in the reactor. Post-irradiation examinations were performed at GE's Vallecitos Nuclear Center before the fuel was transferred to Argonne National Laboratory (ANL) for characterization and use in the evaluation of the post-closure Yucca Mountain Repository. ANL sent pieces of the ATM-109 fuel to the Pacific Northwest National Laboratory (PNNL), and the segment of fuel used in this work had an initial enrichment of $3 \%$ and a burn up of approximately $70 \mathrm{MWd} / \mathrm{kgM}$, a relatively high burn-up value for a commercial spent fuel.

\section{A.5 ORIGEN Calculations}

Because the specifics of the initial composition, the irradiation periods and decay periods were not detailed for the ATM-109, many of the ORIGEN-ARP default values were used. The GE $8 \times 8$ BWR fuel bundle was used including its cross section libraries and fuel composition. The uranium composition was slightly adjusted according to some reference data but the ${ }^{235} \mathrm{U}$ enrichment remained $3 \%$, keeping it in accordance with the library options in ORIGEN. The moderator density was kept at the BWR default of 0.7332 grams per cubic centimeter. The irradiation was split into two blocks representing the two different periods the rods spend in the reactor. Due to the large exposure amount during each stint in the reactor, the first block was split into four cases, the second irradiation period into two cases, and a decay case was included between the two reactor exposures. The total exposure reached $70 \mathrm{MWd} / \mathrm{kgU}$. This is within the parameters listed for use of the Ge $8 \times 8$ fuel type (the maximum valid burnup is $72 \mathrm{MWd} / \mathrm{kgU}$ ). The final decay was modeled through August 2008, the date the fuel was dissolved.

\section{A.6 Spent Fuel Dissolution}

Fuel solutions were prepared using segments of the ATM-109 commercial fuel. Fuel segments underwent de-cladding, dissolution, acid variation, and separation procedures. The fuel segments were cut with a diamond saw, allowing $12.4 \mathrm{~g}$ of fuel to be harvested. The harvested fuel was placed in $25 \mathrm{~mL}$ of $16 \mathrm{M}$ nitric acid, warmed for few hours to encourage oxidation and dissolution, and centrifuged to remove non-dissolved residue. The fuel supernatant was heated to near-dryness on a hot plate, followed by addition of 20 to $30 \mathrm{~mL}$ of $0.1 \mathrm{M} \mathrm{HNO}_{3}$. This solution was again heated to near-dryness and $0.1 \mathrm{M}$ $\mathrm{HNO}_{3}$, acid solution was added to adjust volume to $30 \mathrm{~mL}$ with creating a parent fuel solution.

The parent solution was used to make a set of dilutions containing the same amount of the dissolved fuel in variable nitric acid. Five dilutions were made: $5 \mathrm{~mL}$ of the parent solution was brought up to $10 \mathrm{~mL}$ final volume with varying amounts of $0.1 \mathrm{M}$ and $16 \mathrm{M} \mathrm{HNO}_{3}$, so that each set of dilutions had identical fuel component concentrations, but $\mathrm{HNO}_{3}$ concentrations of 0.3, 1.3, 2.5, 3.8, or $5.1 \mathrm{M}$.

\section{A.7 Batch Contact Experiments}

Batch contact experiments were performed on spent fuel solutions (fuel feed solutions) and simulated fuel feed solutions. The spent fuel solutions contained variable $\mathrm{HNO}_{3}$ concentrations as discussed above and the fuel feed stimulants contained $0.60 \mathrm{M} \mathrm{UO}_{2}\left(\mathrm{NO}_{3}\right)_{2}$ in $0.3,1.3,2.5$, 3.8, or $5.1 \mathrm{M} \mathrm{HNO}_{3}$. All aqueous feed contact solutions $(4.0 \mathrm{~mL}$ each) were equilibrated with equal volume of water-washed 30 volume\% TBP in $n$-dodecane using a vortex mixer at room temperature. The extraction mixtures were centrifuged, and the aqueous (raffinate) and loaded organic phases were separated. Two milliliters of 
each phase (aqueous feed, aqueous raffinate, and organic extract) from each of the 10 spent fuel solutions was placed in a glass 2-dram vial and transferred out of the hot cell for the spectroscopic analysis.

\section{A.8 Spectroscopic Measurements}

Raman measurements were performed with an InPhotonics RS2000 high resolution Raman spectrometer containing a thermoelectrically-cooled CCD detector operating at $-55^{\circ} \mathrm{C}$; a $670 \mathrm{~nm} 150 \mathrm{~mW}$ visible diode laser as the excitation source; and an InPhotonics RamanProbe ${ }^{\mathrm{TM}}$ focused fiber optic probe operated in a $180^{\circ}$ back reflection mode. The laser beam focal point was $5 \mathrm{~mm}$ beyond the end of the laser probe tip, and the measured laser intensity at the sample was typically $50 \mathrm{~mW}$. An integration time of 10 seconds was used for each acquisition, and 20 acquisitions were taken and averaged for each sample.

Vis-NIR measurements were performed using a Mikropack HL-2000-FHSA Halogen Light Source with attenuator, Ocean Optics fiber optic cables, and an Ocean Optics USB2000 Miniature Fiber Optic Spectrometer (500-1200 nm wavelength detection range). Each acquisition had 100 scans, each with an integration time of $12 \mathrm{~ms}$. NIR measurements in the 900-1700 nm wavelength range were performed using a Mikropack HL-2000-FHSA halogen light source with attenuator and a 0.3 neutral density filter, Ocean Optics fiber optic cables, and an Ocean Optics NIR-512 Temperature-regulated NIR Spectrometer. Each acquisition averaged 100 scans, each with 15 ms integration time. Deionized water or water-washed $\mathrm{TBP} / n$-dodecane solution was used to collect reference spectra for vis-NIR measurements of the aqueous or organic solutions, respectively.

Spectroscopic measurements were performed on individual samples placed in 2-dram vials (Opticlear, Kimble Glass Inc.) with an average inner diameter of $1.448 \pm 0.005 \mathrm{~cm}$ positioned in the sample holder that allowed for measurements using vis-NIR light source and the Raman excitation probe. The sample holder set-up was placed in a lead cave to shield the researchers from the high radiation dose from the spent fuel solutions.

\section{A.9 ICP-MS Measurements}

Metals analysis for Nd, Np, $\mathrm{U}$, and Pu were performed using an inductively coupled plasma mass spectrometer (ICP-MS) unit using high-purity calibration standards to generate calibration curves and verify continuing calibration during the analysis run. Dilutions of $1000 \times, 500 \times, 200 \times, 100 \times, 50 \times$, and $10 \times$ were made of each sample for analysis to investigate and correct for matrix interferences. This method is similar to EPA Method 6020 [27].

\section{A.10 Results and Discussion}

The use of Raman spectroscopy to investigate the $\mathrm{UO}_{2}\left(\mathrm{NO}_{3}\right)_{2} /$ nitric acid system is well established [3, 11-14, 28, 29] and experimental studies have indicated several solution species exist for uranyl nitrate including, $\mathrm{UO}_{2}\left(\mathrm{NO}_{3}\right)^{+}$[14, 30-34], the neutral complex $\mathrm{UO}_{2}\left(\mathrm{NO}_{3}\right)_{2}[14,34,35]$, and $\mathrm{UO}_{2}\left(\mathrm{NO}_{3}\right)_{3}{ }^{-}[34,36]$. We have measured solutions of spent commercial fuel in variable nitric acid solutions using Raman spectroscopy in order to probe the $\mathrm{UO}_{2}$-nitrate interaction under fuel reprocessing conditions and identify spectral regions that can be used for the on-line monitoring of uranyl nitrate. 
Raman spectra of the ATM-109 fuel solutions with variable $\mathrm{HNO}_{3}$ concentrations are shown in Figure A.1 and Figure A.2. For comparison, Figure A.2 also contains spectra of $5.1 \mathrm{M} \mathrm{HNO}_{3}$ and fuel simulant containing $0.6 \mathrm{M} \mathrm{UO}_{2}\left(\mathrm{NO}_{3}\right)_{2}$ in $5.1 \mathrm{M} \mathrm{HNO}_{3}$. The bands observed in $5.1 \mathrm{M} \mathrm{HNO}_{3}(644,697$, 718, 962, 1047, 1302, 1416, and $1650 \mathrm{~cm}^{-1}$ ) are assigned to $\mathrm{HNO}_{3}$ and nitrate. For nitrate ion in acid media, the three major bands associated for the $v_{1}$ symmetric stretch $\left(\sim 1050 \mathrm{~cm}^{-1}\right), v_{3}$ asymmetric stretch $\left(\sim 1350 \mathrm{~cm}^{-1}\right)$, and $v_{4}$ in-plane deformation $\left(\sim 700 \mathrm{~cm}^{-1}\right)$ modes are observed; the $v_{2}$ band for nitrate is Raman forbidden and was not observed [37-39]. The $718 \mathrm{~cm}^{-1}$ band is assigned to the $v_{4}$ in-plane deformation mode of the nitrate moiety, and has E' symmetry in $\mathrm{D}_{3 \mathrm{~h}}$; this band splits into $\mathrm{A}_{1}$ and $\mathrm{B}_{2}$ pairs in decent in symmetry to $\mathrm{C}_{2 \mathrm{v}}$ upon interaction with cations (such as $\mathrm{H}^{+}$, or $\mathrm{UO}_{2}{ }^{2+}$ ); the two Raman bands observes at 644 and $697 \mathrm{~cm}^{-1}$ are assigned to these modes in the $5.1 \mathrm{M} \mathrm{HNO}_{3}$ spectrum. The three bands located at 1302, 1416 and $1650 \mathrm{~cm}^{-1}$ all associated with the $v_{3}$ asymmetric stretch of the $\mathrm{NO}_{3}$ moiety. The unperturbed nitrate asymmetric stretch mode has E' symmetry under $\mathrm{D}_{3 \mathrm{~h}}$ which is expected to gives rise to a single band (assigned to $1416 \mathrm{~cm}^{-1}$ ), while in aqueous acid solution the degeneracy of the asymmetric stretching mode is expected to be lifted resulting in two bands with $A_{1}$ and $B_{2}$ symmetry under the $C_{2 v}$ point group (assigned to 1302 and $1650 \mathrm{~cm}^{-1}$ ) [40]. The strong band located at $1047 \mathrm{~cm}^{-1}$ is assigned to the $v_{1}$ symmetrical stretching mode for $\mathrm{NO}_{3}{ }^{-}$and has $\mathrm{A}_{1}$ symmetry under $\mathrm{D}_{3 \mathrm{~h}}$ [40].

A new set of bands is observed in the Raman spectra when $0.6 \mathrm{M} \mathrm{UO}_{2}\left(\mathrm{NO}_{3}\right)_{2}$ is added to $5.1 \mathrm{M} \mathrm{HNO}$. In addition to the bands associated with $\mathrm{HNO}_{3}$ alone as described above, new bands (750, 870, 1539, and $1617 \mathrm{~cm}^{-1}$ ) are assigned to a combination of $\mathrm{UO}_{2}{ }^{2+}$ and nitrate [14]. The band at $870 \mathrm{~cm}^{-1}$ is characteristic of the $v_{1}$ symmetric stretch of $\mathrm{UO}_{2}{ }^{2+}$, while the band at $750 \mathrm{~cm}^{-1}$ is due to the $v_{4}$ frequency of uranylbound $\mathrm{NO}_{3}{ }^{-}\left(\mathrm{UO}_{2} \mathrm{NO}_{3}{ }^{+}\right)$[14]. The two bands located at 1539 and $1617 \mathrm{~cm}^{-1}$ are attributed to the $v_{3}$ asymmetric stretch of the $\mathrm{UO}_{2} \mathrm{NO}_{3}{ }^{+}$moiety, resulting in two bands with $\mathrm{A}_{1}$ and $\mathrm{B}_{2}$ symmetry under the $\mathrm{C}_{2 \mathrm{v}}$ point group.

Within the commercial fuel spectra (Figure A.2), the most prominent Raman bands are due to symmetrical stretch of $\mathrm{UO}_{2}{ }^{2+}\left(871 \mathrm{~cm}^{-1}\right), \mathrm{NO}_{3}^{-}\left(718,1047,1416 \mathrm{~cm}^{-1}\right), \mathrm{HNO}_{3}(644,697,962,1302,1416$ and $\left.1650 \mathrm{~cm}^{-1}\right)$, and $\mathrm{UO}_{2} \mathrm{NO}_{3}{ }^{+}\left(750,870,1539\right.$, and $\left.1617 \mathrm{~cm}^{-1}\right)$. Comparison of the Raman spectra acquired using fuel simulant solution of $0.6 \mathrm{M} \mathrm{UO}_{2}\left(\mathrm{NO}_{3}\right)_{2}$ in $5.1 \mathrm{M} \mathrm{HNO}$ and commercial ATM-109 fuel solution indicates no appearance of new bands except the emergence of a small band located at $840 \mathrm{~cm}^{-1}$ for the ATM-109 fuel spectrum. This new band $\left(840 \mathrm{~cm}^{-1}\right)$ within the ATM-109 fuel is characteristic of the $\mathrm{PuO}_{2}{ }^{2+}$ ion in nitric acid solution [10] which is evident in the expanded spectra shown in Figure A.2, right. The similarity between the fuel simulants and the commercial fuel spectra suggests that $\mathrm{UO}_{2}\left(\mathrm{NO}_{3}\right)_{2} / \mathrm{HNO}_{3}$ solutions can be used to generate Raman spectral datasets for the purpose of development of quantitative methods for the measurement of the $\mathrm{UO}_{2}\left(\mathrm{NO}_{3}\right)_{2}$ and $\mathrm{HNO}_{3}$ in the dissolved commercial fuel.

Raman measurements of the organic extracts from batch contact experiments are shown in Figure A.3. Comparison of the aqueous $\mathrm{UO}_{2}\left(\mathrm{NO}_{3}\right)_{2}$ nitric acid solution and its TBP/n-dodecane extract shows a shift of the Raman band for $\mathrm{UO}_{2}{ }^{2+}$ located at $871 \mathrm{~cm}^{-1}$ in the aqueous phase compared to $860 \mathrm{~cm}^{-1}$ in the organic solvent, and that for $\mathrm{NO}_{3}{ }^{-}$shifting from $1047 \mathrm{~cm}^{-1}$ in aqueous $\mathrm{HNO}_{3}$ to $1030 \mathrm{~cm}^{-1}$ in the organic solvent. The nitrate peak at $1030 \mathrm{~cm}^{-1}$ is seen only in solutions containing $\mathrm{UO}_{2}\left(\mathrm{NO}_{3}\right)_{2}$ and spent fuel. 


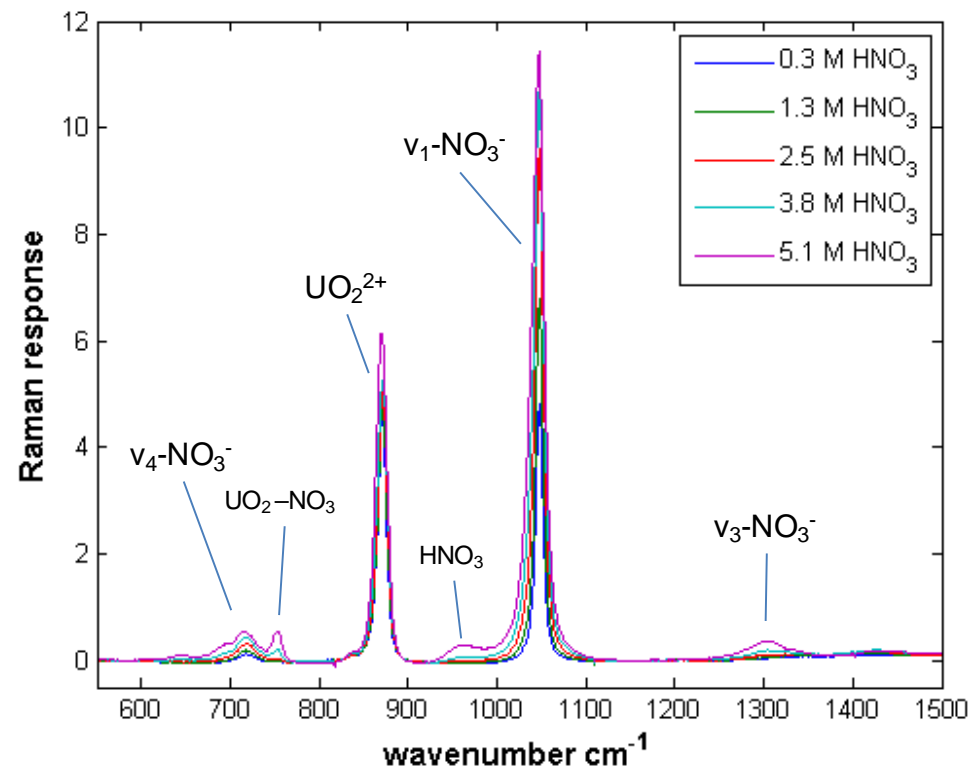

Figure A.1. Raman Spectra of ATM-109 Fuel Feed in Variable $\mathrm{M} \mathrm{HNO}_{3}$
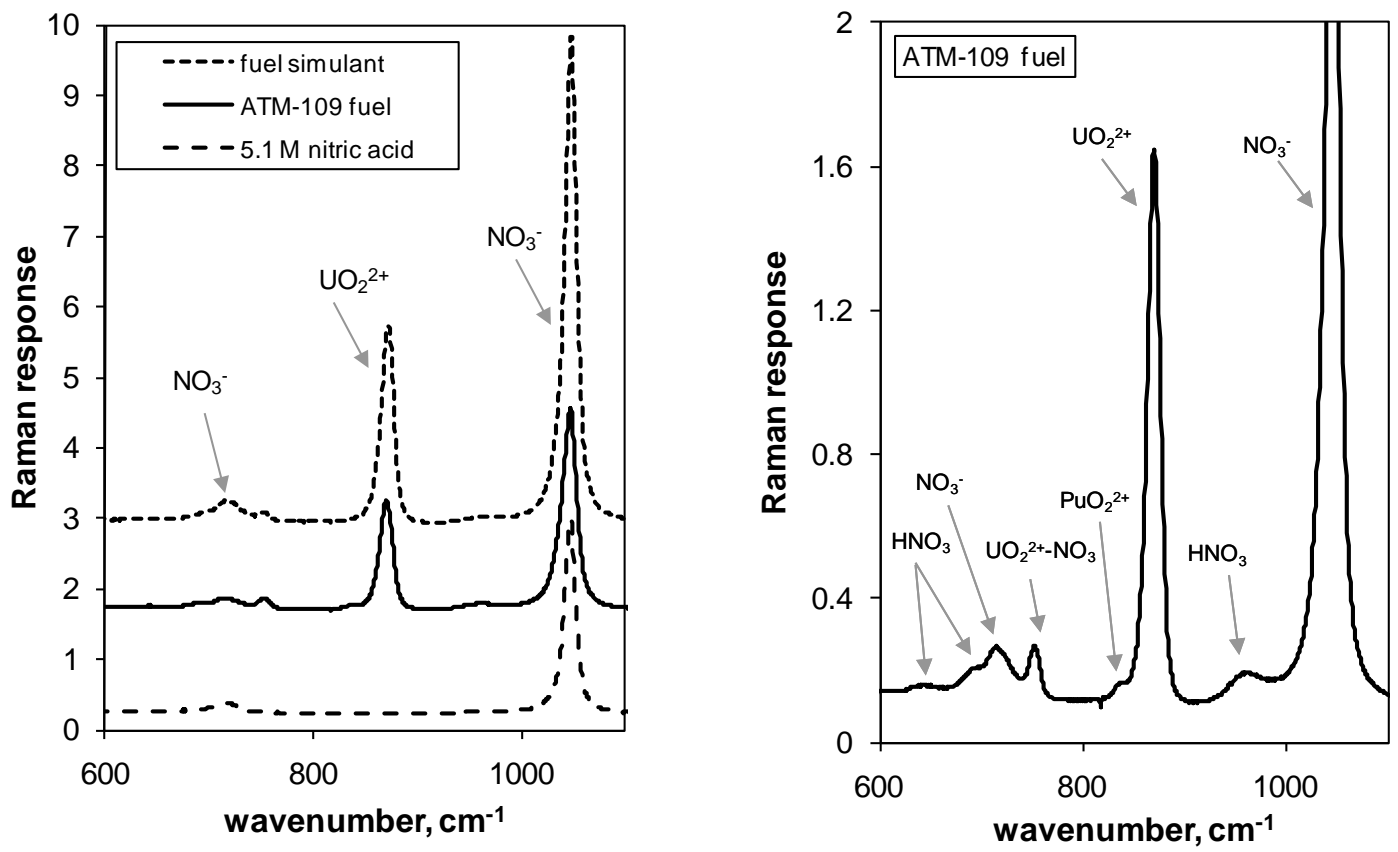

Figure A.2. On left, Raman spectra of fuel simulant (0.6 $\mathrm{M} \mathrm{UO}_{2}\left(\mathrm{NO}_{3}\right)_{2}$ in 5.1M HNO 3$)(---)$, ATM-109

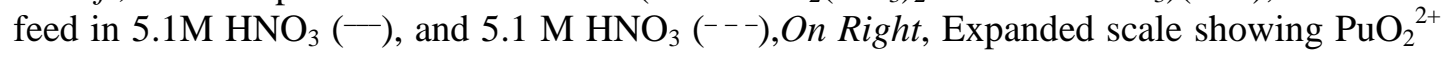
and $\mathrm{HNO}_{3}$ components within ATM-109 fuel feed spectrum. 


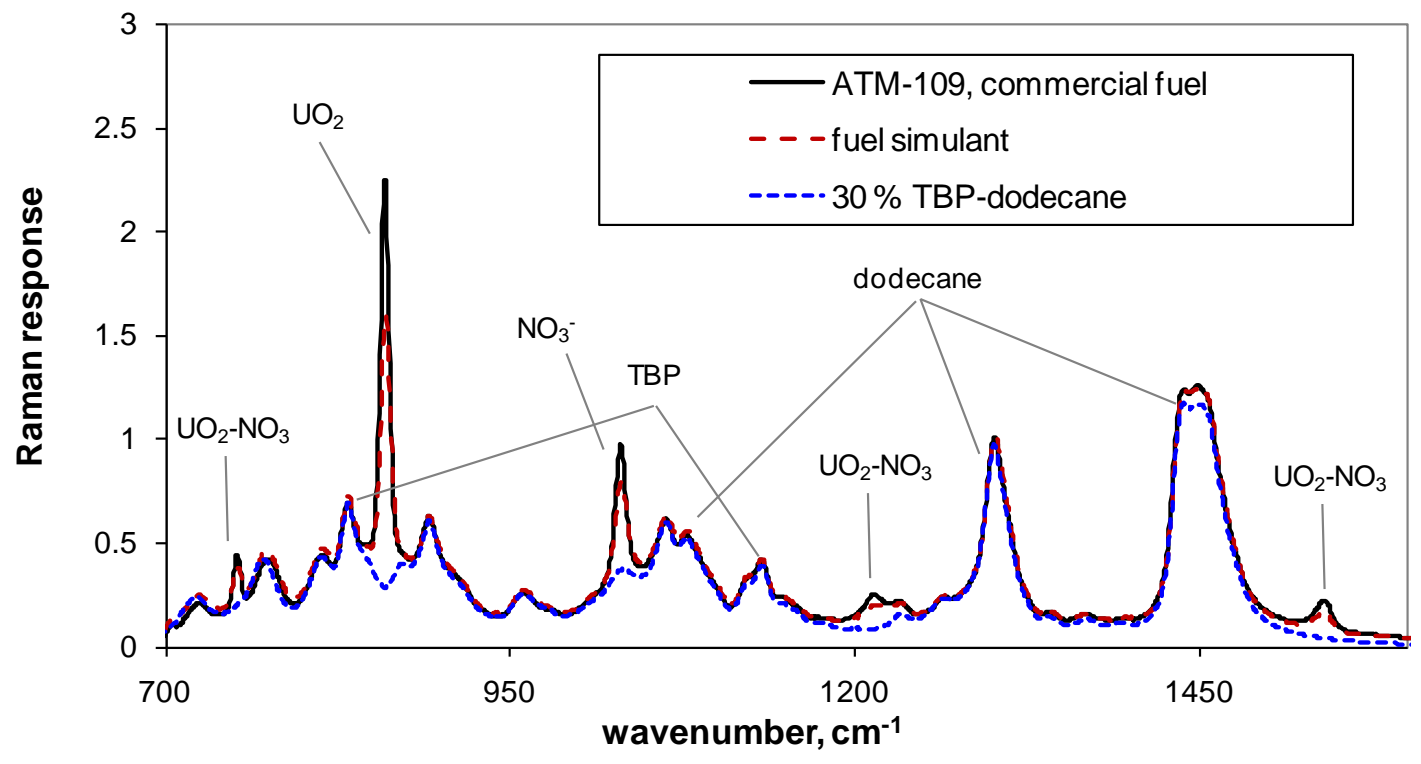

Figure A.3. Raman spectra of 30\% TBP in n-dodecane (----); loaded upon contact with ATM-109 fuel in $5.1 \mathrm{M} \mathrm{HNO}_{3}(-)$; and loaded upon contact with fuel feed simulant $\left(0.6 \mathrm{M} \mathrm{UO}_{2}\left(\mathrm{NO}_{3}\right)_{2} 0.6 \mathrm{M}\right.$ in $\left.5.1 \mathrm{M} \mathrm{HNO}_{3}\right)(---)$.

ATM-109 extract spectra, but not in the TBP/n-dodecane solution contacted with $5.1 \mathrm{M} \mathrm{HNO}_{3}$. The lack of observance of the nitrate band in the TBP/n-dodecane contacted with nitric acid is presumably due to the formation of the $\mathrm{HNO}_{3} \bullet \mathrm{n}$ TBP complexes resulting in greater shift of the nitrate and possible overlapping with TBP/n-dodecane bands. The Raman band at $1030 \mathrm{~cm}^{-1}$ is assigned to nitrate symmetric stretch, $v_{1}$ as well as the additional bands associated with the TBP- $\mathrm{UO}_{2}\left(\mathrm{NO}_{3}\right)_{2}$ extraction complex assigned to the nitrate in-plane deformation $v_{4}\left(751 \mathrm{~cm}^{-1}\right)$ and the nitrate asymmetric stretch $v_{3}$ $\left(1226 \mathrm{~cm}^{-1}\right.$, and $\left.1539 \mathrm{~cm}^{-1}\right)$ modes based on comparison to the aqueous system. Also present in the Raman spectra containing TBP/n-dodecane, are the bands associated with the solvent (Figure A.3). The strong bands due to the hydrocarbon backbone are observed between $1300-1450 \mathrm{~cm}^{-1}$, with the band at $\sim 1300 \mathrm{~cm}^{-1}$ primarily due to $-\left(\mathrm{CH}_{2}\right)_{\mathrm{n}}$ - in-phase twist and the $1430 \mathrm{~cm}^{-1}$ band assigned to the $\mathrm{CH}_{2}$ scissoring mode [41]. A strong band at $1170 \mathrm{~cm}^{-1}$ and a medium band at $850 \mathrm{~cm}^{-1}$ were observed in the samples containing TBP and is assigned to the $\mathrm{P}=\mathrm{O}$ and $\mathrm{P}-\mathrm{O}-\mathrm{R}$ stretching vibrations respectively [41].

Observed Raman bands characteristic of $\mathrm{UO}_{2}\left(\mathrm{NO}_{3}\right)_{2}$, within the organic extract, are resolved from the TBP/ n-dodecane bands, confirming the utility of the Raman spectroscopy for the quantification of the uranyl and nitrate in the TBP/ $n$-dodecane solvent. The quantitative determination of the $\mathrm{UO}_{2}{ }^{2+}$ concentrations in the aqueous feed solutions was performed by comparison of the Raman response of the $870 \mathrm{~cm}^{-1}$ band versus measurements of analytical standards of $\mathrm{UO}_{2}\left(\mathrm{NO}_{3}\right)_{2}$ in similar nitric acid solutions. 


\section{A.11 Visible and Near Infrared Spectroscopy of Commercial Fuel Solutions}

The visible-near infrared (Vis-NIR) absorption spectra of ATM-109 spent fuel feed solutions over the nitric acid in 0.3 to $5.1 \mathrm{M}$ range are shown in Figure A.4 and Figure A.5. Prominent features of this series of spectra are the absorption bands associated with $\mathrm{Pu}(\mathrm{IV})$ (observed 648-662, 707, 790, 860, and $1075 \mathrm{~nm}$ ) [15, 18, 42-44] and Pu(VI) (observed 625, 817, 831, 857, 948, 983, and $1160 \mathrm{~nm}$ ) [44-46]. The absorbance bands associated with $\mathrm{Pu}(\mathrm{IV})$ are attributed to $\mathrm{Pu}\left(\mathrm{NO}_{3}\right)_{\mathrm{n}}{ }^{4-\mathrm{n}}$ nitrato complexes determined to be dominant below $5 \mathrm{M}$ nitric acid [15, 46, 47]. The absorbance bands associated with $\mathrm{Pu}(\mathrm{VI})$ are negligible at low $\mathrm{HNO}_{3}$ concentration and greatly enhanced for the nitric acid solutions of 3.8 and $5.1 \mathrm{M}$. The absorbance bands at $831 \mathrm{~nm}$ and $815 \mathrm{~nm}$ are assigned to the mono- and dinitrato complexes $\mathrm{PuO}_{2}\left(\mathrm{NO}_{3}\right)^{+}$and $\mathrm{PuO}_{2}\left(\mathrm{NO}_{3}\right)_{2}(831 \mathrm{~nm})$ and to the trinitrato complex, $\mathrm{PuO}_{2}\left(\mathrm{NO}_{3}\right)_{3}{ }^{-}(815 \mathrm{~nm})$ indicating that these complex ions of $\mathrm{Pu}(\mathrm{VI})$ are present in the fuel feed solutions. With the increase in acid from 3.8 $\mathrm{M}$ to $5.1 \mathrm{M} \mathrm{HNO}_{3}$, the increase in the $815 \mathrm{~nm}$ band is consistent with the dominant formation of the trinitrato $\mathrm{Pu}(\mathrm{VI})$ complex at higher acid strength [46]. Characteristic $\mathrm{Pu}(\mathrm{VI})$ bands at 948, 983, and $1160 \mathrm{~nm}$ were also observed in the NIR spectra (Figure A.5) [44, 46]. At lower acid strengths $\left(\mathrm{HNO}_{3}=\right.$ $0.3-2.5 \mathrm{M}$ ), the $983 \mathrm{~nm} \mathrm{Pu}(\mathrm{VI})$ band is partially occluded by the $\left[\mathrm{NpO}_{2}{ }^{+}\right]$, species in solution due to the predominance of neptunium being in the $\mathrm{Np}(\mathrm{V})$ form in solution at these lower acid strengths, and the prevalence of plutonium in the $\mathrm{Pu}(\mathrm{IV})$ oxidation state over $\mathrm{Pu}(\mathrm{VI})$. At higher acid strengths the 983 and $1160 \mathrm{~nm} \mathrm{Pu(VI)}$ band is more evident in the NIR spectrum (Figure A.4 and Figure A.5). At the higher acid strengths (3.8 and $5.1 \mathrm{M}$ ), the interference with $\mathrm{Np}(\mathrm{V})$ is decreased, since at the higher acid strengths $\mathrm{Np}(\mathrm{VI})$ is the dominant neptunium species in these solutions and does not interfere within this region (see discussion below).

The distribution of $\mathrm{Pu}(\mathrm{IV})$ from the aqueous phase into the organic phase was followed using vis-NIR spectroscopy of both the aqueous and organic phases. Interestingly, only $\mathrm{Pu}(\mathrm{IV})$ was found in the organic phases based on visible absorption spectroscopy. Figure A.6 shows the representative spectrum of $\mathrm{TBP} / n$-dodecane extraction phase from $5.1 \mathrm{M} \mathrm{HNO}_{3}$ solution of ATM-109 fuel. The characteristic $\mathrm{Pu}(\mathrm{IV})$ bands in the TBP/n-dodecane solution were slightly shifted relative to those in the aqueous nitrate solution, which reflects expected change in the inner coordination environment of the $\mathrm{Pu}(\mathrm{IV})$ ion upon coordination with TBP and transport into the organic solvent. The organic extract of the fuel simulant containing $\mathrm{Pu}(\mathrm{IV})$ exhibited nearly identical visible spectrum to that of the ATM-109 fuel (Figure A.6) supporting the conclusion about absence of the $\mathrm{Pu}(\mathrm{VI})$ in the commercial fuel extracts. The absence of the $\mathrm{Pu}(\mathrm{VI})$ in the TBP/n-dodecane phase can be in part attributed to the delay between extraction contacts performed in the hot cell and collection of the optical spectra a few days later, possibly allowing reduction of $\mathrm{Pu}(\mathrm{VI})$ to $\mathrm{Pu}(\mathrm{IV})$ to take place [48]. This reduction can be caused by presence of the organic reducing impurities in TBP/n-dodecane and facilitated by stronger thermodynamic affinity of TBP to Pu(IV) versus $\mathrm{Pu}(\mathrm{VI})$ [49], promoting the reduction reaction.

Neptunium is present in the dissolved spent fuel as $\mathrm{Np}(\mathrm{V})$ in the $\mathrm{NpO}_{2}{ }^{+}$chemical form, as observed by the presence of the $981 \mathrm{~nm}$ band within the aqueous phase (Figure A.5) for this species [50]. The aqueous speciation of $\mathrm{Np}(\mathrm{V})$ is complex because of its coordination with nitrate anion and formation of cation-cation complexes [9]. In nitric acid solutions of $\mathrm{Np}(\mathrm{V})$ containing high concentrations of $\mathrm{UO}_{2}{ }^{2+}$ typical to the dissolved spent fuel streams, the cation-cation complex species $\left[\mathrm{NpO}_{2}{ }^{+} \cdot \mathrm{UO}_{2}{ }^{2+}\right]$ is formed and the band at $981 \mathrm{~nm}$ for the $\mathrm{NpO}_{2}{ }^{+}$species is observed to split into two bands. This is the case in the dissolved spent fuel measurements as seen in the NIR spectra within Figure A.5, where both the $\mathrm{NpO}_{2}{ }^{+}$ 


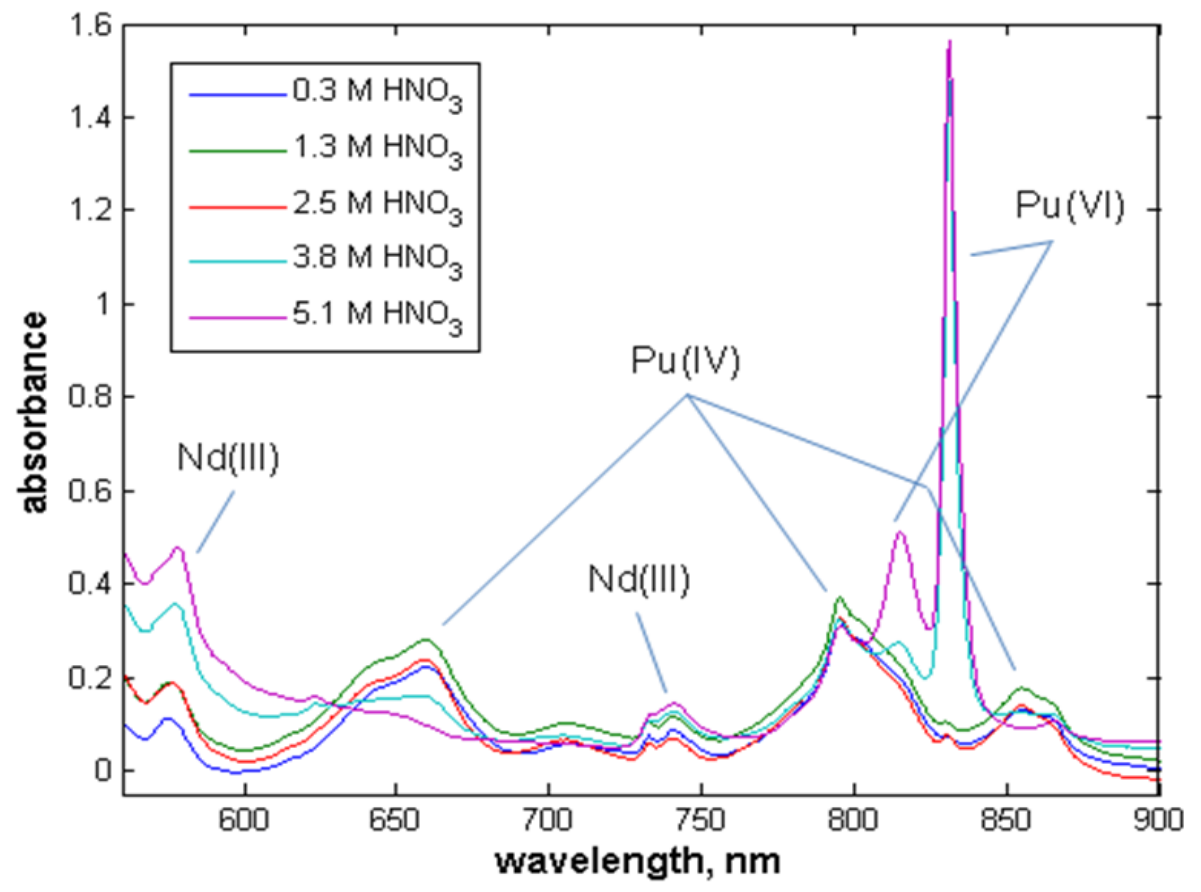

Figure A.4. Vis-NIR spectra of ATM-109 high-burn-up fuel in variable $\mathrm{HNO}_{3}$.

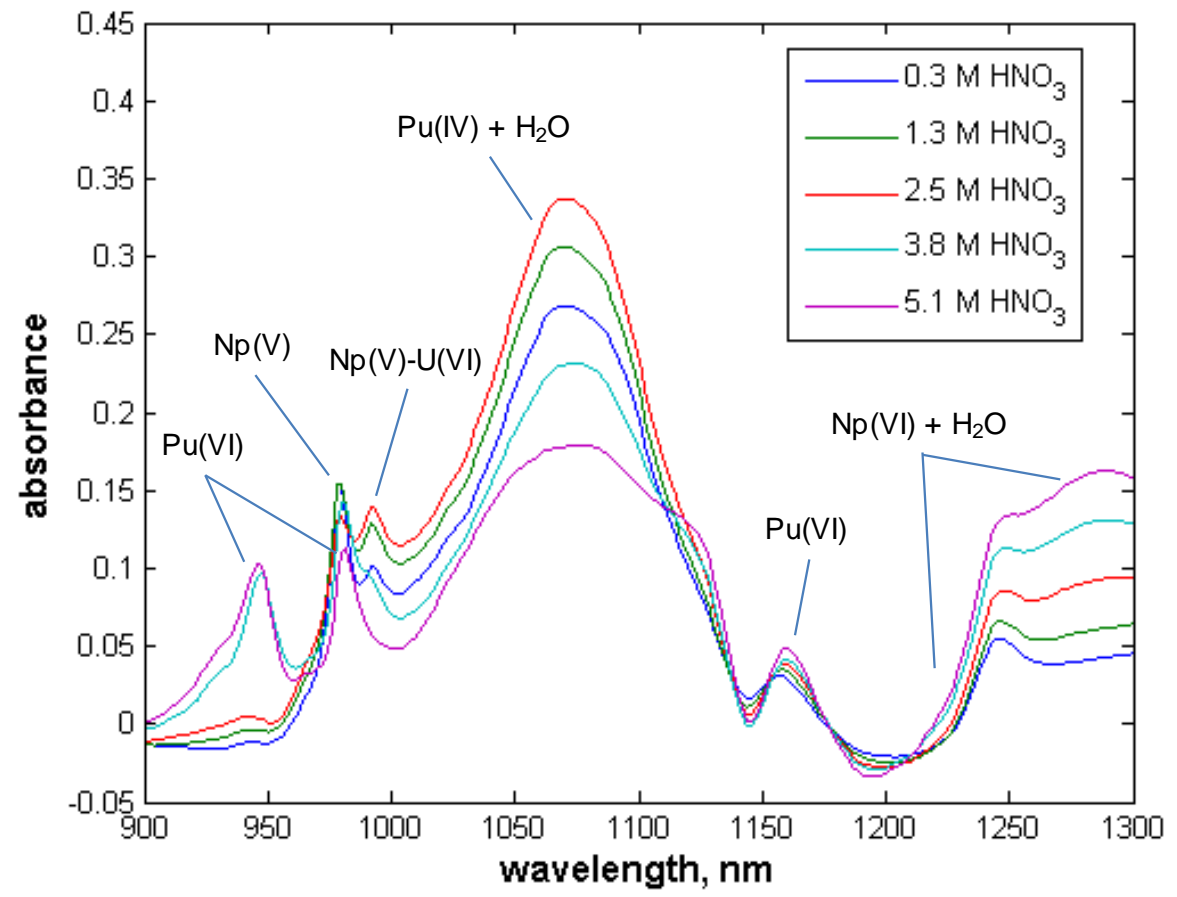

Figure A.5. NIR Spectrum of ATM-109 fuel feed in variable $\mathrm{HNO}_{3}$. 


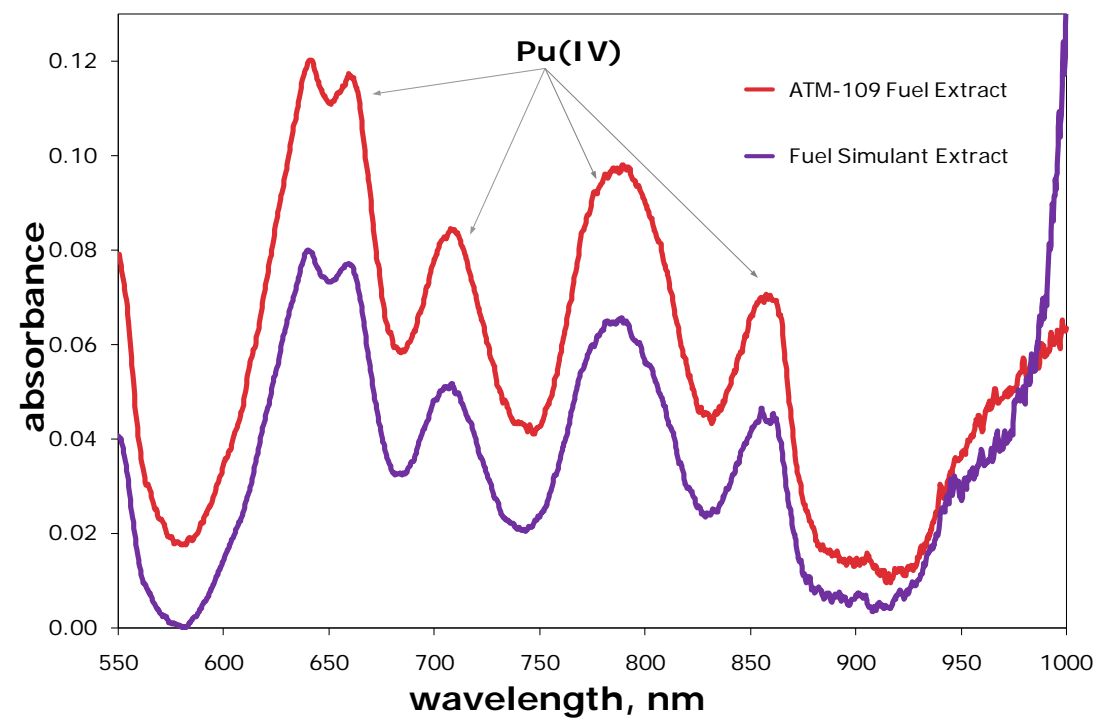

Figure A.6. TBP/n-dodecane extraction phase of ATM-109 fuel and fuel simulant from $5.1 \mathrm{M} \mathrm{HNO}_{3}$ solution. The $\mathrm{U}(\mathrm{VI})$ content in the aqueous phase of ATM-109 was $0.7 \mathrm{M}$, and for the fuel simulant, $0.6 \mathrm{M}$.

(free) and $\left[\mathrm{NpO}_{2}{ }^{+} \cdot \mathrm{UO}_{2}{ }^{2+}\right]$ (bound) forms are observed. It should be noted that $\mathrm{Np}(\mathrm{V})$ is present in the fuel feed solutions at the lower nitric acid solutions (0.3 - $2.5 \mathrm{M} \mathrm{HNO}_{3}$, Figure A.5). For the higher acid concentrations the $\mathrm{Np}(\mathrm{V})$ bands are less prominent (for $\mathrm{HNO}_{3}=3.8 \mathrm{M}$ ), and non-observable (for $\mathrm{HNO}_{3}=$ $5.1 \mathrm{M})$ due presumably to the disproportionation of $\mathrm{Np}(\mathrm{V})$ into $\mathrm{Np}(\mathrm{IV})$ and $\mathrm{Np}(\mathrm{VI})$ that has been demonstrated to be second order with respect to the proton concentration [51] or oxidation to $\mathrm{Np}(\mathrm{VI})$ as the nitric acid concentration increases above $\sim 3 \mathrm{M}$. Due to the low concentration and overlapping with $\mathrm{Nd}(\mathrm{III})(740 \mathrm{~nm})$ [52] and $\mathrm{Pu}(\mathrm{VI})(948 \mathrm{~nm})$ [44] bands, the Np(IV) spectrum (723 nm and $960 \mathrm{~nm})$ [53] was not identified. The Np(VI) $1220 \mathrm{~nm}$ band [53] was observed in the NIR spectrum as a shoulder shift of the water band, but quantitative determination was not possible due to the overlap with water bands, which were themselves strongly influenced by changes in nitric acid concentration [54].

Figure A.7 contains a NIR spectrum containing the $\mathrm{Np}(\mathrm{V})$ region $(970-1005 \mathrm{~nm})$, for both the feed and raffinate phases of the $2.5 \mathrm{M} \mathrm{HNO}_{3}$ fuel solution sample. As observed in this spectrum, the feed solution contains two bands attributed to the $\mathrm{NpO}_{2}{ }^{+}$(free) at $981 \mathrm{~nm}$ and $\left[\mathrm{NpO}_{2}{ }^{+} \cdot \mathrm{UO}_{2}{ }^{2+}\right]$ (bound) forms of

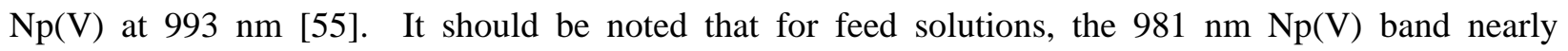
completely overlaps with $\mathrm{Pu}(\mathrm{VI}) 983 \mathrm{~nm}$ band (Figure A.5). However, equilibration with TBP/ndodecane phase preferentially extracts the $\mathrm{U}(\mathrm{VI})$ species, leaving the $\mathrm{Np}(\mathrm{V})$ complex in the raffinate phase as $\mathrm{NpO}_{2}{ }^{+}[56]$. As can be seen in Figure A.7, the $\mathrm{NpO}_{2}{ }^{+}$species in the raffinate phase is now nearly free from the $\mathrm{Np}(\mathrm{V})-\mathrm{U}(\mathrm{VI})$ cation-cation interaction and this spectral region is also free from $\mathrm{Pu}(\mathrm{VI})$ bands, allowing for the unobstructed detection of the $\mathrm{Np}(\mathrm{V})$ complex. This allows quantification of $\mathrm{Np}(\mathrm{V})$ in the solution since it is not extractable by TBP/dodecane [56].

Neodymium (III) ion was observed within the ATM-109 vis-NIR spectra shown in Figure A.4 for all nitric acid concentrations. The absorbance bands located at 577-580 nm and 735-743 nm are consistent with known aqueous neodymium nitrate solutions [57]. 


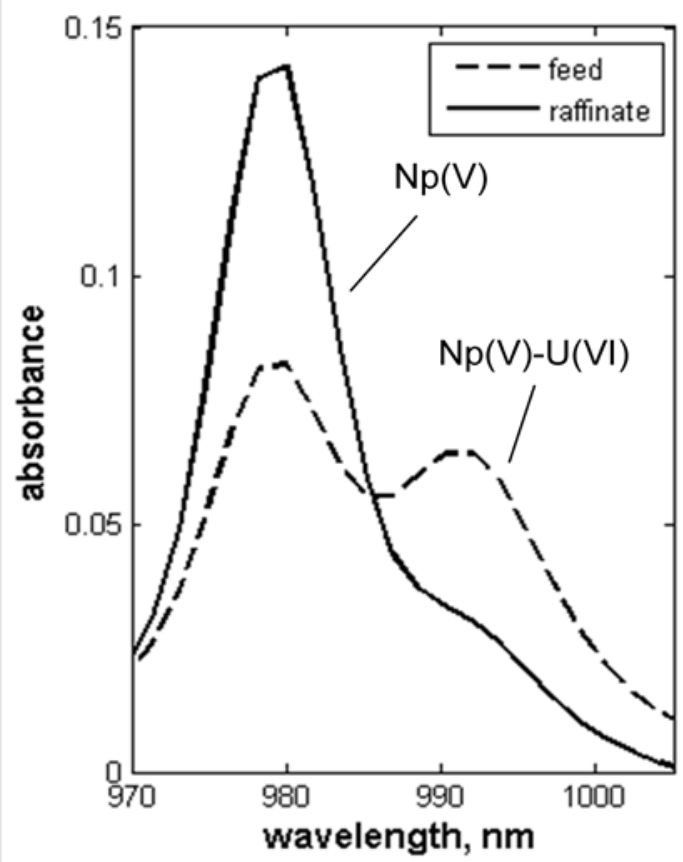

Figure A.7. NIR Spectra of ATM109 Feed and Raffinate. Initial concentration of $\mathrm{HNO}_{3}$ in Feed was $2.5 \mathrm{M}$.

\section{A.12 Analytical Results}

The results from the ORIGEN calculation for the ATM-109 fuel are shown in

Table A.1 along with the ICP-MS and spectroscopic analyses. The ICP-MS and spectroscopic analyses were performed on fuel feed samples dissolved in nitric acid unless otherwise noted. The constituents of the spent fuel are displayed in molar quantities for uranium, plutonium, neptunium, and neodymium.

In general, comparisons of the metal analyses results obtained by the various methods are in good agreement. Starting with U, the highest metal component within the feed solutions, the predicted concentration based on ORIGEN code is $0.72 \mathrm{M}$. This value is in excellent agreement with the average values for the ICP-MS and spectroscopic methods of $0.721 \mathrm{M}$ and $0.716 \mathrm{M}$ respectively. The relative standard deviation for the ICP-MS and spectroscopic values for $\mathrm{U}$ analysis is $7.7 \%$ and $5.7 \%$ respectively, and represents the total deviation from all sources including instrument variability and sample preparation, which can be quite variable within a shielded hot cell facility. The analytical results for Nd from all methods are also in generally good agreement. The predicted ORIGEN code calculation is $1.1 \times 10^{-2} \mathrm{M}$, compared to $0.84 \times 10^{-2} \mathrm{M}$ and $1.1 \times 10^{-2} \mathrm{M}$ for the average values of the ICP-MS and spectroscopic methods, respectively. Quantitative determination of neodymium by the visible spectroscopic method was performed using $575 \mathrm{~nm}$ band of $\mathrm{Nd}(\mathrm{III})$, molar extinction coefficient $(\varepsilon)=7.0 \mathrm{M}^{-1} \mathrm{~cm}^{-1}[57]$.

The comparison between the ORIGEN code and analytical results for neptunium is in good agreement. The predicted ORIGEN code value of $4.6 \times 10^{-4} \mathrm{M}$, compares well with $4.7 \times 10^{-4} \mathrm{M}$ for 
ICP-MS. However, the used spectroscopic method only yields the $\mathrm{Np}(\mathrm{V})$ value, and not the total $\mathrm{Np}$ value, which is anticipated to be a sum of $\mathrm{Np}(\mathrm{V})$ and $\mathrm{Np}(\mathrm{VI})$ species in solution. At lower acid strengths, the $\mathrm{Np}(\mathrm{V})$ concentration values are observed to be greater than at high acid strength, where at the highest acid (5.1 $\mathrm{M} \mathrm{HNO}_{3}$ ), the measured $\mathrm{Np}(\mathrm{V})$ observed in solution was zero $(0 \mathrm{M})$. The lowest acid solution $\left(0.3 \mathrm{M} \mathrm{HNO}_{3}\right)$ was determined to contain $4.7 \times 10^{-4} \mathrm{M} \mathrm{Np}(\mathrm{V})$ by the spectroscopic method in good agreement with the ICP-MS and ORIGEN code values. The $\mathrm{Np}(\mathrm{V})$ values were determined using molar absorptivities of 297 and $180 \mathrm{M}^{-1} \mathrm{~cm}^{-1}$ for 980 and $992 \mathrm{~nm}$ bands, respectively [58].

Table A.1. Analytical Results for ATM-109 Commercial Fuel Sample. Comparison of ORIGEN Code calculation, ICP-MS results, and Spectroscopic analysis. All sample quantities are in Molar (mol L ${ }^{-1}$ ) units.

\begin{tabular}{cccccc} 
ORIGEN & Fuel Feed $^{\mathbf{a}}$ & $\mathbf{N d}$ & $\mathbf{N p}$ & $\mathbf{U}$ & $\mathbf{P u}$ \\
\hline & & 0.011 & 0.00046 & 0.72 & 0.0075 \\
ICP-MS & & & & & \\
\hline & [HNO $\left._{3}\right]$ & $\mathbf{N d}$ & $\mathbf{N p}$ & $\mathbf{U}$ & $\mathbf{P u}$ \\
\hline 0.3 & 0.0082 & 0.00045 & 0.69 & 0.0086 \\
1.3 & 0.0082 & 0.00045 & 0.67 & 0.0084 \\
2.5 & 0.0079 & 0.00045 & 0.69 & 0.0089 \\
3.8 & 0.0089 & 0.00050 & 0.81 & 0.0095 \\
& 5.1 & 0.0087 & 0.00049 & 0.74 & 0.0094 \\
\cline { 2 - 6 } & & 0.0084 & 0.00047 & 0.72 & 0.0090 \\
& Average $^{\mathrm{h}}$ & 0.0004 & 0.00003 & 0.06 & 0.0005
\end{tabular}

\begin{tabular}{cccccccc} 
Spectroscopic & [HNO $\left._{3}\right]$ & $\mathbf{N d}(\mathbf{I I I})^{\mathbf{b}}$ & $\mathbf{N p ( V )}$ & $\mathbf{U}(\mathbf{V I})^{\mathbf{d}}$ & $\mathbf{P u ~ t o t a l}^{\mathbf{e}}$ & $\mathbf{P u ( I V})^{\mathbf{f}}$ & $\mathbf{P u ( V I )})^{\mathbf{g}}$ \\
\hline 0.3 & 0.0077 & 0.00047 & 0.68 & 0.0069 & 0.0069 & 0.00001 \\
1.3 & 0.0089 & 0.00035 & 0.69 & 0.0075 & 0.0075 & 0.00003 \\
2.5 & 0.010 & 0.00037 & 0.71 & 0.0076 & 0.0075 & 0.00009 \\
3.8 & 0.013 & 0.00033 & 0.71 & 0.011 & 0.0049 & 0.0058 \\
5.1 & 0.016 & 0 & 0.79 & 0.012 & 0.0039 & 0.0076 \\
\hline & 0.011 & 0.00030 & 0.72 & 0.0089 & & \\
& Average $^{\mathrm{i}}$ & 0.003 & 0.00018 & 0.04 & 0.002 & &
\end{tabular}

a. Feed composition is based ORIGEN-ARP modeling of $12.4 \mathrm{~g}$ ATM109 fuel irradiated to $70 \mathrm{MWd} / \mathrm{kgU}$.

b. $\mathrm{Nd}(\mathrm{III})$ determined by Vis-NIR spectroscopic method using $575 \mathrm{~nm}$ band, molar extinction coefficient $(\varepsilon)=7.0 \mathrm{M}^{-1} \mathrm{~cm}^{-1}[57]$.

c. $\mathrm{Np}(\mathrm{V})$ determined by Vis-NIR spectroscopic method using 980 and $992 \mathrm{~nm}$ bands; $\varepsilon=297$ and $180 \mathrm{M}^{-1} \mathrm{~cm}^{-1}$ respectively [58].

d. U(VI) concentrations were determined by Raman spectroscopic method.

e. Pu total is sum of $\mathrm{Pu}(\mathrm{IV})$ and $\mathrm{Pu}(\mathrm{VI})$.

f. $\mathrm{Pu}(\mathrm{IV})$ was determined by Vis-NIR spectroscopic method using $640 \mathrm{~nm}$ band; $\varepsilon=25 \mathrm{M}^{-1} \mathrm{~cm}^{-1}$ [46].

g. $\mathrm{Pu}(\mathrm{VI})$ was determined by Vis-NIR spectroscopic method; $\varepsilon\left(\mathrm{Pu}(\mathrm{VI}) \mathrm{O}_{2}\left(\mathrm{NO}_{3}\right)_{3}{ }^{-}, 815 \mathrm{~nm}\right)=118.5 \mathrm{M}^{-1} \mathrm{~cm}^{-1} ; \varepsilon\left(\mathrm{Pu}^{-}(\mathrm{VI}) \mathrm{O}_{2}(\mathrm{NO})^{+}\right.$, $\left.\mathrm{Pu}(\mathrm{VI}) \mathrm{O}_{2}\left(\mathrm{NO}_{3}\right)_{2}, 831 \mathrm{~nm}\right)=158 \mathrm{M}^{-1} \mathrm{~cm}^{-1}[46]$.

h. The experimental precision of the ICP-MS values was estimated to be uniformly $\pm 5 \%$ from a combination of replicate determinations, volumetric error, and instrumental precision.

i. The values listed as “Average" and "Standard Deviation” for the ICP-MS and spectroscopic methods are the average values and standard deviations of the five variable-acid feed measurements.

A comparison between methods for the plutonium analyses shows an approximate $20 \%$ difference between the ORIGEN value and those for the ICP-MS and spectroscopic methods. The ORIGEN code 
value for plutonium of $7.5 \times 10^{-3} \mathrm{M}$ is lower than the ICP-MS and spectroscopic values of $8.99 \times 10^{-3} \mathrm{M}$ and $8.9 \times 10^{-3} \mathrm{M}$, respectively. Additionally, the spectroscopic method shows the general trend that the $\mathrm{Pu}(\mathrm{IV})$ species are dominant under low acid conditions (0.3 to $2.5 \mathrm{M} \mathrm{HNO}_{3}$ ) and the $\mathrm{Pu}(\mathrm{VI})$ species are dominant under high acid conditions (3.8 to $5.1 \mathrm{M} \mathrm{HNO}_{3}$ ). The spectroscopic measurements are sensitive to plutonium in both the $\mathrm{Pu}(\mathrm{IV})$ and $\mathrm{Pu}(\mathrm{VI})$ oxidation states; for comparison of the spectroscopic measurements to ICP-MS and ORIGEN code values, the total Pu value, which is the sum of $\mathrm{Pu}(\mathrm{IV})$ and $\mathrm{Pu}(\mathrm{VI})$, is used. Plutonium(IV) and $\mathrm{Pu}(\mathrm{VI})$ were determined by the spectroscopic method using the following values of molar absorptivities; $(\mathrm{Pu}(\mathrm{IV}) 640 \mathrm{~nm})=25 \mathrm{M}^{-1} \mathrm{~cm}^{-1}$; $\left(\mathrm{Pu}(\mathrm{VI}) \mathrm{O}_{2}\left(\mathrm{NO}_{3}\right)_{3}{ }^{-}, 815 \mathrm{~nm}\right)=$ $118.5 \mathrm{M}^{-1} \mathrm{~cm}^{-1}$; and $\left(\mathrm{Pu}(\mathrm{VI}) \mathrm{O}_{2}\left(\mathrm{NO}_{3}\right)^{+}, \mathrm{Pu}(\mathrm{VI}) \mathrm{O}_{2}\left(\mathrm{NO}_{3}\right)_{2}, 831 \mathrm{~nm}\right)=158 \mathrm{M}^{-1} \mathrm{~cm}^{-1}[46]$.

\section{A.13 Conclusions}

The potential applicability of optical spectroscopic techniques for on-line monitoring of reprocessing streams has been demonstrated using spent nuclear fuel solutions, comprised of high burn-up (70 MWd/kgM), metal commercial fuel, dissolved in 0.3 to $5.1 \mathrm{M} \mathrm{HNO}_{3}$, measured spectroscopically without further modification (e.g., dilution, separation of fuel components, etc.). The spent fuel feed solutions, equilibrium aqueous raffinates, and loaded TBP/n-dodecane organic fractions were subjected to Raman and Visible/Near Infrared (vis-NIR) spectroscopic measurements. Concentration values obtained using these methods for U(VI), $\mathrm{Pu}(\mathrm{IV}), \mathrm{Pu}(\mathrm{VI}), \mathrm{Np}(\mathrm{V})$, and $\mathrm{Nd}(\mathrm{III})$ were compared to ICP-MS analytical results of the same solutions, and to ORIGEN code calculations for fuel of similar burn-up and composition. The spectroscopic measurements were in good agreement with both the ICP-MS and ORIGEN calculations. This result demonstrates applicability of optical spectroscopy for quantitative online determination of the dissolved spent fuel streams.

\section{A.14 Acknowledgements}

Pacific Northwest National Laboratory (PNNL) is operated for the U.S. Department of Energy (DOE) by Battelle under Contract DE-AC05-76RL01830. This work was funded by DOE through the Fuel Cycle Research and Development Program (FCRD-NE), the Office of Safeguards (NA-243) and the Sustainable Nuclear Power Initiative Program (Laboratory Directed Research and Development). Funding from FCRD-NE for Postdoctoral Research Associate AMJ is greatly appreciated. We thank Chuck Z. Soderquist and Eric T. Clayton for assisting in fuel dissolution, sample preparation, and analytical services within the Radiochemical Processing Laboratory, PNNL.

\section{A.15 References}

1. Hou, X. L.; Roos, P.: Critical comparison of radiometric and mass spectrometric methods for the determination of radionuclides in environmental, biological and nuclear waste samples. Analytica Chimica Acta 608, (2), 105-139 (2008).

2. Parus, I.; Kierzek, J.; Zoltowski, T.: Online Control of Nuclear-Fuel Reprocessing. Nukleonika, 22, (9), 759-776 (1977).

3. Armenta, S.; Garrigues, S.; de la Guardia, M.: Recent developments in flow-analysis vibrational spectroscopy. Trac-Trends in Analytical Chemistry 26, (8), 775-787 (2007). 
4. Schmiede H; Kuhn, E.: Automatic Measurement and Control of Nuclear Fuel Reprocessing by Spectrophotometry and Conductivity Measurements. Chemie Ingenieur Technik 44, (3), 104 (1972).

5. Ertel, D.: Analysis of Nitrogen-Containing Compounds in Purex Solutions. AtomkernenergieKerntechnik 47, (2), 87-90 (1985).

6. Ertel, D.; Groll, P.; Knittel, G.; Thessis, W.: Process Analysis in Purex Method. Journal of Radioanalytical Chemistry 32, (2), 297-314 (1976).

7. Baumgartner, F.; Ertel, D.: The Modern Purex Process and Its Analytical Requirements. Journal of Radioanalytical Chemistry 58, (1-2), 11-28 (1980).

8. Burck, J.: Spectrophotometric Determination of Uranium and Nitric-Acid by Applying Partial LeastSquares Regression to Uranium(VI) Absorption-Spectra. Analytica Chimica Acta 254, (1-2), 159-165 (1991).

9. Colston, B. J.; Choppin, G. R.: Evaluating the performance of a stopped-flow near-infrared spectrophotometer for studying fast kinetics of actinide reactions. Journal of Radioanalytical and Nuclear Chemistry 250, (1), 21-26 (2001).

10. Madic, C.; Begun, G. M.; Hobart, D. E.; Hahn, R. L.: Raman-Spectroscopy of Neptunyl and Plutonyl Ions in Aqueous-Solution - Hydrolysis of $\mathrm{Np}(\mathrm{VI})$ and $\mathrm{Pu}(\mathrm{VI})$ and Disproportionation of $\mathrm{Pu}(\mathrm{V})$. Inorganic Chemistry 23, (13), 1914-1921 (1984).

11. Madic, C.; Hobart, D. E.; Begun, G. M.: Raman Spectrometric Studies of Actinide(V) and Actinide(VI) Complexes in Aqueous Sodium-Carbonate Solution and of Solid Sodium Actinide(V) Carbonate Compounds. Inorganic Chemistry 22, (10), 1494-1503 (1983).

12. Guillaume, B.; Begun, G. M.; Hahn, R. L., Raman Spectrometric Studies of Cation Cation Complexes of Pentavalent Actinides in Aqueous Perchlorate Solutions. Inorganic Chemistry 21, (3), 1159-1166 (1982).

13. Maya, L.; Begun, G. M., A Raman-Spectroscopy Study of Hydroxo and Carbonato Species of the Uranyl(VI) Ion. Journal of Inorganic \& Nuclear Chemistry 43, (11), 2827-2832 (1981).

14. Nguyentrung, C.; Begun, G. M.; Palmer, D. A.: Aqueous Uranium Complexes .2. RamanSpectroscopic Study of the Complex-Formation of the Dioxouranium(VI) Ion with a Variety of Inorganic and Organic-Ligands. Inorganic Chemistry 31, (25), 5280-5287 (1992).

15. Ryan, J. L.: Species Involved in the Anion-Exchange Absorption of Quadrivalent Actinide Nitrates. Journal of Physical Chemistry 64, (10), 1375-1385 (1960).

16. Friedman, H. A.; Toth, L. M.: Absorption-Spectra of Np(III), (IV), (V) and (VI) in Nitric-Acid Solution. Journal of Inorganic \& Nuclear Chemistry 42, (9), 1347-1349 (1980).

17. Toth, L. M.; Friedman, H. A.: The Photochemistry of Neptunium in Aqueous Nitric-Acid Solutions. Radiochimica Acta 27, (3), 173-176 (1980).

18. Cleveland, J. M.: The Chemistry of Plutonium. American Nuclear Society: La Grange, IL, 1979; p 653. 
19. Carnell, W. T.: Handbook on the Physics and Chemistry of Rare Earths. North-Holland, 1979.

20. Lascola, R. J.; Livingston, R. R.; Sanders, M. A.; McCarty, J. E.; Cooper, G. A.: On Line Spectrophotometric Measurement of Uranium and Nitrate in H Canyon.; Savannah River Site. 2002.

21. Bryan, S. A.; Levitskaia, T. G.; Schlahta, S. N. In Raman Based Process Monitor For Continuous Real-Time Analysis Of High Level Radioactive Waste Components, Waste Management WM2008 Conference, Phoenix, AZ, February 24 -28, 2008, 2008; Phoenix, AZ.

22. Bryan, S. A.; Levitskaia, T.G.: Monitoring and Control of UREX Radiochemical Processes, GLOBAL 2007, Boise, ID, September 8-10, 2007, 2007; Boise, ID.

23. Janssens-Maenhout, G.; Nucifora, S.: Feasibility study of a microsystem to analyse radioactive solutions. Nuclear Engineering and Design 237, (11), 1209-1219 (2007).

24. Janssens-Maenhout, G., J. Buyst, and P. Peerani: Reducing the radioactive doses of liquid samples taken from reprocessing plant vessels by volume reduction. Nuclear Engineering and Design 237(8): p. 880-886 (2007).

25. Wolf, S. F.; Bowers, D. L.; Cunnane, J. C.: Analysis of high burnup spent nuclear fuel by ICP-MS. Journal of Radioanalytical and Nuclear Chemistry 263, (3), 581-586 (2005).

26. Vaidyanathan, S.; Reager, R. D.; Warner, R. W.: In High Burnup BWR Fuel Pellet Performance., American Nuclear Society, Portland, OR, March 2-6, 1997, Portland, OR, 1997; p 471.

27. Inductively Coupled Plasma - Mass Spectrometry, Revision 1 (February 2007) U.S. Environmental Protection Agency, Office of Solid Waste and Emergency Response: Washington, D.C, 2007; pp 6020A-1-6020A-30 .

28. Madic, C.; Begun, G. M.; Hobart, D. E.; Hahn, R. L.: Cation Cation Complexes of Pentavalent Actinides - Complexes Formed by $\mathrm{NpO}_{2}{ }^{+}$or $\mathrm{VO}_{2}{ }^{+}$with $\mathrm{VO}_{2}{ }^{+}$in Aqueous Perchlorate Solutions. Radiochimica Acta 34, (4), 195-202 (1983).

29. Brooker, M. H.; Huang, C. H.; Sylwestrowicz, J.: Raman-Spectroscopic Studies of Aqueous UranylNitrate and Perchlorate Systems. Journal of Inorganic \& Nuclear Chemistry 42, (10), 1431-1440 (1980).

30. Day, H. O.; Gill, J. S.; Jones, E. V.; Marshall, W. L.: Use of a Cation Exchange Resin for Total Anion Analysis of Aqueous Solutions Containing Uranyl Ion. Anal Chem 26, (3), 611-612 (1954).

31. Ahrland, S.: On the Complex Chemistry of the Uranyl Ion .1. The Hydrolysis of the 6-Valent Uranium in Aqueous Solutions. Acta Chem Scand 3, (4), 374-400 (1949).

32. Ahrland, S.; Hietanen, S.; Sillen, L. G.: Studies on the Hydrolysis of Metal Ions .10. The Hydrolysis of the Uranyl Ion, UO22+. Acta Chem Scand 8, (10), 1907-1916 (1954).

33. Fratiell A.; Kubo, V.; Lee, R. E.; Schuster, R. E.: Direct Proton Magnetic Resonance Cation Hydration Study of Uranyl Perchlorate, Nitrate, Chloride, and Bromide in Water-Acetone Mixtures. Journal of Physical Chemistry 74, (21), 3726 (1970). 
34. Lahr, H.; Knoch, W.: Stability Constants of Actinide Complexes .2. Nitrate Complexes and Chloride Complexes of Uranium, Neptunium, Plutonium and Americium. Radiochimica Acta 13, (1), 1 (1970).

35. Banerjea, D.; Tripathi, K. K.: Association of Uranium(VI) with Anions in Aqueous Perchloric Acid Medium. Journal of Inorganic \& Nuclear Chemistry 18, 199-206 (1961).

36. Bednarczyk, L.; Fidelis, I.: Determination of Stability-Constants of U(VI), Np(VI) and Pu(VI) with Chloride-Ions by Extraction Chromatography. Journal of Radioanalytical Chemistry 45, (2), 325-330 (1978).

37. Xu, M.; Larentzos, J. P.; Roshdy, M.; Criscenti, L. J.; Allen, H. C.: Aqueous divalent metal-nitrate interactions: hydration versus ion pairing. Phys Chem Chem Phys 10, (32), 4793-4801 (2008).

38. Waterland, M. R.; Stockwell, D.; Kelley, A. M.: Symmetry breaking effects in NO3-: Raman spectra of nitrate salts and ab initio resonance Raman spectra of nitrate-water complexes. Journal of Chemical Physics 114, (14), 6249-6258 (2001).

39. Aksenenko, V. M.; Murav'ev, N. S.; Taranenko, G. S.: Raman-Scattering Study of Nitric-Acid Solutions. Zhurnal Prikladnoi Spektroskopii 44, (1), 89-91 (1984).

40. Carter, R. L.: Molecular Symmetry and Group theory. John Wiley and Sons, Inc.: Hoboken, NJ, 1997; p 299.

41. Lin-Vien, D.; Colthup, N. B.; Grasselli, J. G., The Handbook of Infrared and Raman Characteristic Frequencies of Organic Molecules Academic Press: 1991; p 503.

42. Lipis, L. V.; Pozharskii, B. G.; Pozharskaya, M. E.; Fomin, V. V.: Kompleksnye Sulfaty Chetyrekhvalentnogo Plutoniya I Shchelochnykh Metallov. Zh Neorg Khim 5, (10), 2190-2203 (1960).

43. Day, R. S.; Vigil, A. R.; Marsh, S. F.: A Visible/Near-IR Spectral Database for Plutonium Solutions of Known Nitric Acis, Fluoride, and Oxalate Composition; Los Alamos National Laboratory: Los Alamos, April 1989, 1989; p 20.

44. Cohen, D.: The Absorption Spectra of Plutonium Ions in Perchloric Acid Solutions. Journal of Inorganic \& Nuclear Chemistry 18, 211-218 (1961).

45. Ryan, J. L.: Actinide(IV) Chloride Species Absorbed by Anion Exchange Resins from Chloride Solutions. Journal of Physical Chemistry 65, (10), 1856 (1961).

46. Lee, M. H.; Park, Y. J.; Kim, W. H.: Absorption spectroscopic properties for Pu(III, IV and VI) in nitric and hydrochloric acid media. Journal of Radioanalytical and Nuclear Chemistry 273, (2), 375382 (2007).

47. Berg, J. M.; Veirs, D. K.; Vaughn, R. B.; Cisneros, M. A.; Smith, C. A., Plutonium(IV) mononitrate and dinitrate complex formation in acid solutions as a function of ionic strength. Journal of Radioanalytical and Nuclear Chemistry 235, (1-2), 25-29 (1998).

48. Zhang, A. Y.; Li, K.; Hu, J. X.: Hydroxylamine derivative in Purex process - Part VIII. The kinetics and mechanism of the redox reaction of $\mathrm{N}$-methylhydroxylamine and vanadium(V). Journal of Radioanalytical and Nuclear Chemistry 261, (2), 301-307 (2004). 
49. Cleveland, J. M.: Plutonium Handbook, A Guide to the Technology. Gordon and Breach, Science Publishers: New York, 1967; Vol. 1, p 520.

50. Steele, H.; Taylor, R. J.: A theoretical study of the inner-sphere disproportionation reaction mechanism of the pentavalent actinyl ions. Inorganic Chemistry 46, (16), 6311-6318 (2007).

51. Hindman, J. C.; Sullivan, J. C.; Cohen, D.: Kinetics of Reactions between Neptunium Ions - the Neptunium(IV)-Neptunium(VI) Reaction in Perchlorate Solution. Journal of the American Chemical Society 76, (12), 3278-3280 (1954).

52. Coward, N. A.; Kiser, R. W.: A Spectrophotometric Study of Nd3+-NO3-Association. Journal of Physical Chemistry 70, (1), 213 (1966).

53. Hagan, P. G.; Cleveland. J.: Absorption Spectra of Neptunium Ions in Perchloric Acid Solution. Journal of Inorganic \& Nuclear Chemistry 28, (12), 2905 (1966)

54. Sakudo, A.; Tsenkova, R.; Tei, K.; Onozuka, T.; Ikuta, K.; Yoshimura, E.; Onodera, T.: Comparison of the vibration mode of metals in HNO3 by a partial least-squares regression analysis of nearinfrared spectra. Biosci Biotech Bioch 70, (7), 1578-1583 (2006).

55. Sullivan, J. C.; Zielen, A. J.; Hindman, J. C.: Specific Interaction between Np(V) and U(VI) in Aqueous Perchloric Acid Media. Journal of the American Chemical Society 83, (16), 3373 (1961).

56. Schulz, W.W., L.L. Burger, and J.D. Navratil: CRC Science and Technology of Tributyl Phosphate. Vol. III, 126 (1990).

57. Foos, J.; Kertes, A. S.; Peleg, M., Spectra of Neodymium(III) in Nitrate-Water and Nitrate-Chloride Melts. Journal of Inorganic \& Nuclear Chemistry 36, (4), 837-840 (1974).

58. Madic, C.; Guillaume, B.; Morisseau, J. C.; Moulin, J. P.: Cation-Cation Complexes of Pentavalent Actinides .1. Spectrophotometric Study of Complexes between Neptunium(V) and $\mathrm{UO}_{2}{ }^{2+}$ and $\mathrm{NpO}_{2}{ }^{2+}$ Ions in Aqueous Perchloric and Nitric Solutions. Journal of Inorganic \& Nuclear Chemistry 41, (7), 1027-1031 (1979). 




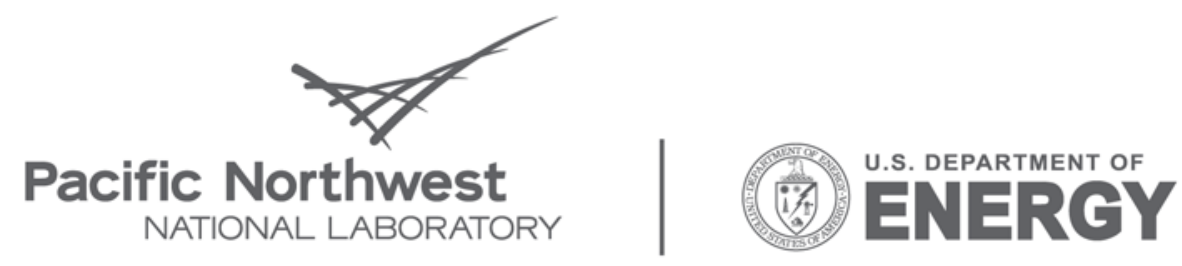

Proudly Operated by Battelle Since 1965

902 Battelle Boulevard

P.O. Box 999

Richland, WA 99352

1-888-375-PNNL (7665)

www.pnl.gov 